LBL-36178

UC-1600

\title{
What Is A Low-Energy House and Who Cares?
}

Barbara R. Litt

\section{Energy and Environment Division \\ Lawrence Berkeley Laboratory \\ University of California \\ Berkeley, CA 94720}

December 1994

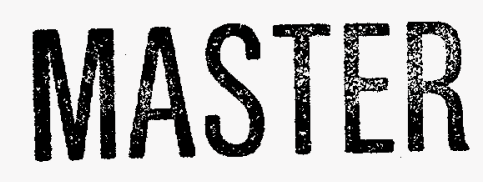

This work was supported by the Assistant Secretary for Conservation and Renewable Energy, Office of Building and Community Systems, Building Systems Division of the U.S. Department of Energy under Contract No. DE-AC03-76SF00098. 


\section{DISCLAIMER}

This report was prepared as an account of work sponsored by an agency of the United States Government. Neither the United States Government nor any agency thereof, nor any of their employees, make any warranty, express or implied, or assumes any legal liability or responsibility for the accuracy, completeness, or usefulness of any information, apparatus, product, or process disclosed, or represents that its use would not infringe privately owned rights. Reference herein to any specific commercial product, process, or service by trade name, trademark, manufacturer, or otherwise does not necessarily constitute or imply its endorsement, recommendation, or favoring by the United States Government or any agency thereof. The views and opinions of authors expressed herein do not necessarily state or reflect those of the United States Government or any agency thereof. 


\section{DISCLAIMER}

\section{Portions of this document may be illegible in electronic image products. Images are produced from the best available original document.}




\begin{abstract}
Most energy analysts view low-energy houses as good things, yet differ in their expectations of what exactly a low energy house is. There are two intertwining threads to this report. The first is an evaluation of 50 buildings that have been claimed to be low-energy residences, for which monitored energy performance data have been collected. These data represent the preliminary effort in the ongoing update of the Buildings Energy-Use Compilation and Analysis (BECA) data base for new residences. The second thread concerns the definition of a low-energy house. After the elements of a definition are presented, their implications for actors involved in providing housing are identified. Several more tractable definitions are applied to the houses in this compilation. The outcomes illustrate ways in which different interests are served by various definitions. Different definitions can yield very different energy rankings. No single definition of a low-energy house is universally applicable.
\end{abstract}




\section{Acknowledgements}

People who contributed or made it possible to collect data for the houses discussed herein are gratefully acknowledged: Perry Bigelow and Cynthia Cocchi (Bigelow Homes), Keith Denner (Professional Property Management), Stephen Heckeroth (Homestead Enterprises), Danny Parker (Florida Solar Energy Center), Frank Varnedoe, John Putnam (Tampa Electric Company), Masatoshi Kudo (Tsuchiya Twoby Home Company), Ismet Ugarsal (Technical University of Nova Scotia), Peter Suter (ETH Zürich), Tom Wuelpern and Anne Helwig (Rammed Earth Solar Homes), and Hiroshi Yoshino (Tohoku University). At Lawrence Berkeley Laboratory Alan Meier provided guidance, support, and encouragement, Brian Pon provided invaluable help with many telephone calls to builders, and Ellen Franconi reviewed and commented. The review comments of Nancy Carlisle (National Renewable Energy Laboratory) are also much appreciated. At UC Berkeley's Energy and Resources Group Mark Christensen provided guidance, criticism, and encouragement, and Bill Golove and many others made helpful comments. This work was supported by the Assistant Secretary for Conservation and Renewable Energy, Office of Building and Community Systems, Building Systems Division of the U.S. Department of Energy under Contract No. DE-AC0376 SF00098. 


\section{Table of Contents}

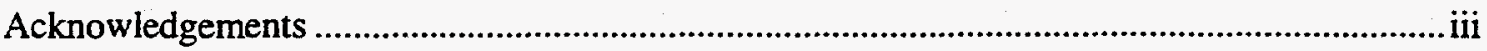

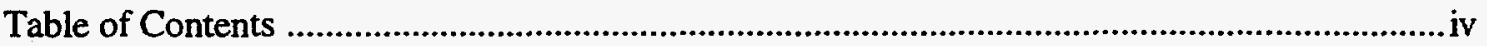

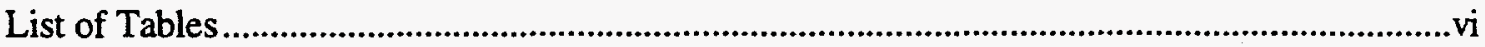

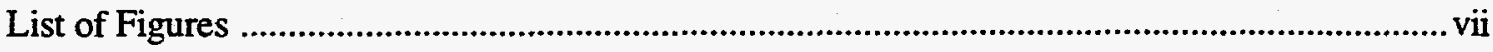

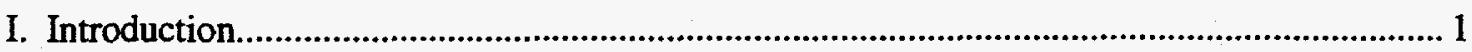

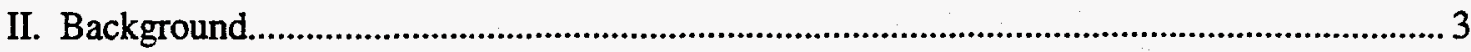

A. Residential Energy-Use Performance Monitoring: Previous Work .......................... 3

B. Recent Developments in Building Low-Energy Houses.........................................5

C. Post-1986 Home Energy Performance Compilation ..................................................... 7

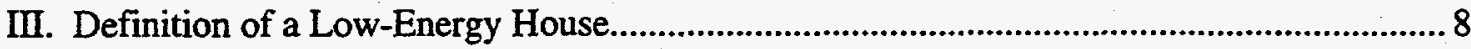

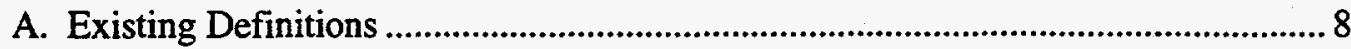

B. What Is a Low-Energy House? ........................................................................... 10

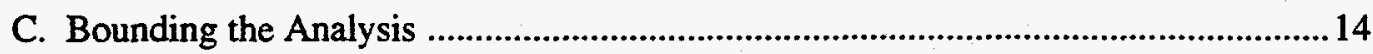

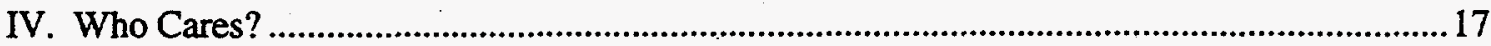

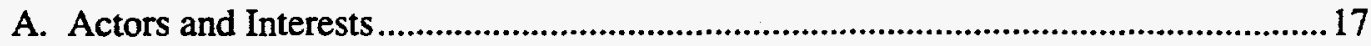

B. Low-Energy House Definitions: Implications for Actors .......................................19

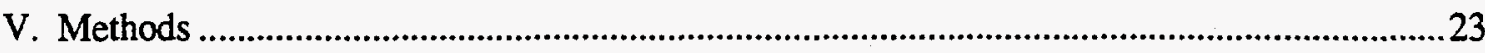

A. Working Definition for Comparative Research ........................................................23

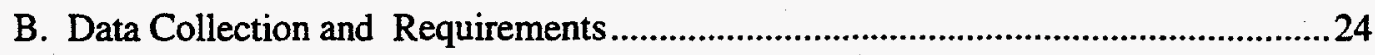

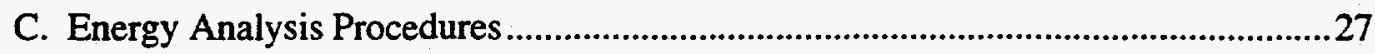

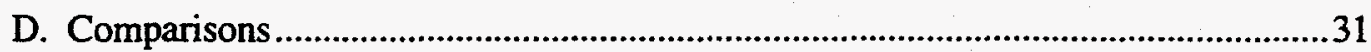

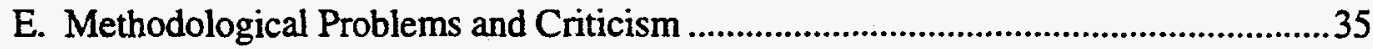

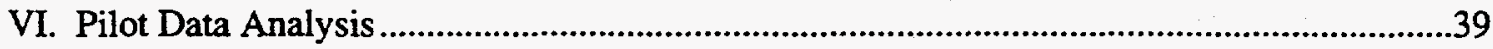

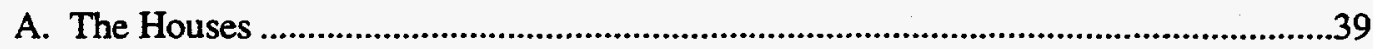

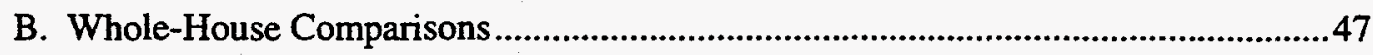

C. Space Heating Estimates and Comparisons .....................................................50 


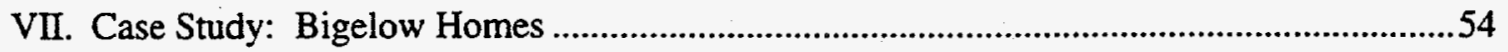

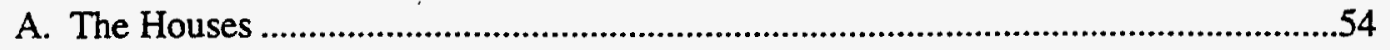

B. Sampling Procedures and Sample Composition ......................................................54

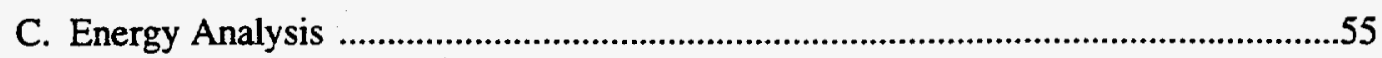

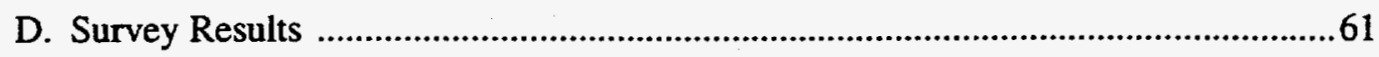

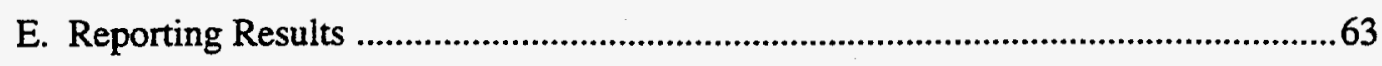

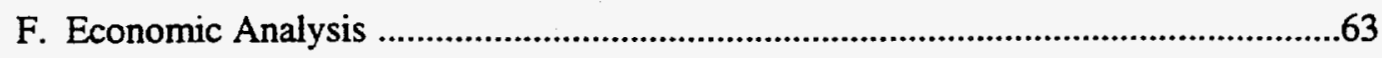

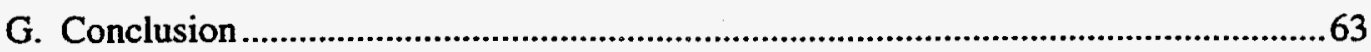

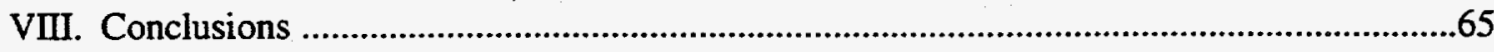

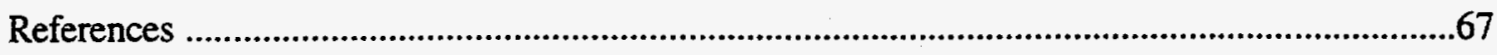

Appendix A. Flyer for Solicitation

Appendix B. Occupant Questionnaire

Appendix C. Baseline Data from the 1990 Residential Energy Conservation Survey

Appendix D. Letter Reporting Results 


\section{List of Tables}

Table 1. Energy Magnitudes for a Generic House ….............................................................14

Table 2. Differing Perspectives about a Low-Energy House ................................................. 18

Table 3. Breakdown of 1990 RECS Baseline Sample .............................................................33

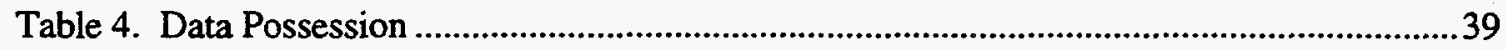

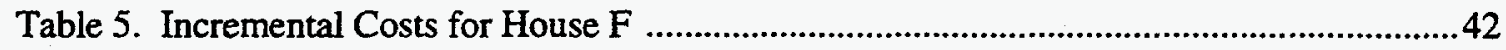

Table 6. Energy Performance Indicators ................................................................................48

Table 7. Ranking of Example Houses According to Different Normalizations ........................49

Table 8. Space-Heating Energy Consumption Estimates .....................................................52

Table 9. Energy Performance Indicators for Bigelow Homes ...............................................56

Table 10. Energy Use of Identical Houses .......................................................................61

Table 11. Perceptions of Comfort and Indoor Environment, Compared to a Previous House ...62 


\section{List of Figures}

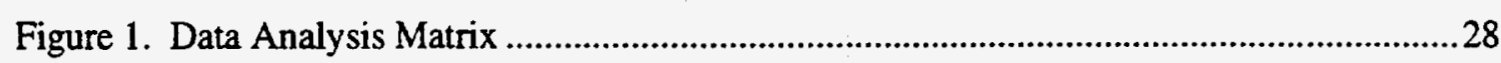

Figure 2. Geographic Distribution of 1990 RECS Baseline Houses ........................................34

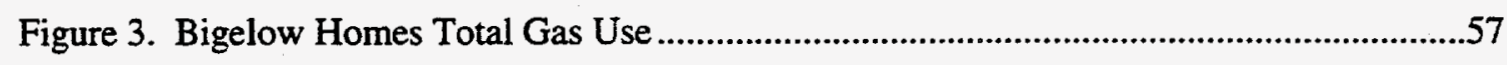

Figure 4. Bigelow Homes Gas Used for Space Heating ….....................................................57

Figure 5. Bigelow Homes Area-Adjusted Space Heating Energy Intensity ............................58

Figure 6. Bigelow Homes Total Electricity Use ......................................................................58

Figure 7. Annual Fumace Output Historical Comparison ..................................................60 


\section{Introduction}

The US construction industry builds more than one million dwelling units per year, producing three to five percent of the gross domestic product. The US residential sector currently consumes about 20 percent of US primary energy (18 EJ/yr). Housing is long-lived (usually more than 50 years) so what is built today will impact the future for a long time. Policies governing the energy efficiency of new housing have potentially major social, political, and environmental effects. The net present value of the energy savings alone could have significant redistributive effects. There are many actors involved in providing housing and they have varying ideas about exactly what a low-energy house is. The absence of a consistent definition of "low energy" is an important issue because policies, at many different levels, have been created to encourage construction of low-energy houses. If not based on a consistent understanding, the combination of these policies may be unsuccessful or, worse, even counter-productive. Because alternate definitions can lead to different policy outcomes · it is important to consider the implications of existing and proposed definitions.

Most energy analysts view low-energy houses as good things, yet differ in their expectations of what exactly a low energy house is. Articles about low-energy or energy-efficient houses rarely include definitions of these terms. Among building scientists a low-energy house has conventionally meant one with low space heating energy demand. As building practices have improved, however, space heating energy use has dropped-sometimes to as low as the third largest end use-in new houses located in cold climates. At the same time, energy use for cooling has increased as more houses have become air conditioned and more houses are built in warmer climates. Clearly, equating low energy with low space heating energy will not apply to a house in Miami or San Diego just as equating low-energy with low-cooling-energy will not apply in Minneapolis. Increasingly, the total energy used by a house is evaluated, rather than only energy used for space conditioning. Questions of how to count and how to normalize whole-house energy use are major subjects of this paper.

There are two intertwining threads to this paper. The first is an evaluation of 50 buildings that have been claimed to be low-energy residences, for which monitored energy performance data have been collected. These data represent the preliminary effort in the ongoing update of the Buildings EnergyUse Compilation and Analysis (BECA) data base for new residences. ${ }^{1}$ The goal of the compilation is to identify more and less successful energy designs by collecting data on the actual field performance of example houses. The houses studied and data analyzed in this paper can be considered a pilot analysis. Data from many more houses will be assembled during 1994 and 1995.

1. The BECA series of data compilations includes (among others) energy used in new residences; energy saved by retrofits of residences; energy used in new commercial buildings; and energy saved in retrofits of commercial buildings. This paper is a contribution to the new residential compilation. 
By analyzing these data within the technical and economic framework of increased first costs versus saved energy (or cheaper operating costs), technically and economically desirable strategies can be identified or confirmed. Because one barrier to widespread design and construction of low-energy houses is the lack of concrete information about their performance, evaluation results can make important contributions to improving the efficiency of the housing stock. Clear evidence of the existence of comfortable, affordable, low-energy houses helps overcome resistance to policies intended to encourage their construction.

The second thread of the paper concerns the definition of a low-energy house. After the elements of a definition are presented, their implications for actors involved in providing housing are identified. Several more tractable definitions are applied to the houses in this compilation. The outcomes illustrate ways in which different interests are served by various definitions. Different definitions can yield very different energy rankings. No single definition of a low-energy house is universally applicable. 


\section{Background}

A number of researchers have monitored energy used by houses. Before discussing the current research project it is useful to review their past work, with an emphasis on energy-use compilations of relatively new houses. There have been policy, technical, and other changes since this earlier research was done. An understanding of these changes helps explain the differences in scope and approach of the current project from earlier ones.

\section{A. Residential Energy-Use Performance Monitoring: Previous Work}

The earliest houses in the US explicitly intended to save operating energy were passive solar houses built in the midwest during the 1930s and 1940s (Keck and Keck 1983), but it was not until the 1970 s that there was widespread interest in low-energy houses and a large number were built. A few researchers, builders, and policy makers wanted to know how they were performing. Individual houses built as research projects were well studied and even some houses built simply to be lived in were monitored or evaluated qualitatively, although these were the exceptions rather than the rule. Passive and active solar houses received the most attention (AIA Research Corp. 1978; Duffy and Odegard 1982; Hamilton and others 1981; Shurcliff 1978; Swisher 1983), but highly insulated houses (Dumont 1991) and conventional houses (Socolow 1978) were also studied. Issues of particular concern were technical performance, cost-effectiveness, occupant acceptance, satisfaction, and interaction, and house marketability. The monitoring and reporting of results focused on the thermal performance of the building.

It was difficult to generalize results from isolated houses which used one-of-a-kind systems, especially when the parameters and monitoring methods varied from house to house. Methods to enable comparison of a variety of houses in different places, with different occupants, using different design strategies, began to be developed. The Solar Energy Research Institute defined three levels of monitoring protocols (Shea et al. 1980), Classes A, B, and C, and coordinated a program of standardized data collection in passive solar houses. Class A houses were operated under tightly controlled conditions, that is, unoccupied. Extremely detailed data were collected in a few houses at a level required to validate models of individual component performance and system dynamics. Solar aspects of the houses were carefully studied but the rest of the house was often ignored. Class $B$ houses were occupied and received less detailed hourly monitoring than Class A houses. They were to be used for model calibration and house performance evaluation. Forty houses were studied in 1981 and 1982 (Swisher 1983). Class C houses were not instrumented, but received detailed audits and had their utility bills analyzed. Hundreds of Class $C$ houses were studied in the early 1980s (Hamilton et al. 1981). 
In the-early 1980s the thermal performance of different types of low-energy houses was studied in detail with the first of Lawrence Berkeley Laboratory's Buildings Energy-Use Compilation and Analysis (BECA) projects (Busch and Meier 1986; Rosenfeld et al. 1981) Energy design strategy, ${ }^{2}$ space heating energy use, thermal performance, and incremental cost data for 319 houses in the US, Canada, and Europe built between 1973 and 1983 were assembled. Researchers used these data to compare the technical and economic performance of various design strategies (the analytical methods used in that work are described below). Passive solar houses and superinsulated houses both performed well, with their costs of conserved energy comparing favorably with those of supplying energy. The few earth-sheltered houses studied also performed very well. One important conclusion was that active solar measures were expensive, and houses in which they were installed had relatively poor thermal performance. The poor performance was probably because more emphasis was placed on the active solar aspects of these houses than on their thermal integrity, although it could also have been due to regional differences, as all but one of the active solar houses in the sample was in Europe (Busch and Goldman 1986). Another interesting observation was the wide variation in energy use and cost-effectiveness seen among houses with the same design strategy, even after normalization to eliminate differences in climate, living area, and internal gains.

Other compilations have used approaches similar to Busch and Meier (1986). Heard and others (1985) collected utility billing data for 133 tract houses in California. They found results similar to those of Busch and Meier but on a statewide scale, for example, long payback times for active solar systems. The California data set consisted of relatively similar houses so other issues were also investigated. One result was that "similarly constructed, physically-identical homes at the same location had widely varying annual energy consumptions" (Heard et al. 1985, p. 1). Estimates of average annual space heating, based on PRISM, ${ }^{3}$ exceeded the energy budgets calculated according to state regulations by 10 to 40 percent. Survey results and subsequent site visits showed that some people did not understand the proper use of the passive solar aspects of their houses.

Meier and Nordman (1988) studied thermal performance of 232 electrically heated houses in the Pacific Northwest, built to Bonneville Power Administration's Model Conservation Standards (MCS) and 292 control houses. Meier and Nordman showed that MCS houses used $41 \%$ less space heating energy per unit of floor area than control houses. The MCS houses had $28 \%$ more floor area on average, so the absolute difference in space heating energy use was $27 \%$. Consumption for other end-uses did not appear to vary systematically between the two groups.

2. Energy design strategies used were passive solar, active solar, superinsulation, double-envelope, earthsheltering, and combinations.

3. The model, PRISM, is discussed below on p. 23. 
Marchio and Rabl (1991) studied gas use in 220 energy-efficient, gas-heated houses in France. They estimated space-heating energy use from utility bills using PRISM. Observed space heating energy use agreed well with model predictions. They also found a tendency of their model to underpredict energy use (or the house and its occupants to overconsume) in houses with large floor area.

In the late 1980s the California Energy Commission funded a major project to evaluate and monitor energy use in houses built between 1984 and 1988 under the state building energy efficiency standards (Berkeley Solar Group and Xenergy 1990). A four tiered approach involved mail surveys of 2900 households, on-site audits to 299 of these, utility billing data collected for 154 of these, detailed measurements including energy use, infiltration, and indoor temperatures in 40 houses, and short term energy monitoring tests in 4 houses which were unoccupied for three days. Lots of information about the correspondence of assumptions used in forecasting and simulation models with actual conditions was obtained. In particular, people did not use their heating and air conditioning systems as often as had been expected, and much less solar gain entered through windows during the cooling season than had been assumed. It was also found that builders were not installing enough insulation to meet the standards. The study also documented the cost-effectiveness of the standards, deriving an average of $\$ 18,000$ (discounted net present value) over the life of the conservation measures.

Common aspects of the studies discussed above are that they focus on energy used for space heating and that they evaluate strategies for reducing energy use. Another important task is to document energy use in typical houses. For example, the U.S. Department of Energy (USDOE) conducts the Residential Energy Consumption Survey (RECS) approximately every three years. In the 1990 survey, researchers collected detailed data on housing characteristics for more than 5000 households, and obtained complete data for electricity and fuel use for $62 \%$ of these. Researchers estimated the average energy consumption for many appliances and energy end uses, using a conditional demand analysis. The report (U.S. Department of Energy 1993) contains estimates of many aspects of US residential energy use. The text aggregates the data to such an extent that a lot of important information is obscured (for example, for many statistics electricity and fuel use are lumped together and reported as a single quantity, total energy consumed at the site). In spite of the shortcomings of the RECS report, actual data for individual houses are available electronically, enabling independent data analysis. Upon analyzing the 1990 RECS data base it was found that, of the 206 houses built in or after 1987, 127 have complete energy data and can therefore be used as a comparison group for the new houses in the BECA compilation. The RECS data are discussed further below, in the context of determining baseline energy use from which to compare that of low-energy houses.

\section{B. Recent Developments in Building Low-Energy Houses}


Most of the houses in the compilations discussed above 4 were built before 1985 and most before 1980. The energy situation with respect to buildings has changed dramatically since 1980 . Success in reducing space heating energy consumption has brought other end uses into the spotlight (in particular, cooling, water heating, refrigeration, miscellaneous and "parasitic" uses, such as fans and pumps). New technologies and materials have greatly changed the costs of achieving energy efficiency. Incremental costs of energy-efficiency measures have changed significantly since 1985 . In addition, there are now off-the-grid houses that deliver all the comforts expected of a modern US home (Tatum 1994) - in other words being unconnected to the grid no longer requires sacrificing amenities.

Technological changes have occurred since the low-energy houses studied in the earlier research were built. Technological progress since the early 1980s includes both improved materials for existing applications, qualitatively new (at least in application to houses) technologies, and improvements in the speed or the effectiveness with which components or systems can be installed. Examples of the first category are high-thermal resistance, chlorofluorocarbon-free insulation materials and specialized sealants. Improvements of the second type include low-emissivity windows, compact fluorescent lights, high-efficiency heat pumps, and energy management and control systems. Examples of the final category are duct tightening routines, sealing against air infiltration, and the success of some builders with quality assurance in the field. Technological progress has greatly improved the energy efficiency of many appliances, but has also increased the number and sophistication of "miscellaneous" appliances in houses.

In addition to technical changes, many policies intended to encourage construction of low-energy houses have been developed or strengthened. These policies or programs include :

- building energy efficiency standards (e.g., California's Title 24)

- appliance efficiency standards (e.g., the National Appliance Energy Conservation Act of 1987)

- home energy rating systems (HERS)

- energy efficient mortgages (EEM)

- utility demand side management (DSM) programs

- single-technology tax credits, subsidies, or incentives

- utility bill leveling options

Many states now have standards for energy efficiency of new houses. In addition to standards, HERS and EEMs can make energy efficiency a factor in the housing market. Recently, utility DSM programs to encourage efficient residential construction, HERS, and EEMs have proliferated. Most of these programs are still young, awaiting refinements before receiving widespread use (Faesy

4. Except the 1990 RECS and the CEC study, which did not target low-energy houses. 
1992; Farhar and Eckert 1993; Millhone et al. 1992). "In aggregate, home energy rating programs have had a relatively small impact compared to the size of the residential housing market" (Vories and George 1992, p. 400).

A notable recent development has been the ability of some production builders to build cost-effective "superinsulated" houses, townhouses, and apartments, at prices competitive with conventional houses. This change has been at least partly in response to larger social and economic changes, such as the reduced affordability of single-family detached houses for first-time home buyers and the slow housing market of the late 1980s and early 1990s (Andrews 1993). Builders can use energy efficiency as a means to distinguish their product from the competition (Russell 1993). Energy efficiency still has a reputation as something extra, only found in the "high end." But as shown by examples in the current compilation, energy-efficient houses are no longer only for the wealthy or the eccentric, but also for the discerning consumer.

\section{Post-1986 Home Energy Performance Compilation}

So much has changed since the compilations discussed above were done that it is important to revisit the energy perfromance of new low-energy houses. A new BECA compilation (the subject of much of this paper) is underway to evaluate houses built in 1987 or later.

The type of houses and the degree of detail of the data are different in the new BECA compilation than in the earlier one. Busch and Meier (1986) received submetered heating data for 319 houses that were monitored by various researchers. In 1994, there are still a number of houses throughout the world for which submetered data are being collected. Examples are Canada's Advanced House Program (CANMET 1993) and the International Energy Agency Task XIII, Advanced Solar Low Energy Buildings (Erhorn et al. 1993) and others (Enermodal Engineering 1992; Kriesi 1990; Nieminen 1993; Sinha et al. 1993; Ugursal 1992; Yoshino et al. 1993). But another kind of house is more prevalent in the new BECA compilation. Increasingly, successful prototypes researched ten years ago are being built commercially. These houses are not usually monitored, but their utility bills can often be obtained. Thus, the current compilation includes many houses for which a monthly utility bill is the only form of energy-use monitoring. Houses in which significant wood was burned were not considered in the original BECA new residential compilation (Busch and Meier 1986) but many low-energy houses use wood to supplement passive or active solar heating. The current work includes such houses and estimates of the energy content of the wood burned. The focus of the original compilation was thermal performance. The current work focuses on whole-house energy use, although thermal performance and appliance energy use are considered as well. 


\section{Definition of a Low-Energy House}

The terms "low energy" and "energy efficient" are often applied to houses interchangeably. The vast majority of articles about such houses do not define either term. A look at existing definitions, both explicit and implicit, shows what building scientists and utility DSM program personnel have meant by these terms. Existing definitions tend to be easy to apply to programs but conceptually narrow. To explore alternative definitions, it is useful to disect the phrase, "low-energy house".

\section{A. Existing Definitions}

Most articles about energy-efficient houses do not define the term. Often the author is describing a single house or project and apparently does not consider a definition to be necessary. Showing that the house consumes (or is expected to consume) little energy is sufficient for it to be an energyefficient house. Total energy consumption aside, some people consider a house to be energy efficient if it uses a particularly efficient component, such as a high-efficiency fumace or air conditioner, or a heat pump.

When describing new energy-efficient demonstration houses, research and development program representatives often frame their goals in terms of building a house that uses a small fraction of the energy used by a typical house. This can be stated either in terms of typical new houses or existing houses. For example, Canada's Advanced House program aims to build demonstration houses that use less than half the total purchased energy of new houses meeting Canada's R-2000 program requirements. A recent Finnish research house was intended to use 50\% of the heating energy of typical small Finnish houses (Nieminen 1993). Pacific Gas and Electric's (PG\&E) EnergyWise Showcase Home demonstration program requires that total predicted energy use be $50 \%$ less than that required under California's Title 24 , building energy efficiency standard, which covers only space heat, cooling, water heat, and some lighting. PG\&E's research program, $\mathrm{ACT}^{2}$, aims to build houses that use $75 \%$ less energy than Title 24 allows.

Utility DSM programs aimed at new houses provide good examples of practical definitions, since the programs must determine which houses meet program requirements. Some programs label a new house "efficient" if it is expected to use less than a certain percentage of the maximum energy budget allowed by code. Other programs label the house based on the upgrading of components and systems over what would be used in standard construction. DSM programs do not base program qualification on actual building energy performance (this is not surprising, since there are obvious practical difficulties with criteria involving time lags in administering real programs). Evaluators of DSM programs are less interested in the absolute amount of energy saved than in the energy saved 
due to the program. Therefore it is important that the baseline represent what would be expected to be built in the program's absence.

Here are several examples of DSM programs and their de facto definitions. Sacramento Municipal Utility District (SMUD) has two tiers of prescriptive upgrades builders may use in order to receive rebates (the more systems upgraded, the larger the rebate). Based on which upgrades are done, the utility expects a percentage reduction in energy use for the house (15 or $25 \%$ ) compared to California's energy code requirements, but calculation of predicted energy use is not necessary in order to qualify. ${ }^{5}$ The first level, requires upgrading the air conditioner (from SEER 10 to SEER 12), ceiling insulation (from R-30 to R-38), duct insulation (from R-4.2 to R-8) and upgrading half of the light fixtures to fluorescent. The second level adds wall insulation (from R-13 to R-19), HVAC zone control, and a decreased window shading coefficient. A different approach is taken by New England Electric System's Energy Crafted Home program. Annual heating and cooling budgets are stated in the guidelines: $1.4 \mathrm{Btu} / \mathrm{HDD}\left({ }^{\circ} \mathrm{F}\right) \mathrm{ft}^{2}$ or $29 \mathrm{~kJ} / \mathrm{HDD}\left({ }^{\circ} \mathrm{C}\right) \mathrm{m}^{2}$ for heating and between 2.7 to 3.7 $\mathrm{Btu} / \mathrm{CDD}\left({ }^{\circ} \mathrm{F}\right) \mathrm{ft}^{2}$ or 55 to $76 \mathrm{~kJ} / \mathrm{HDD}\left({ }^{\circ} \mathrm{C}\right) \mathrm{m}^{2}$ for cooling, depending on the climate zone, where the area used for normalization is the building shell area. In order to qualify, a simulation must show that the house meets the target (the simulation assumes a specific operating schedule for the house). Inspectors visit the construction site to verify that what is being built is indeed the plan that was submitted. A number of utilities now perform blower door tests to verify airtightness.

Another source of definitions is existing compilation research (Busch and Meier 1986; Heard et al. 1985). These compilations examine how well so-called low-energy homes were performing. Therefore, the criteria for inclusion were not based on actual performance. Busch and Meier do not explicitly define the term, low-energy house, but their sample consists of houses with "a variety of design strategies including passive and active solar, earth-sheltering, double-envelope, and superinsulated" (p. 2). By implication, low-energy houses are not conventional houses. Heard and others (1985) defined energy-efficient residences as "those developments that received awards from utilities for conservation/solar design. In addition, these developments had to be built to specifications above the mandated standards at the time of their construction" (p. 3). The houses Marchio and Rabl (1991) studied had predicted space heating energy consumptions 75,65 or 55 percent of the standard. Dumont (1991) writes that while there is not a formal definition of a lowenergy house, many of them have "superinsulated exterior envelopes, air-vapour barriers to limit air leakage, heat recovery ventilators, and modest window areas, primarily oriented toward the equator" (p. 3287). But his primary selection criterion for houses in Saskatoon was that the nominal thermal resistance of the wall be greater than $\mathrm{R}-20$.

5. SMUD's program also has a 50\% reduction category, which cannot be attained simply by prescriptive upgrades. 
Although they are easy to apply, these existing definitions are narrowly focused, as is demonstrated in the following section. Later in this paper (Section VII) the implications of these definitions for the various actors involved in providing housing are discussed.

\section{B. What Is a Low-Energy House?}

To explore possible definitions of a low-energy house, it is useful to examine each word separately: house, energy, and low. This decomposition allows explicit identification of many choices and judgements implicit in the reporting of energy consumption data. The questions of how to define the attributes of a house and what to consider appropriate "residential services" for normalization of energy use are important. The answers depend on cultural, social, economic and technical factors and thus differ, depending on the context. On an absolute basis, how energy use is counted greatly influences what is deemed to be low. On a relative basis, to do a comparative analysis a house must be assigned to the comparison group, the control group, or neither.

\section{What Is a House?}

A house by any other name is still a house, so a definition of one might seem unnecessary. But even if general knowledge of a house is shared, a definition helps to focus the compilation. The appropriate technical term is "dwelling unit", which is more inclusive than what may be implied by "house", sometimes taken to mean a single-family detached house. One definition of a dwelling unit is "premises which by virtue of their construction, are meant for habitation by one household" (AlSayyad 1984, p. 33). A household is understood to be any group of people who live together and jointly finance their daily necessities.

For the BECA research, it is assumed that if a house has been legally built as such, then it meets the minimum requirements to be one (note that this is a sufficient but not a necessary condition-houses which have not been approved might also meet minimum requirements). Single-family detached houses, duplexes (also triplexes and fourplexes), townhouses, and low-rise apartments ${ }^{6}$ (both sitebuilt, and manufactured) are included in the compilation. Institutional housing, for example, dormitories and nursing homes, is excluded.

What is a house used for? Basic shelter for the occupants is one requirement. In the US (as in most of the world) most people expect much more than that from a house. A general goal is to provide a household with a place to live comfortably, where "to live" and "comfortably" are broadly defined by the household in question. This general goal is more consistent with the multifaceted uses of

6. High rise apartments are, of course, also dwelling units, but are excluded from the compilation due to their differences from low rise residential buildings. 
housing in a market economy, in which housing is a commodity. Within that paradigm, a household buys the amount and type of residential service wanted, subject to a budget constraint.

Common physical criteria for the minimum attributes of a house are running potable water, sanitary facilities, electricity, a functional heating system, one or more doors, structural soundness, and an impermeable barrier to wind, rain, and snow. In the warmer parts of the US a cooling system has come to be regarded as practically required equipment, but this need not be built into the house. In practice, building codes, zoning, and financing requirements tend to be more specific than these basic criteria. Sometimes such details as the minimum foundation depth, the ratio of house size to lot size, or the set-back from the street are specified. In addition to physical and legal criteria, there are also socio-cultural criteria, by which a house type would be accepted by a society as sub-standard (AlSayyad 1984). Socio-cultural criteria vary around the world, and even across different parts of the same country.

A critical issue is whether the unit of analysis is the house or the home, the former referring only to physical equipment and the latter including the occupants. The benefits of low energy use accrue from the performance of the whole system - the house and its occupants. Long-term monitored data include the influence of the occupants ${ }^{7}$ so if the house alone is to be studied, occupant effects must be controlled for in the analysis. It is common for the physical systems and the social, demographic, psychological, cultural, and economic human systems to be studied separately, but the results of such separate studies are often incomplete. Using Monte Carlo simulations, Pettersen (1994) has concluded that it is not possible to predict total energy use of Norwegian households more accurately than \pm 15 to 20 percent, unless the occupants' behavior is known. In contrast, identical houses in the US can have energy consumptions differing by more than a factor of two due largely to differences in occupants (Sonderegger 1978). Hitchcock (1993) recently proposed a framework for integrating the physical and human systems when studying household energy use, including feedbacks between the two.

In the BECA research, both the home (the combined physical and human system) and the house (the physical system) are of interest. An engineer wanting to evaluate the efficacy of an improved thermal envelope would want to control performance data for variation due to occupant influences. Many other actors concerned with low-energy homes want to understand the larger system of the home. It is also important to better understand the ways in which a given household's energy use deviates from assumptions about what is "standard" energy use.

7. Short-term monitoring such as relaxation measurements or coheating experiments can be done in empty houses, thereby excluding occupant influences. Long-term monitoring can also be done in empty houses, but there is little expectation that the results would be reproduced if the house were occupied. 


\section{What Is Energy?}

Although analysts often talk about energy consumption, actually energy is not consumed. Instead it flows from place to place and from high quality forms, such as electricity, to lower quality forms, such as heat. ${ }^{8}$ In the long term the quantity of energy entering a house must equal the quantity leaving the house, even though on timescales as long as a season this is not necessarily the case. Energy can enter a house in the form of electrical, mechanical, radiation, potential (for example, fuels or wood), or thermal energy. It usually leaves a house in the form of waste heat. Researchers do not measure the quantity of energy leaving a house. Nor do they measure all of the energy entering a house. Instead they measure the quantity of energy that is purposefully brought into a house, and assume that it is all degraded into heat and emitted to the environment. This process of moving high quality energy through the house and converting it to low quality energy is referred to as energy consumption.

There are many ways to count the energy brought into a house, so conventions are needed to keep track consistently. The questions to be decided are what to count, and how to express the results. Basic choices discussed below are site versus source energy, and purchased versus other energy.

The site versus source energy issue is whether to count energy delivered to the house (site energy) or energy consumed in supplying the energy delivered to the house (primary or source energy). The choice depends on why the energy is being counted. If the energy balance inside the house is a focus, then site energy should be counted. If energy balance on local, regional, national, or global scales is a focus, then source energy should be counted. In practice, both site energy and source energy should be reported, so that people interested in a variety of issues can learn from the results. At the least, results should be presented in a way that allows interested parties to convert from site energy to source energy and conversely.

The purchased versus other energy issue involves how to count electricity generated on-site from renewable sources or heat collected and used on-site. Purchased energy generally originates off-site. The distinguishing feature of purchased energy is that its cost to the consumer is based on the quantity of energy delivered. 9 On-site energy is obtained for an initial capital cost and annual maintenance payment, but the quantity of energy supplied is not proportional to the cost. Note that according to the definition given, wood could be considered either purchased energy or on-site energy, depending on how it is obtained. ${ }^{10}$ With a few exceptions (Hammond and Jennings 1991;

8. The term "exergy" refers to the combination of energy quantity (conserved, according to the first law of thermodynamics) and energy quality (consumed, according to the second law of thermodynamics).

9. There are no houses in the compilation from places where consumers pay a flat fee to a utility company for unlimited electricity or fuel use.

10. In practice, in the compilation wood is treated as purchased energy. 
Kimufa et al. 1993), on-site energy is not generally measured. If energy balance inside the house is a focus, then energy from on-site, renewable sources should be counted. If energy consumption on a larger scale is a focus, then it is not necessary to keep track of on-site generation and heat collection.

Counting energy becomes complicated if keeping track of how the energy is used inside the house is of interest. Energy use is often reported as being partitioned between end-use categories. In particular, past compilations of residential energy use and many current home energy rating systems focus on energy used for space heating. But it is not easy to determine how much energy was used for space heating simply by monitoring fuel consumption by heating equipment. There are two complicating factors. First, energy is also used in the distribution of heat, and that energy should be included under the space heating category. Second, energy originally used to power appliances is given off as waste heat, much of which is emitted inside the conditioned space. For example, an electric meter on a refrigerator might show that the unit consumes $700 \mathrm{kWh}$ annually. That energy keeps some food cool and heats the house. In winter such internal gains displace energy use of dedicated space heating equipment, but in summer they increase the need for space cooling. It would be logical to apportion the $700 \mathrm{kWh}$ between the end-use categories of space heating and refrigeration, being careful to avoid double counting. In practice, this kind of apportionment is not made.

\section{What Is Low?}

A "low-energy" house uses little purchased energy relative to a standard house. An energy-efficient house provides residential service in an energy efficient manner. Although analysts often speak about energy efficiency, we use the term loosely. Usually it is energy intensity in which we are interested. ${ }^{11}$ Because the amount of service varies from house to house, to determine intensity the total energy consumed is divided (normalized) by the service provided. A low-energy house that provides sufficient services would be energy efficient, but an energy-efficient house might not be low energy.

What end-use categories should be counted? Comparative analyses of the 1980 s considered only space heating. As discussed earlier, the definition of a low-energy house is evolving from one focused on space heating to something more inclusive, such as whole-house energy use. Should luxurious or unusual end-uses such as swimming pools, heated greenhouses in cold climates, or welding equipment be included in whole house energy use? If their consumption has been

11. In a formal sense, energy efficiency compares energy required to perform a service with a standard energy. The standard can be either the minimum thermodynamically required (second law efficiency), or it can be a baseline energy consumption. Second law efficiency is generally not useful in the residential context because it requires fixed assumptions about how the service is performed, when in fact major decreases in energy use often result from changes in the approach to performing the service. In contrast, energy intensity simply indicates how much energy is required to perform a given amount of the service. 
submetered then the option to discount them exists, but such submetering is rarely done. Does a hot tub belong in a low-energy house? Certainly some hot tubs are more energy efficient than others.

How should whole house energy use be normalized? It is standard practice to normalize space heating energy use by the living area. There is virtually no explicit discussion of the reasons for normalizing by living area in the literature. Perhaps it is under the assumption that more living area provides more service to the occupants. It may also be that living area is used as a surrogate for building envelope area. Many publications that do report whole-house energy use state total energy use in terms of $\mathrm{kWh} / \mathrm{m}^{2}$. It is not clear that this kind of normalization is anything more than a convenient way of displaying numbers. Residential service does not necessarily increase in proportion to living space. In the US a larger house does not necessarily have more occupants than a smaller one. For some end uses, such as water heating, it makes more sense to normalize by the number of occupants. Balcomb (1993) recommends factors ${ }^{12}$ for adjustment of heating and cooling energy performance targets to be normalized by living area because "large houses have an inherent advantage due to a smaller surface-to-volume ratio" (p. 6).

In summary, a low-energy house is not necessarily the same as an energy-efficient house. Conventions are needed to determine what kinds of energy use to count and how to report the results.

\section{Bounding the Analysis}

Another question that is important to anyone compiling performance data is where to bound the analysis. Should transportation energy used in commuting to work, shopping, and school be included? What about the energy embodied in building materials and practices? Neither transportation energy nor embodied energy are considered in the BECA compilation. Their relative magnitudes compared to operating energy, and the reasons they are not inciuded are discussed below. Table 1 lists magnitudes for various energy types for a generic house with generic occupants.

12. The factors are $1.30,1.07,1.00,0.96,0.93$, and 0.91 for $500,1000,1500,2000,3000$, and $4000 \mathrm{ft}^{2}$ houses.

Table 1. Energy Magnitudes for a Generic House

\begin{tabular}{|l|c|}
\hline Category & Annual Energy Use (GJ/y) \\
\hline \hline Whole House & 200 \\
\hline Space Heat & 100 \\
\hline Refrigerator & 3 \\
\hline Transportation & 100 \\
\hline Embodied & $1000^{\mathrm{a}}$ \\
\hline
\end{tabular}

a. A one-time expenditure (GJ). 
Calculating the energy embodied in building materials and construction requires knowledge of many variables and the results apply only on a case-by-case basis (Buchanan and Honey 1994). Decisions about what to include as well as assumptions made about such things as processing and transportation of building materials greatly influence the outcome. Embodied energy is not trivial when compared to operating energy. A sample of office buildings in Japan required "total energy consumption caused by construction" of 8 to $12 \mathrm{GJ} / \mathrm{m}^{2}$ (Oka and others 1994) and a typical New Zealand house embodies $4 \mathrm{GJ} / \mathrm{m}^{2}$ (Buchanan and Honey 1994). Several sources estimate that energy embodied in a typical house is equivalent to 20 to 25 years of operating energy (Buchanan and Honey 1994; Miner and Loken 1994). Energy-efficient design measures can decrease embodied energy by decreasing the amount of material used in a house (Friedman and Cammalleri 1994), There are also cases in which they increase embodied energy by using energy-intensive products (Suter 1993).

Embodied energy is difficult to include in the BECA research for two reasons. First, it is usually poorly documented and relatively complicated to estimate. Second, the economic treatments of the two types of energy are different. That is, the householder probably does not see the cost of the embodied energy reflected in the price of the house because energy costs are usually only a small fraction of the cost of the materials and construction. In contrast, he or she certainly pays for the operating energy.

Transportation energy is easier to think about than embodied energy. The amount of energy used in transportation is influenced by peoples' decisions about where to live. It can easily exceed the amount of energy used at home. ${ }^{13}$ but compiling it is beyond the scope of this research. It is convenient to draw the boundary at the property line. Most, but not every house in this compilation could be conceptually moved to a location for which transportation energy could be minimal (i.e. an urban area near jobs). In 1988 an average American household used $130 \mathrm{GJ}$ (about 1000 gallons of gasoline) for automobile trips (U.S. Bureau of the Census 1992). This is slightly more than the average $110 \mathrm{GJ} / \mathrm{y}$ of site energy that the average new house built in 1990 is estimated to consume (U.S. Department of Energy 1993).

There are trade-offs between energy used in the residential, commercial, and transportation sectors. If instead of driving to work the occupants were to telecommute, an increase in "miscellaneous" energy used at home would occur but the overall energy savings would be large. An example of a trade-off between the commercial and residential sectors is the contrast in energy used for residential refrigeration in the US and Japan. In the US people have big refrigerators at home (often more than one) and store lots of food, shopping infrequently. In Japan, where space is at a premium, residential

13. For example, an 80-km round-trip weekday commute for one year would consume about $70 \mathrm{GJ}$. 
refrigerators are smaller than those in the US and people shop for food every day. The Japanese distribution system is one of the world's more energy intensive, involving frequent, small deliveries. Structural differences make Japanese residential appliance use appear less energy intensive than that in the U.S (Hayashi 1991). On the other hand, the Japanese retail/wholesale sector appears to be more energy intensive than that of the U.S. (Nagata 1993). Keeping track of intersectoral trade-offs is often beyond the scope of single research projects, but it is important not to ignore the existence of such trade-offs.

Finally, why do compilations focus on energy use alone? What about other environmental damages and health hazards? Builders today build not only energy-efficient houses, but also "green" houses, with appropriate materials, low flow plumbing fixtures, and special attention to minimizing indoor pollutants and construction waste. "For those attempting to build an 'environmentally friendly' house, the selection of appropriate materials requires consideration of cost, availability, embodied energy, sustainability of the resource base, toxicity, energy efficiency, water conservation, durability, maintenance, recycled content, and recyclability" (Miner and Loken 1994, p. E-39).

Rather than focus on energy, Suter (1993) calculated a pollution payback time, which aggregated embodied environmental damages, including those resulting from embodied energy, for energy efficiency measures in a low-heating-energy house in Switzerland. This type of detailed total environmental impact life cycle analysis is helpful for identifying energy conservation measures that save energy at the expense of other environmental damage, but it is even more complicated to carry out than embodied energy analysis. 


\section{Who Cares?}

As discussed above and demonstrated below, how energy use is defined, counted, and normalized greatly influences what are considered to be low-energy houses. This is an obvious but important statement. A consistent understanding of a low-energy house is necessary because a number of policies to encourage their construction have been created and are undergoing refinement. Conventions to be used in a definition do not merely involve technical factors, but also embody decisions about what is best for the actors involved. Therefore, it is important to examine these actors, their interests, and the implications for various actors of choosing one definition over another. Who gains and who loses from the use of a given definition? Both definitions in use and alternative definitions are considered.

\section{A. Actors and Interests}

Many actors are involved in providing housing in general and low-energy housing in particular. They have many different perspectives about why (or whether) low-energy housing is important. Table 2 illustrates the diversity of actors and their interests. Also shown are the implications of these interests for "low-energy house" definitions preferred by these actors. The interests attributed to the actors are based on attitudes found in the professional literature of each group, except for those of builders and occupants. Attitudes attributed to them in the literature are supplemented by interviews and the questionnaire discussed here (Sections V and VII). Note that decreasing the energy use of houses is a secondary concern (at best) for many of these actors.

Interests of some actors conflict with those of others. For example, potential lenders of EEMs are concerned that the supposed energy savings are too dependent on the occupant's lifestyle to bank on, while HERS have been more focused on the house in the context of real estate transactions, independent of occupant influences (Millhone and others 1992). Yet HERS and EEMs need to be well integrated to function successfully. Another conflict is between utility companies and environmentalists. While a hypothetical environmentalist would want to decrease the total amount of energy consumed, a utility company is usually only interested in conservation measures that are compatible with its corporate needs. During research for this report, several utility companies were found to have discontinued successful DSM programs because new sources of electricity had come on line. These ompanies are now more interested in load growth than in conservation. Another conflict is between advocates of fuel neutrality (the idea that a HERS should not provide incentives for fuel switching, thereby having no influence on competition between electric and gas utilities) and actors wanting to decrease greenhouse gas emissions, such as the environmentalist and the forecaster. 
Table 2. Differing Perspectives about a Low-Energy House

\begin{tabular}{|c|c|c|}
\hline Actor & Interests & Implications for Definition \\
\hline Occupant & $\begin{array}{l}\text { Amenities, quality construction, resale } \\
\text { value, affordable, low utility bills, } \\
\text { contributing to sustainable use of resources }\end{array}$ & $\begin{array}{l}\text { Don't trade off amenities for low } \\
\text { energy use }\end{array}$ \\
\hline Builder & $\begin{array}{l}\text { Profit, differentiation from other builders } \\
\text { houses, providing a quality product, keeping } \\
\text { incremental costs down, lower operating } \\
\text { costs can increase low income demand for } \\
\text { housing, public opinion }\end{array}$ & $\begin{array}{l}\text { Consider incremental costs; should } \\
\text { not be too easy, nor too difficult for a } \\
\text { house to qualify as low energy }\end{array}$ \\
\hline $\begin{array}{l}\text { Utility DSM } \\
\text { Program Manager }\end{array}$ & $\begin{array}{l}\text { Avoiding construction of additional } \\
\text { generating capacity, providing satisfactory } \\
\text { service at an acceptable cost, cost- } \\
\text { effectiveness for the utility, recovery of } \\
\text { revenue losses due to decreased sales }\end{array}$ & $\begin{array}{l}\text { Consider time of use; address energy } \\
\text { provided by the utility; include credit } \\
\text { for load shifting; energy savings } \\
\text { should be verifiable }\end{array}$ \\
\hline Rater (HERS) & $\begin{array}{l}\text { Energy saving technologies must be simple } \\
\text { to assess; keep the cost of rating down; the } \\
\text { context is real estate transactions }\end{array}$ & $\begin{array}{l}\text { Focus on the house, eliminating } \\
\text { occupant influence }\end{array}$ \\
\hline Lender (EEM) & $\begin{array}{l}\text { Reducing defaults, accuracy and reliability } \\
\text { of energy ratings, increasing the number of } \\
\text { people who can qualify for a loan; the } \\
\text { context is real estate transactions }\end{array}$ & $\begin{array}{l}\text { Consider the predictability of actual } \\
\text { energy savings, including occupant } \\
\text { influence }\end{array}$ \\
\hline Community & $\begin{array}{l}\text { Location and appearance of new } \\
\text { construction, use of public sevices, } \\
\text { compliance with zoning }\end{array}$ & $\begin{array}{l}\text { Consider not just the structure, but its } \\
\text { place within the community }\end{array}$ \\
\hline Environmentalist & $\begin{array}{l}\text { Decreasing environmental damage } \\
\text { (greenhouse gas emissions, acid rain, } \\
\text { damming of rivers, nuclear waste and risk of } \\
\text { accidents); maximal savings--no skimming; } \\
\text { sustainable (i.e. } 100 \% \text { renewable) energy }\end{array}$ & $\begin{array}{l}\text { Not just low-energy, but "green" } \\
\text { buildings; renewable energy is OK; } \\
\text { not just the house, but its occupants } \\
\text { and their lifestyle; consider } \\
\text { transportation energy. }\end{array}$ \\
\hline $\begin{array}{l}\text { Advocate for the } \\
\text { Poor }\end{array}$ & $\begin{array}{l}\text { Low operating costs, low first costs, equity } \\
\text { implications }\end{array}$ & $\begin{array}{l}\text { Include houses affordable by low- } \\
\text { income people }\end{array}$ \\
\hline Health Regulator & Healthy indoor environment & Include indoor air standards \\
\hline Politician & $\begin{array}{l}\text { Avoid making enemies and appear } \\
\text { proactive; macroeconomic and national } \\
\text { security issues }\end{array}$ & Fuel neutrality \\
\hline $\begin{array}{l}\text { Government } \\
\text { Forecaster }\end{array}$ & $\begin{array}{l}\text { Future patterns of energy use and } \\
\text { greenhouse gas emissions, international } \\
\text { commitments to cut emissions }\end{array}$ & $\begin{array}{l}\text { Consider fuel mix, source of } \\
\text { electricity, and choice of materials }\end{array}$ \\
\hline Architect & $\begin{array}{l}\text { Aesthetics, good design, energy not a major } \\
\text { consideration }\end{array}$ & Consider whole house as a system \\
\hline Building Scientist & $\begin{array}{l}\text { Individual technologies, monitored } \\
\text { consumption, research funding }\end{array}$ & $\begin{array}{l}\text { "If it isn't monitored, then it wasn't } \\
\text { used." }\end{array}$ \\
\hline
\end{tabular}




\section{B. Law-Energy House Definitions: Implications for Actors}

Given the diversity of actors shown in Table 2, the interests of some and not of others are likely to be served by any single definition. Not surprisingly, existing definitions tend to favor the interests of the organizations that promulgated them. This aspect of existing definitions is illustrated below. Then some alternative definitions are presented and analyzed similarly.

\section{Existing Definitions}

Recall the de facto definitions of a low-energy house, discussed in Section III. One of these is a house with an expected reduction in the energy budget from that allowed by code. Fifteen to 25 percent reductions are required by some utility DSM programs. The energy budget usually includes only space conditioning (and sometimes only heating), although it occasionally includes water heating and some lighting. Other important aspects of the energy budget are that it is normalized by the size of the house, usually by floor area, and that it is stated in terms of site energy, not primary energy. For houses built as research and demonstration projects this type of definition is usually applied more stringently. A 50 percent or greater reduction is often sought, and whole-house energy use is considered. Still, the performance indicators are usually stated in terms that have been normalized for living area. Another de facto definition used by some utility DSM programs is a house having certain components commonly associated with energy efficiency, for example, additional insulation, an efficient furnace or air conditioner, and an infiltration control package.

These definitions ignore interests of some actors and oppose those of others. Focusing on energy intensity rather than absolute energy use ignores environmentalist and forecaster concerns about total energy use. Developers should like it because it allows them to build large houses that consume a lot of energy, provide a significant profit margin, and still have a marketing edge as low-energy houses. It also assuages the consciences of people who live in them-if they are going to consume conspicuously, at least they can feel as though they are doing their part to protect the environment at the same time.

None of the definitions mention cost-effectiveness. The definition (found in a number of DSM programs) based on upgraded components implicitly includes a cost-effectiveness criterion. Only components which are in some way cost-effective for the utility are deliberately included in major programs (sometimes measures that are not cost-effective are included unintentionally). There are many ways to define cost-effectiveness, and builders, occupants, utility companies, and environmentalists all have varying perspectives from which to judge.

Labeling a house "low-energy" because it includes several more efficient components gives builders little incentive to include additional conservation measures which are cost-effective but invisible. 
Also it fails to take account of synergies, that is, possible increases in efficiency or decreases in costs due to interactions between the component systems of a building (Lovins and Lovins 1991). Such synergistic effects are seen clearly for houses in this compilation. For example, Bigelow Homes' superinsulated houses can now be built for effectively the same cost as conventional houses (Andrews 1994). The added costs of extra insulation, sealing, and low-emissivity windows are offset by eliminating ductwork and downsizing heating and cooling equipment. An analytical framework that gives credit for this kind of comprehensive approach is needed.

The existing definitions address site energy. The focus on site energy reflects a preoccupation with the single house rather than its contribution to resource consumption and its environmental impact. It can lead to absurd conclusions, such as that heating with gas is more energy intensive than heating with electricity. In the case of all-electric houses, stating results in terms of site energy is reasonable, as it is relatively easy to convert the values to primary energy.

\section{Alternative Definitions}

Definitions in use have favored ease of application while paying less attention than might be desirable to larger environmental and equity concerns. Below, several alternative definitions intended to rectify this slight are proposed. All of these apply to whole-house energy use. Despite political difficulties in getting them adopted and practical difficulties in implementing them, it is important to consider alternatives to existing definitions.

The simplest definition would limit whole-house primary energy use (not normalized for house size, climate, or any other levels of service). This kind of heavy-handed definition would be vehemently opposed by most actors as being overly restrictive. Some form of normalization is needed, to allow flexibility in the type of houses that can be considered low-energy houses.

Normalization by the number of occupants is one possible scheme. It shifts the focus away from building science toward broader issues of lifestyle and equitable resource use. The implication is that people, not houses, consume energy but because the building partially determines how much energy a person consumes it is still meaningful to talk about a low-energy house. The per occupant approach is motivated by analyses such as that of Holdren (1991) in which it is suggested that in order to have a liveable future the disparity between energy used by members of "rich" countries and "poor" countries (in $1990240 \mathrm{GJ} /$ person-y and $32 \mathrm{GJ} /$ person-y respectively) should be eliminated by decreasing the per capita energy use of the rich and increasing that of the poor. By 2025 the rich should consume $120 \mathrm{GJ} / \mathrm{y}$ and the poor $63 \mathrm{GJ} / \mathrm{y}$, and by 2050 the distinction should be gone and the rate of energy use should be $95 \mathrm{GJ} / \mathrm{y}$. 
A hypothetical environmentalist would support normalizing by occupancy because that method would encourage reduction of energy use per capita (for occupants of low-energy houses) to a more sustainable level. Developers would probably oppose such a definition because it would be more difficult for them to build large houses that could be marketed as low-energy houses. The target value for a maximum whole-house energy budget could be chosen with reference to either typical consumption of standard new construction, or with reference to a desired value for future per capita energy use. For example, the median value in the pilot data analysis, $40 \mathrm{GJ} /$ person-year (Section VI), could be chosen. This value is one-third of the 2025 target for total energy use of 120 GJ/person-year.

Many institutions would initially oppose normalization by the number of occupants because of the difficulties in implementation. It is hard to know how many people will live in a house before they move in, and it is hard to predict how many and what kind of appliances and gadgets they will acquire and how they will use them. For cases in which it is important to rate the house without reference to its occupants the number of occupants could be estimated based on the design of the house and on cultural norms. The number of occupants and other assumptions could then be used as inputs to simulations of building energy use. Current simulation programs take information on internal gains into account, but use it mainly to correct the space heating demand, not to determine whole-house energy use. The difference between simulated energy use per person and the actual value would be relatively large for any single house. If instead of hypothetical occupants, the actual occupants were to be considered, then actual energy consumption data could be evaluated. But using data for the actual occupants would lead to inconsistencies as families passed through life cycleswhen a child is born (or grows up and moves away), the house might enter (or exit) the low energy category. If the context is not a real estate transaction it makes more sense to talk of a low-energy household than a low-energy house.

An alternative to strict normalization by the number of occupants is to normalize whole-house energy use by both the number of occupants and by the floor area. This would be a compromise between the standard practice and the per capita approach, giving both big, efficient houses and smaller houses intended for lots of people a chance to qualify as low energy. The median value of this indicator in the pilot analysis is approximately $200 \mathrm{GJ} / \mathrm{m}^{2}$ per person per year.

Predictions of performance indicators based on whole-house energy use and the number of occupants have their good points and their drawbacks. One good point is that they provide direct information about how the energy use of a particular house fits into the big picture. Many occupants of the houses studied here were motivated to choose low-energy houses at least partially by concern about environmental protection and sustainable use of resources. These alternative indicators speak to that 
concern. A possible drawback is that they would probably be more complicated to predict and more uncertain than simulations of space heating energy use. Another drawback is that the number of people living in a house is irrelevant to many actors involved in providing housing and energy services. These alternative indicators may not make it into the mainstream institutional framework for providing low-energy houses, but they are very simple and informative when used to analyze past performance, as in the BECA compilation.

In the end, no single best performance indicator stands out. Different indicators are more appropriate for different actors. To keep as many actors as possible interested in low-energy houses, energy ratings for houses should be presented in multiple formats, ranging from unnormalized whole-house energy use, through area-normalized space heating energy intensity and whole-house energy use per person, to whole-house energy use per person per unit floor area. 


\section{Methods}

The general objective of the compilation is to examine the performance of new low-energy houses in order to determine which designs and components are working well and which are not. Items of interest are the overall energy performance of a house and its component systems, the kind of problems that have occurred, and the incremental cost of the energy-efficiency measures. To evaluate energy performance actual measurements of energy consumption are used, not simulations. ${ }^{14}$ Methods for collecting and analyzing performance data vary from house to house, depending on the detail of the data available. After describing the methods for collecting and analyzing these data from an idealized perspective, I discuss problems in applying them to real data.

Houses included in the compilation are identified from published materials, personal contact with builders and researchers, or both. People who contribute data receive a chance to review the data before it is entered into the final database, a letter summarizing how their house compares to other similar houses, and (if they want) a copy of the final report. They are also told that any reports describing the project will not use the occupants' names or addresses and will not link names of data contributors to specific houses, although contributors of data will be acknowledged as such.

The level of analysis applied to any given house depends on which data are available. With only the minimum data needed for inclusion in the compilation the total energy use of various houses can be compared, but it is difficult to tell what contributes to good or poor performance of an individual house. Still, such simple data collected on a broad scale may, depending on the results, provide convincing documentation regarding general trends associated with a given energy design strategy. With more detailed data it is possible to discern the contributions of the different systems which make up the house. With even more detailed data, the energy used by each system can be adjusted to what it would have been had the house been occupied by a standard household. Then the performance of component systems of different houses can be compared.

In the compilation, whole-house energy use is reported in terms of total purchased energy (not normalized), energy per unit area, and energy per person. Unusual end uses such as swimming pools or welding machines are included in the whole-house energy figures and their presence is noted.

\section{A. Working Definition for Comparative Research}

The lack of an agreed upon definition of a low-energy house poses a challenge for the compilation research. One of the research goals is to identify improved definitions of a low-energy house, but the

14. The correspondence between predicted and actual energy consumption is also of interest. 
prerequisite is to collect performance data for low-energy houses. A working definition is needed, to guide the data collection.

The main criterion for including a house in the compilation is self-identification. That is, houses are identified by their builders, occupants, or utilities as being energy efficient (or low energy). Data for houses that appear to use only slightly less energy than standard houses are not actively sought. If researchers contribute them, such data are kept in a separate category-not quite baseline data and not quite low-energy houses. An example of such a borderline house is a conventional one in whichan efficient air conditioner has been installed. Houses built with this kind of relatively small improvement are not included. Houses resulting from utility programs with high market penetration (e.g., 20 percent of all new houses built in a large service territory) are not included. Another criterion is that a house must be its occupants' primary residence. No vacation homes need apply.

\section{B. Data Collection and Requirements}

Although the detail of data available for different houses varies widely, there are minimum requirements for inclusion in the compilation. The type of data available usually vary with the reason a house was built. Houses built as demonstration projects often have detailed energy monitoring data, but little information on how the occupants use the house. Conversely, houses built as commercial ventures tend to have less detailed energy performance data, but often the occupants can be contacted and asked about their house. Below, the procedures for collecting and handling the data are discussed.

\section{Data Requirements}

The minimum data needed for a house to be included in the compilation are (1) annual total purchased energy use (see p. 12, above) as determined from measurement while the house was normally occupied, and (2) a physical description of the building and the things done to make it a low-energy house. Beyond these, additional data are sought. If energy data are available by end use or by time of use (for example, monthly, weekly, daily, or more frequently) the number of analyses and comparisons that can be done increases. Desired data about the occupants are how many, when they were home during the monitoring period, how they used the house (that is, what temperature they like, what appliances they have, and how often they use them), how they like living there, and what motivated them to choose a low-energy house, Other useful data include the incremental cost of the low-energy features, indoor air quality data, and ventilation or infiltration data. In addition, daily average, minimum, and maximum temperatures at a nearby weather station can be obtained for both the period over which the energy use was measured and a longer period to be used in adjusting for effects of climate. 


\section{House Types}

There are many kinds of houses in the compilation. It is convenient to categorize them in a number of ways. For energy performance analysis they are divided according to physical structure type and energy design strategy. For data collection and handling they are grouped according to different institutional mechanisms of production. The latter categorization is relevant to why and how a house was built, how it was identified for inclusion in the compilation, and how detailed the performance data are, as well as how these data are presented.

At one end of the spectrum are the demonstration homes. Built to be studied, these houses are often open for exhibition for several months to a year. Before a household moves in short term testing and monitoring of the unoccupied house is carried out. After occupation the house is monitored in detail for one or more years (for example, Enermodal Engineering 1992). Research results are often published in journal articles and technical reports. ${ }^{15}$ Usually the reports do not contain information about the peoples' use of the house, beyond mentioning the number and life-stage of occupants.

Owner-builder houses are often written up in books and magazines aimed at builders, architects, other professionals, and potential customers (from Solar Today to Fine Homebuilding). These publications rarely contain energy data so the occupants are asked to provide data or to allow access to their utility bills. In most cases energy consumption has not been monitored, but often utility billing data can be obtained. Some owner-builder houses are not connected to the grid, so utility billing data are unavailable.

A third house type is made by production builders, developers who build variations of the same design repeatedly in new housing developments. The developments vary from starter homes to luxury homes and are not necessarily single-family detached houses. Builders of potentially lowenergy houses are identified through trade journals and discussions with utility companies, state energy offices, and home energy rating organizations. Builders are contacted directly and asked to let researchers send a questionnaire (described below) and utility bill release form to a sample of customers. Sometimes the builder distributes the surveys or lets Lawrence Berkeley Laboratory (LBL) distribute them. Many builders decline to participate.

The final house type is social housing, ${ }^{16}$ intended for low-income or elderly occupants. This can be rental or owner-occupied housing. Only a few examples of low-energy housing for low-income

15. Few researchers have been willing to contribute raw consumption data. Such data are needed because articles do not usually describe the house completely enough to exceed the minimum requirements for inclusion in the compilation.

16. Social housing is a term not used in the US technical housing literature (to my knowledge) but often used in Canada, England, and other countries. 
people have been identified so far in the compilation research, one of which is included in this paper. Financial mechanisms giving landlords incentives to decrease operating costs in social housing are still relatively rare.

Identifying houses and obtaining data requires a multifaceted approach. Besides library work and telephoning, the compilation has been publicized to attract voluntary contributions. A flyer describing the project and soliciting contributions was distributed at the 1993 Innovative Housing conference (Vancouver, BC, June 1993) and is sent to people who are interested in contributing data (Appendix A). The project has also been mentioned in Home Energy ${ }^{17}$ and in LBL's Recent Research from the Building Energy Analysis Group. Only a few contributions have resulted from this passive approach, although several people have called to request a report on the project.

\section{Occupant Questionnaire}

The questionnaire is used to obtain various information from occupants: physical information such as house size, layout, and construction type; their use of the house (e.g., indoor temperature settings and occupancy patterns); low-energy design features present; incremental cost of the efficiency measures (if known); their satisfaction with house; and their motivation for buying a low-energy house. The 8-page questionnaire is included here as Appendix B.

For many houses the questionnaire is the only way to obtain information other than interviewing the builder. Therefore, it must be detailed enough without being unduly onerous to complete. It must also be understandable by ordinary people. To limit the number of open-ended responses, most questions are in multiple choice format (Bailey 1987). Earlier questionnaires used for similar purposes (Heard et al. 1985) were studied. Because indoor air quality in tight houses is a concern, questions about this are included. 18 The questionnaire was pre-tested on a small group of houses. Based on the responses, several questions were revised.

During a visit to the office of the builder of the first group of houses studied, the occupants' responses were compared with the builder's records of what had been built. There was a good correspondence for most of the questions. The only major discrepancy was that many people did not correctly identify the type of ventilation system (the results of this cross-check are described further in section VI). Subsequently the ventilation question was revised. Because some people did not even know that they had a ventilation system, the revision has probably not solved the problem completely. In many cases the occupants can be called to check unlikely or nonsensical questionnaire responses.

17. March/April 1994, p. 17.

18. Consultation with Joan Daisey and Greg Traynor, Lawrence Berkeley Laboratory, November 9, 1993. 


\section{Data Handling and Storage}

Data are received in a variety of formats, ranging from paper to diskette or email. Depending on the format, individual house data are entered into spreadsheets or ASCI files. The relational database management system for Unix, /rdb (pronounced RDB), is convenient for organizing and manipulating the data (Manis et al. 1988). Once the data for each house have been checked and performance indicators have been calculated, they are entered into an / rdb table, which contains the information to be used in the comparative analysis. Besides the electronic data, each house (or group of houses if more than one house by the same builder is included) has its own paper file where hard copies of reports and articles, questionnaires, utility bills, and correspondence are kept.

\section{Energy Analysis Procedures}

Because there are many levels of data completeness for houses in the compilation, many levels of data analysis are needed. Choice of analytical procedure is based on both the available data for a given house and the goals of the comparison. The various analytical methods to be applied to different levels of data are shown as a matrix in Figure 1. Most of these methods address energy used for space conditioning. The models discussed below are known as measurement-based building energy models or energy signature models. They predict long term energy use under typical conditions from shorter periods of measured data, and they estimate parameters which can be interpreted as indicators of (usually thermal) performance.

There are several possible approaches to comparing energy use of whole houses, listed here in order of decreasing complexity. One approach which requires submetered data is to consider disparate uses of energy separately, and to normalize each by the level of service provided. A second approach applicable to houses with submetered data is to determine which end-use is dominant, calculate a normalized consumption for that component, and add the remaining consumption without normalization, to come up with an effective normalized annual consumption (NAC). A third approach, applicable to houses without submetering, is that of PRISM (Fels et al. 1986), which normalizes not only heating (or cooling) energy by degree-days but also other energy use which is correlated with outdoor temperature variations (e.g., lighting) regardless of whether the correlation is due to a causal relationship. Finally, normalization can be ignored completely so that unadjusted monitored data are compared.

\section{Simple Procedures}

Simple procedures are mainly arithmetic estimates, applied to the least detailed data. Results are indicators such as annual energy use, per unit area, and per person. If utility bills are available, for some climates and heating systems summer energy use can be treated as a baseload, subtracted from 


\begin{tabular}{|c|c|c|c|c|c|c|}
\hline \multirow[b]{2}{*}{$\begin{array}{l}\text { Frequency of Data } \\
\text { Collection }\end{array}$} & \multirow{2}{*}{$\begin{array}{l}\text { Thermal } \\
\text { Performance } \\
\text { Indicators }\end{array}$} & \multicolumn{3}{|c|}{ Other Information } & \multirow[b]{2}{*}{$\begin{array}{l}\text { Analytical } \\
\text { Procedures }\end{array}$} & \multirow{2}{*}{$\begin{array}{l}\text { Other Per- } \\
\text { formance } \\
\text { Indicators }\end{array}$} \\
\hline & & $\begin{array}{l}\text { Simulated } \\
\text { Energy Use }\end{array}$ & $\begin{array}{l}\text { Indoor Temp. } \\
\text { and Humidity }\end{array}$ & Occupancy & & \\
\hline \multirow[t]{2}{*}{ Annual } & E/DD-area & & & & Simple & E/DD-pers. \\
\hline & (EXX)DD-area & & & & Simple & $\mathrm{X} /$ person \\
\hline \multirow[t]{2}{*}{ Monthly } & $\begin{array}{l}\text { baseload } \\
\text { slope } \\
\text { reference temp. }\end{array}$ & & & & PRISM & \\
\hline & $\begin{array}{l}\text { (E-XYDD } \\
\text { k-value } \\
\text { balance temp. }\end{array}$ & & & & SUBMET & $\begin{array}{l}\text { service- } \\
\text { adjusted X }\end{array}$ \\
\hline \multirow[t]{2}{*}{ Weekly } & $\begin{array}{l}\text { (E-XYDD } \\
\text { k-value } \\
\text { balance temp. }\end{array}$ & 2. & & & $\begin{array}{l}\text { SUBMET } \\
\text { (better fit than } \\
\text { monthily data) }\end{array}$ & $\begin{array}{l}\text { compare } \\
\text { measured } \\
\text { to predicted }\end{array}$ \\
\hline & $\begin{array}{l}\text { E-XYDD } \\
\text { improved } \mathrm{k} \text {-value } \\
\text { balance temp. } \\
\text { internal gains } \\
\text { solar heat }\end{array}$ & (1.0. & $\checkmark$ & & $\begin{array}{l}\text { SUBMET } w / \\
\text { solar gains } \\
\text { comrection }\end{array}$ & $\begin{array}{ll}2 \\
\mathrm{~s} \\
\mathrm{~s} \\
\mathrm{~s}\end{array}$ \\
\hline Daily or Hourly & $\begin{array}{l}\text { thermal mass } \\
\text { improved } k \text {-value } \\
\text { balance temp. }\end{array}$ & 1:- : & Pi: & 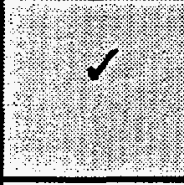 & $\begin{array}{l}\text { relaxation } \\
\text { STEM tests } \\
\text { co-hearing tests } \\
\text { (if done) }\end{array}$ & $\begin{array}{l}\text { compare } \\
\text { physical to } \\
\text { simulated } \\
\text { parameters }\end{array}$ \\
\hline Short term & $\begin{array}{l}\text { thermal mass } \\
\text { improved } k \text {-value } \\
\text { balance temp. }\end{array}$ & 2. & & 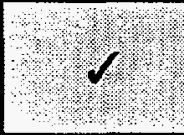 & $\begin{array}{l}\text { relaxation, } \\
\text { STEM tests, } \\
\text { co-heating tests: }\end{array}$ & \\
\hline
\end{tabular}

$E=$ total purchased energy, $X=$ non-heating purchased energy, $D D=$ heating degree day

Each performance indicator or analytical procedure can be applied to houses having more detailed data as well as the category opposite its listing.

$\checkmark \quad$ means that data are available.

indicates that space heating has been submetered.

Figure 1. Data Analysis Matrix

the total to get a zeroth order estimate of annual heating energy use and a zeroth order estimate of heating energy per unit area per heating degree day. But there is no way to adjust the performance indicators for differences in services provided (for example, differences in the weather during the measurement period from average weather, or differences in the occupants' use of the house from a standard family).

\section{PRISM}

The next level of sophistication uses the model PRISM to estimate "what energy consumption would be during a year under typical weather conditions." (Fels 1986) The method was developed for 
analysis of utility billing data but it can be applied to more detailed data as well. PRISM performs a linear regression on energy consumption and heating (or cooling) degree days for each billing period. The reference temperature used to calculate the degree days is varied until the maximum coefficient of determination is obtained. PRISM then uses long term average degree day data with the regression parameters (best reference temperature, slope, and intercept) to calculate the normalized annual consumption (NAC).

Inputs to PRISM are periodic energy use data, daily temperature data over the measurement period, and long term average heating or cooling degree days. Outputs are the NAC, reference temperature, slope, and percent of NAC used for heating/cooling, as well as standard errors of these parameters. The NAC provides a reliable estimate of total energy use, but the other parameters are not as reliable. Their standard errors are relatively larger than that of the NAC and there are also systematic biases, the extent of which depend on many factors particular to the house. For example, PRISM tends to overestimate the energy used for space heat, due to the temporal correlation between appliance use and cold temperatures (Fels et al. 1986).

PRISM is probably the best temperature normalization method available for use with such limited data sources as utility bills, but it has many shortcomings. If the same fuel is used for both heating and cooling (e.g., electric heat pumps) PRISM cannot be used unless the heating and cooling seasons are separated by at least one period during which neither activity occurs (Stram and Fels 1986). In mild climates, such as the Bay Area, nonlinearities in the relationship of energy use per day versus heating degree days per day ${ }^{19}$ can cause distortions as great as $40 \%$ in the regression parameters (Minehart and Meier 1994), although this problem could probably be fixed by using hourly temperature data instead of daily temperature data. Also, PRISM cannot handle solar gains, nor other energy not accounted for with utility billing data, such as wood burning. As with the simple indicators, there is no way to adjust the parameters for differences in services provided.

\section{SUBMET}

The model, SUBMET (Busch and Meier 1986; Meier et al. 1988), allows adjustment for some factors not included in PRISM. It is also a regression-based model but, as the name suggests, one of its inputs is submetered data for space heating energy use. It also requires information about interior temperature, internal gains from occupants and appliances, and heating system efficiency. Outputs are annual space heating energy use, balance temperature, and $k$-value. The balance temperature is the outdoor temperature below which the heating system will be needed. The $k$-value indicates the thermal integrity of the building shell (units of W/C). One difference between SUBMETs k-value

19. The nonlinearity is present for each day that average daily temperature is within the range of one diurnal temperture variation of the reference temperature (Minehart and Meier 1994). 
and PRISM's slope is that PRISM folds the efficiency of the heating system into the slope, whereas SUBMET treats the efficiency as a separate parameter.

The objective of using SUBMET is to remove the influence of particular occupants and weather conditions, to "compare the energy performance of buildings as if they were operated under similar conditions" (Busch and Meier 1986, p.3). Standard values for internal gains and indoor temperature are defined for the group of houses being compared. ${ }^{20}$ Excessive internal gains are added to the heating system energy output and the difference between the actual and the standard indoor temperature is added to the outdoor temperature. The resulting balance temperature and $\mathrm{k}$-value for each house are used to calculate space heating energy use under typical weather conditions. These parameters can be compared with those of other houses so that the only factor being assessed is the thermal efficacy of the building shell. Solar gains are not included explicitly but manifest themselves as lower $\mathrm{k}$-values.

\section{Other}

Not including solar gains in energy signature models can cause systematic bias in the estimation of building parameters. In particular, solar gains tend to correlate with outside temperature, which can lead to an overprediction of a building's lossiness (Flouquet 1992). For simulated buildings in France, Flouquet demonstrated that omission of a variable for the total solar radiation in a vertical southern plane is "the main factor of error in the parameter estimates of a building" (p. 121). This conclusion cannot be generalized to all climates or buildings. Nevertheless, if solar radiation data are available over the measurement periods it would be worth adding a term proportional to this variable to both the PRISM and the SUBMET models. Such data are collected at 29 weather stations in the US through 1993 (although many of the houses in the compilation are not near these stations). These data could be obtained in the future, but they are expensive. An alternate method would be to convert daily data for percent sunshine to solar insolation.

Short-term energy monitoring (STEM) tests have been performed on some houses in the compilation. Such tests as coheating and relaxation experiments are used to characterize thermal paramaters of the house. Annual heating load can be estimated based on the number of heating degree days. Loads drawn by appliances are sometimes measured briefly. Estimates of annual usage are made, based on assumptions about the amount of time the appliance is used. Sometimes houses have STEM test results but do not have long-term monitoring results. Estimates of annual energy

20. One way to do this is to simply pick a standard indoor temperature and to choose the internal gains value based on a statistical analysis of the sample at hand. For example, Busch and Meier (1986) used a floor-area weighted formula. 
use derived from STEM tests are not used as a substitute for monitored data in the compilation, so these houses are not included.

\section{Comparisons}

Several kinds of comparisons are made among the houses in the compilation. First, the performance of the houses are compared to each other. The emphasis is on comparing distributions of energy performance indicators across and within various groups of houses. Second, the differences between performance of each house and an appropriate baseline house are compared. In this way the technical factors (the energy savings) and the economic factors (the incremental costs) are evaluated. Estimating a baseline from which to calculate energy savings is a critical aspect of the technical analysis. Estimating the incremental costs is important to determining whether an energy design strategy is cost-effective.

One way to judge the cost-effectiveness of low-energy houses is to calculate the cost of conserved energy (CCE) and compare it to the cost of supplying energy (Meier 1982). The definition is:

$$
C C E=\frac{I C}{E} \cdot \frac{d}{1-(1+d)^{-n}}
$$

where IC is the incremental cost of the low-energy house over a standard one (\$), $E$ is the annual energy savings (GJ/y), $d$ is the annual discount rate, and $n$ is the lifetime of the investment. Assumptions about the discount rate and the lifetime of the conservation measure are also needed. Busch and Meier (1986) used a three percent real discount rate and assumed that all conservation measures had 30-year lifetimes, but did not explain the reasons for these choices. Difficulties in determining incremental costs are discussed further below.

\section{Baseline Energy Üse}

An important part of comparative research is estimating one or more baselines, representing energy use of conventional new houses. This aspect has historically been the Achilles heel of residential comparative research, and the present compilation is no exception. There are a number of approaches to estimating baseline energy use, all of which have problems. The three approaches used most often in this study are discussed in more detail below.

\section{a. Comparison Groups}

One approach is to try to collect measured consumption data for matched groups of conventional houses, with a control group in each area that has a low-energy house. This approach maintains the emphasis on actual monitored data, but is difficult in practice. Heard and others (1985) found that recruiting control group members was significantly more difficult than recruiting builders and occupants of low-energy houses. Another problem is that small sample sizes can cause efficient 
houses to appear inefficient (and conversely) due to variations in household habits influencing energy use. Sometimes monitored data for a large control group are available for an individual study. These data can be used as a baseline specifically for the houses in that study. An alternative source of baseline data is individual utility companies, which can often provide estimates of energy consumption for typical new houses just meeting local energy codes. The local nature makes this an improvement over a single national baseline data point, but the estimates usually come from simulations and are not necessarily good indicators of how much energy is actually consumed in typical houses.

\section{b. The 1990 Residential Energy Consumption Survey}

One source of baseline data is the 1990 Residential Energy Consumption Survey (RECS) (U.S. Department of Energy 1993). The 1990 RECS sampled more than 5000 dwelling units in the US. The RECS report includes statistics for new houses built between 1988 and 1990 inclusive. The statistics reported are so aggregated that they are of little use as baseline data. ${ }^{21}$ Fortunately, complete data for individual houses are available electronically, enabling researchers to conduct independent analyses.

To develop a baseline, I extracted data from the 1990 RECS data base for dwelling units meeting the following criteria: (1) built in 1987 or later; (2) eleven months or more of actual energy data were collected; (3) less than one third of household energy was estimated to be used for non-residential purposes; and (4) energy data do not include consumption by people in an additional dwelling unit. Of a possible 206 units of the correct vintage, $127(62 \%)$ met the criteria for use. The RECS data do not include the house location on a finer scale than one of nine census regions, but annual heating and cooling degree day data provide additional clues (especially necessary in the Pacific region, which includes Alaska, Hawaii, and the whole west coast). The geographic distribution of RECS baseline houses is shown in Figure 2. The breakdown of the baseline dwelling units by type and region is shown in Table 3. Baseline energy-use data for each house type in each region are given in Appendix C.

\section{c. Simulations}

A third approach to estimating baseline data is to simulate it. Energy consumption for houses meeting local and national energy codes can be calculated for a variety of climates, using building energy simulation program, such as DOE-2. Simulations have not been done explicitly for use as baseline data in this compilation, but existing simulation results have been used. Ritschard and others (1992) calculated the annual energy use of several prototype single-family detached houses in

21. For example, houses with actual utility billing data are combined with houses for which energy consumption was estimated using a regression. Also, all statistics are reported as site energy use. 
Table 3. Breakdown of 1990 RECS Baseline Sample

\begin{tabular}{|l|c|c|l|l|l|l|}
\hline \multicolumn{1}{|c|}{ Region } & $\begin{array}{l}\text { Number } \\
\text { Possible }\end{array}$ & $\begin{array}{l}\text { Number } \\
\text { Meeting } \\
\text { Criteria }\end{array}$ & $\begin{array}{l}\text { Single- } \\
\text { Family } \\
\text { Detached }\end{array}$ & $\begin{array}{l}\text { Townhouse, } \\
\text { Duplex, } \\
\text { Rowhouse }\end{array}$ & $\begin{array}{l}\text { Building } \\
\text { with >5 } \\
\text { units }\end{array}$ & $\begin{array}{l}\text { Mobile } \\
\text { Home }\end{array}$ \\
\hline \hline New England & 26 & 13 & 2 & 4 & 3 & 4 \\
\hline Middle Atlantic & 11 & 8 & 3 & 4 & 0 & 1 \\
\hline East North Central & 29 & 19 & 16 & 0 & 0 & 3 \\
\hline West North Central & 25 & 15 & 11 & 1 & 0 & 3 \\
\hline South Atlantic & 31 & 18 & 7 & 6 & 1 & 4 \\
\hline East South Central & 32 & 24 & 18 & 1 & 0 & 5 \\
\hline West South Central & 7 & 5 & 4 & 0 & 0 & 1 \\
\hline Mountain & 15 & 11 & 6 & 3 & 0 & 2 \\
\hline Pacific & 30 & 14 & 10 & 3 & 1 & 0 \\
\hline Total & 206 & 127 & 77 & 22 & 5 & 23 \\
\hline
\end{tabular}

16 US cities. 22 The houses simulated included (1) base case, with a 1980 s vintage thermal envelope and appliance and equipment efficiencies; (2) ASHRAE 90 Standard (90.2P) thermal envelope and base case appliance and equipment efficiencies; and (3) ASHRAE 90 Standard thermal envelope and 1995 appliance and equipment efficiencies, as expected under the National Appliance Energy Conservation Act of 1987 and the amendments of 1988. The simulated consumption data provide several alternatives to using only the 1990 RECS data as a baseline. Because the simulation results of Ritschard and others (1992) have not been calibrated against monitored data for each city, they must be used warily. ${ }^{23}$. In this paper, the simulated data for Chicago are used as one of several possible baselines for houses built in that area.

\section{Incremental Costs}

Collecting good data for the incremental costs of energy-efficiency measures is a complicated task. Even when researchers or builders provide incremental cost data, these cannot be taken at face value. Usually the data are poorly documented, making it difficult to tell what costs have been included and what has been left out. Often only capital costs are considered. Many design features do not require more capital but require attention to design, for example proper placement of windows. What is the

22. Boston, New York, Chicago, Minneapolis, Kansas City, Washington, Atlanta, Miami, Fort Worth, New Orleans, Denver, Albuquerque,Phoenix, Seattle, San Francisco, and Los Angeles.

23. Joe Huang, LBL, personal communication, June 21, 1994. 


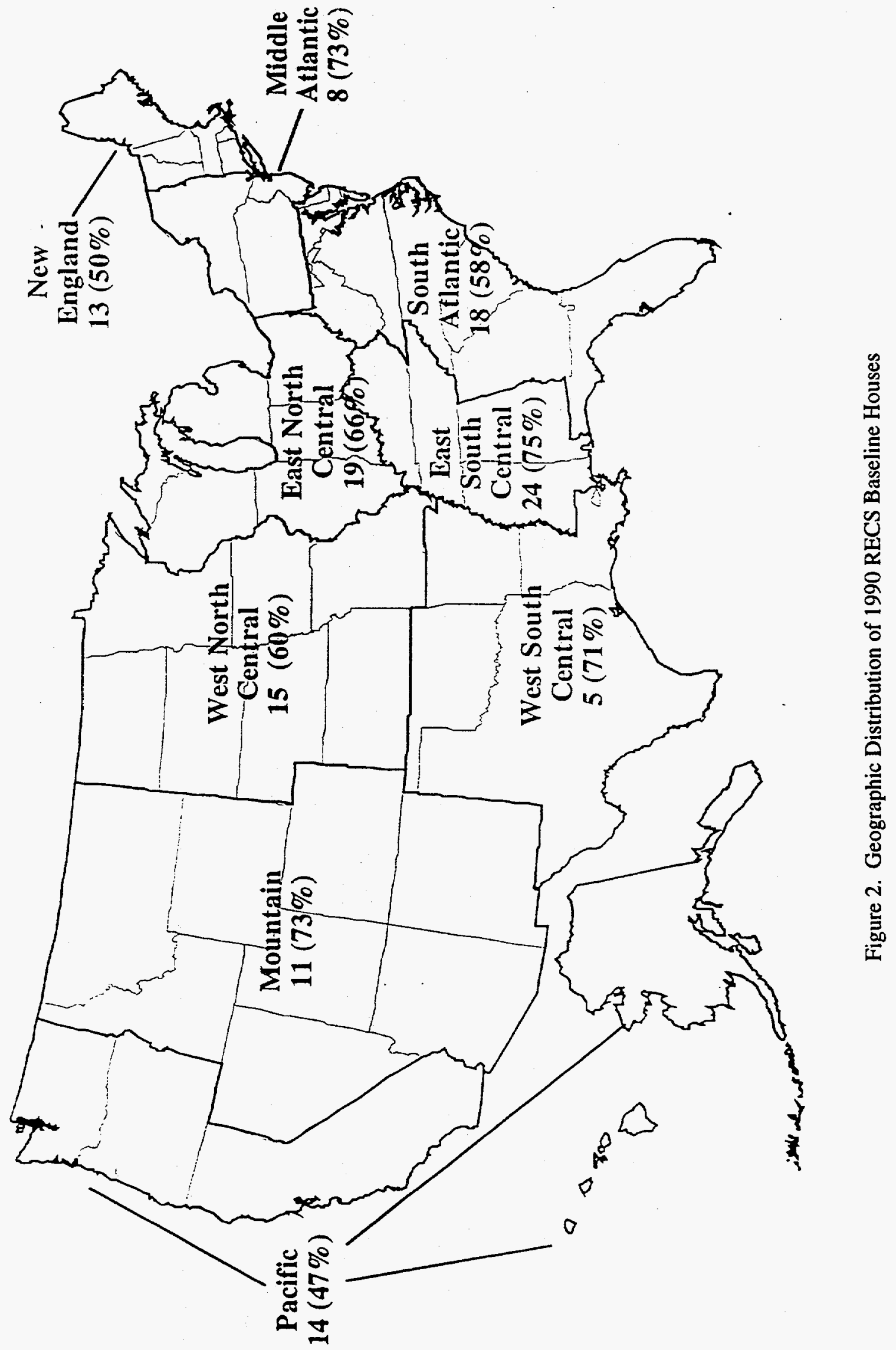


cost of putting a window on the south side rather than somewhere else? An action may cost no more in building materials, but it requires planning. This type of expense is not captured by the incremental cost framework. As a rule, donated labor, as well as previous research and tinkering done by the builder are not included. Another problem with incremental costs is that the concept really applies only to incremental improvements. Houses for which incremental cost data can be considered accurate are houses that are not very different from conventional ones, with energyefficiency upgrades tacked on. Only a few of the houses in this compilation fit that description.

After studying the incremental costs to substitute four passive solar components (one at a time) in place of a standard frame wall, Sullivan and Katz (1979) conclude that "the determination of the incremental cost associated with the substitution of a building system component...for another component may involve a great deal more than a trade-off of \$/unit cost of material swapped. The change may alter the entire building composition" (p. 671). They note that incremental costs depend sensitively on the local cost of materials, and on the specific details of the system being installed. They also discuss ways to decrease incremental costs by using designs that minimize the number of different types of tradespeople needed.

For the compilation, when incremental cost data are provided we attempt to determine what they include and exclude. Although these data are accepted, in most cases they should be treated with a grain of salt. For the pilot data set it has been the exception, rather than the rule to obtain incremental costs data.

\section{E. Methodological Problems and Criticism}

There are several problems with executing the research methods described above. For several reasons discussed below, it is difficult to obtain monitored energy consumption data. Often sufficient records of energy use are not kept. In other cases, the data exist but people will not contribute it to the compilation. Gathering incremental cost data is also difficult and it is not clear that the information to be gained is worth expending the effort necessary to ensure good data quality. The relevance of incremental costs data is discussed and questioned below.

\section{Insufficient Data}

In practice it is not easy to obtain measured data for low-energy houses. One of the main difficulties is in accounting for energy in the form of wood used for space heating. Another difficulty is collecting accurate data for houses that are not connected to utility grids or distribution systems. A third problem is that some utility companies will not provide the data. 
Many low-energy houses are partially heated by wood. The 1990 RECS (U.S. Department of Energy 1993) included an illustration of how much wood makes a cord (128 $\left.\mathrm{ft}^{3}\right)$ and asked people to estimate their consumption. The analysts assumed an energy content of $20 \mathrm{MBtu}$ per cord, which is an average value for a wide variety of woods and is expected to be good to within a factor of two. For lack of a better method, this same approach is used here, but it has many flaws. There is no way to check the occupant's estimate. To know how much of the energy content provides useful heat the efficiency of the fireplace or wood stove is needed. This efficiency is rarely reported, and depends on the way the occupant uses the system. In addition to the energy content of the wood, knowledge of where and how the wood was obtained would be useful in estimating environmental impact.

Most of the houses included in this pilot analysis used wood only infrequently for ceremonial occasions or not at all. In these cases wood is neglected as an energy source. Exceptions are a research house in which wood use was estimated by the researchers (Enermodal Engineering 1992) and several rammed earth houses where occupants reported using fireplaces or wood stoves for about 10 hours per week in January and February, which is too much to neglect.

Off-the-grid houses do not fit the methodology discussed above. There is no utility to measure energy use, except in rare cases (Hammond and Jennings 1991). Many of these houses use photovoltaics, wind, and microhydro power, as well as active and passive solar heating. In the economic analysis, the incremental cost would be the cost of the independent power and renewable energy systems, as well as any demand side measures undertaken to decrease the load. The amount of energy supplied by these independent systems would be irrelevant to the comparison since it is not defined as purchased energy, but annual operation and maintenance expenses should be considered in the economic analysis. ${ }^{24}$ Purchased energy is usually in the form of propane, oil, wood, or some other irregularly delivered fuel. There is sometimes a record of the amount and date delivered, but according to responses from occupants, the tanks are not always completely filled. This makes accurate assessment of energy use over time difficult. In many cases, a tank is refilled only once a year, precluding finer time-resolution for energy-use data.

Another problem is utility companies that will not provide data to anyone but the customer, regardless of the utility release form the customer signed. It is helpful to have a personal contact at the utility, although that by no means guarantees access to data. The builder can usually identify the person with whom they work when servicing new units. In the end, the uncooperative utility hurdle can be overcome, either by using personal connections or by asking the occupants to request their billing histories and then submit them to us. The second option involves delays and attrition.

24. Annual operation and maintenance costs for low-energy houses that are connected to the grid are not considered, but for the economic analysis they should be estimated as well. 


\section{Participation Problems}

While some people have been eager to participate and very helpful, many have not. Many architects and builders say that they do not want to expose their clients to researchers (or to further researchers). Some builders who claim to build energy-efficient houses give the impression that they do not want their products to be evaluated by an outside source. Many researchers send their papers but are unwilling or unable to contribute detailed data. Reasons given are lack of funding, lack of time, or confidentiality concerns. Well-known builders are frequently approached by researchers and reporters, making it a challenge to even get their attention. It took six months of polite but persistent requests, including a visit to one of their construction sites, before one builder decided to participate. More houses could be included in the compilation if there were money to compensate researchers for the time spent collating the data.

One class of house that has been systematically underrepresented in the compilation so far is off-thegrid houses. These houses are usually built in a different context than those by merchant builders (Potts 1993; Tatum 1992) and different methods of identifying and contacting participants are needed. One strategy is to contact purveyors of equipment for stand-alone houses and enlist their support in identifying a sample of willing participants. This could be an emphasis of future research.

\section{Incremental Costs}

Incremental costs of conservation measures have been an important focus of previous compilation research. That is because cost-effectiveness of conservation programs has been a major concern of the research sponsors (usually governmental and utility organizations). There are two reasons these groups are interested in incremental costs. One is to document the energy-efficiency investment decisions made by builders. The other is to project costs of policies or programs involving certain conservation measures. Difficulties collecting quantitative incremental cost data that can be generalized to other houses in other locations have been discussed above. If the analyst is trying to document existing investment decisions, collecting detailed data for existing houses is useful. But if the cost of conserved energy (CCE) is being used as a basis to advocate the adoption of conservation measures, leaving out intangible costs and not accounting for local and temporad variability in costs can provide misleading results. Econometric methods exist that attempt to quantify the unmonetized costs, but their application is beyond the scope of this work.

Builders are also concerned with cost-effectiveness and incremental costs of conservation measures, but they are concerned for different reasons than are governments and utilities. Most builders are more concerned with the ability to maintain or enhance their profit than with the amount of energy saved. Builders have a different idea of how to define cost-effectiveness than do energy analysts. 
Without comprehensive incremental cost data, the CCE cannot be accurately estimated. Does this matter? Presently the CCE is important to policy makers but is not a relevant indicator for most builders. The sentiment of one builder sums up their point of view:

I can't tell you how much more it cost me because, first of all, I've never built these houses the 'bad' way....Besides, even if I did try to tell you, that's not what it would cost someone else to build it, because I've spent years perfecting my system....The point is that I can build my houses and sell them at affordable, attractive prices.

For this builder the energy design used is cost-effective by definition. But his reasoning is not a justification for ignoring the CCE. At a minimum, the CCE is helpful in determining conservation measures which are far outside the realm of cost-effectiveness. But for the CCE to provide accurate information, the intangible costs must be considered. Whether it is worth applying complex economic methods to find a better estimate of the CCE than one based on today's prices and capital costs depends on the importance of the information to be gained. 


\section{Pilot Data Analysis}

As of June, 1994, performance data have been received for approximately 50 houses. Many more houses have been identified, and owners or builders of many of these have been contacted. Before collecting data for too many houses, it is useful to perform a pilot data analysis, to learn the difficulties involved and make sure the right kind of data are being collected. The results of the pilot data analysis are presented here. First the energy design strategies and any particularly interesting features of each house are described Then the houses are compared, using various normalization schemes. The ranking of house performance depends on the type of normalization used.

\section{A. The Houses}

The buildings included in this pilot analysis span a wide range of types of houses, energy design strategies, and data sources. Their characteristics, along with the types of data collected for each of them are shown in Table 4 (a check mark indicates that data have been collected). In this section each house is described briefly. The letters attached to the house types are the same in the tables and the house descriptions in the text.

Table 4. Data Possession

\begin{tabular}{|c|c|c|c|c|c|c|c|}
\hline \multirow[b]{2}{*}{ House } & \multicolumn{2}{|c|}{ Whole-House } & \multirow{2}{*}{$\begin{array}{c}\text { Sub- } \\
\text { metered }\end{array}$} & \multirow{2}{*}{$\begin{array}{c}\text { Incremental } \\
\text { Costs }\end{array}$} & \multirow[b]{2}{*}{ Occupancy } & \multirow{2}{*}{$\begin{array}{c}\text { Amenity } \\
\text { Levels }\end{array}$} & \multirow{2}{*}{$\begin{array}{c}\text { Indoor Air } \\
\text { Quality }\end{array}$} \\
\hline & Elect. & Other & & & & & \\
\hline A & $a$ & $d$ & & & $\checkmark$ & $\checkmark$ & \\
\hline B & 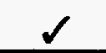 & 1 & & & $\checkmark$ & $\checkmark$ & \\
\hline C & $\checkmark$ & $\checkmark$ & & & $\checkmark$ & $\checkmark$ & \\
\hline D & $\checkmark$ & $\checkmark$ & & & $\checkmark$ & $\checkmark$ & \\
\hline $\mathrm{E}$ & $\checkmark$ & $\checkmark$ & & $\checkmark$ & $\checkmark$ & & \\
\hline F & $\checkmark$ & $\checkmark$ & & $\checkmark$ & & $\checkmark$ & \\
\hline G & $\checkmark$ & $\checkmark$ & & $\checkmark$ & & & \\
\hline $\mathrm{H}$ & $\checkmark$ & & $\checkmark$ & & & & $\checkmark$ \\
\hline I & 1 & & 1 & & & $s$ & $\checkmark$ \\
\hline $\mathrm{J}$ & $\checkmark$ & & 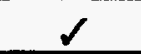 & & & & \\
\hline $\mathrm{K}$ & $\checkmark$ & & $\checkmark$ & $\checkmark$ & & $\checkmark$ & \\
\hline $\mathrm{L}$ & 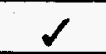 & & $\checkmark$ & $\checkmark$ & & $\checkmark$ & $\checkmark$ \\
\hline $\mathbf{M}$ & $\checkmark$ & & & & 1 & 6 & \\
\hline $\mathrm{N}$ & $\checkmark$ & $\checkmark$ & 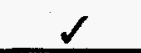 & & & $\checkmark$ & $\checkmark$ \\
\hline
\end{tabular}




\section{Superinsulated Houses in Suburban Chicago, Illinois}

House types $A$ through D are superinsulated 25 single and multifamily houses outside of Chicago, Illinois. The builder has built superinsulated houses since the mid-1980s, and is well-known both for the ability to build quantities of tight houses reliably and affordably and for a successful marketing strategy, which includes guaranteed heating bills for the first three years and a prize for the household with the lowest bill. The houses studied are grouped below according to their energy design strategy and their level of detachment. Types A through D are, respectively, single-family detached superinsulated and passive solar, single-family detached superinsulated, superinsulated duplex, and superinsulated townhouse. The duplexes are joined only at their garages. Of the three townhouses studied, one is an end unit. These houses range in living area from 86 to $350 \mathrm{~m}^{2}$ (930 to $3800 \mathrm{ft}^{2}$ ) including basements, and the incomes of their households range from $\$ 15,000$ to $\$ 200,000$ - a wide range of economic means. Results from a detailed study of these houses are discussed below, in Section VII.

The current construction method has been described recently by Andrews (1994), but the main points are stated here as well. The exterior walls have $2 \times 6$-inch studs, 24-inch on center framing, and R-25 insulation (R-19 fiberglass batt and a layer of 1-inch polyisocyanurate foam sheathing). To avoid compressing wall insulation, conduits are placed at the inner edge of the wall instead of deeper inside. A thorough air sealing job is done, taking between 25 and 30 hours of labor per house (Andrews 1994). Each year a few new houses are blower-door tested as a quality control measure. The windows in the older houses are described as a twin set of single-glazed metal-framed windows with movable insulation between them (Andrews 1994). In newer houses double-glazed lowemissivity argon-filled windows are used. All houses have continuously operating ventilation systems. Those built before May, 1988 have heat recovery ventilation (HRV), while the later ones have exhaust only ventilation. A gas-fired high efficiency water heater also provides space heat, heating air via a heat exchanger. Hot or cool air (for those with central air conditioning) is blown through selected floor joist spaces that are sealed from adjacent floor spaces with caulk, foam, and blocking, eliminating metal ductwork. Central air conditioning is optional and a smaller capacity unit than for conventional construction is used. None of the houses studied had fluorescent light fixtures (the builder began installing fluorescent light fixtures as of 1993). Energy efficiency was not a major concern in the choice of household appliances.

A detailed accounting of incremental costs on a house-by-house basis was not available. Based on cost estimates in Andrews (1994), the cost of conserved energy (CCE) is estimated to be between

25. Unless otherwise stated, henceforth the term "superinsulated" refers to $2 \times 6$-inch studs, 24-inches on center, with at least R-25 exterior wall insulation, R-38 or greater roof insulation, and significant sealing and caulking. 
$\$ 1.00$ and $\$ 2.00$ per GJ 26 for single-family detached houses. This estimate is discussed further below (Section VII.F). For comparison, the average CCE for superinsulated houses with gas heat in the earlier BECA compilation was $\$ 3.92$ per GJ (Busch and Meier 1986).

\section{Superinsulated Apartments, Des Moines, lowa}

The builder and operator of these apartments (E) has focused on life-cycle efficiency. They are designed to be low-energy, low-maintenance, and low-water use. The company pays the tenants' heating bills and guarantees their electric bills. Some of the apartments are for low-income households, having been financed with the Low Income Housing Tax Credit. ${ }^{27}$ These apartments received a USDOE National Award for Energy Innovation in 1992, for documentation of energyefficiency as an investment (Adams 1993). This is one set of buildings for which there are welldocumented incremental cost data. For a 24-plex the incremental cost of the energy efficiency measures comes to $\$ 62,600$, or $\$ 2,610$ per unit. Perhaps because the company owns and manages the buildings they build, they take the attitude that high start-up costs can pay off in the long run. The buildings are master metered, so data for the individual households are not available. Each building has 15 or 24 units, and the consumptions of the buildings are quite consistent, averaging variations of individual households.

The apartments are superinsulated, with special attention to reducing infiltration, such as putting no electrical outlets in the outside walls. Windows are wood thermopane clad-casement windows and each apartment has insulated window quilts that run on tracks and seal on all sides. The occupants apparently use and actually like the window quilts. The appliances and lighting were chosen for their efficiency. The builder has a favorite anecdote about this:

One national appliance company came in $\$ 6,000$ under, but they lost it because it cost $\$ 15$ more per refrigerator per year to operate.... When you're talking about 500 units, it comes out to $\$ 7,500$ per year....The salesman was so distraught that he wanted a copy of my comparison grids to show his boss so he wouldn't think he had bad breath or he had insulted me. (Adams 1993, p. 81)

\section{Passive Solar House, Caspar, California}

This massive custom-built $340 \mathrm{~m}^{2}\left(3700 \mathrm{ft}^{2}\right.$ ) house (F) received the Best Environmentally Sound House award in the 1993 Building Solutions Design Competition (McLees 1994). Built into a hillside on the northern California coast, the northwestern walls are bermed with earth where they extend above the hillside, to deflect the prevailing winds. The roof on the north side is covered by soil and a growing plant cover. The south side has sunspaces, a dark beige Trombe wall, and direct

26. Using a 3\% real discount rate and a 30-year lifetime-the same assumptions as Busch and Meier (1986).

27. The Low Income Housing Tax Credit allows corporations to subtract the amount used to finance non-profit low income housing developments from federal taxes owed. 
gain windows with overhangs to prevent overheating in summer. Ventilation and temperature control are via opening doors and windows. Concrete provides thermal mass, with 95 cubic yards inside the envelope. Under the slab is R-14 rigid insulation, and a continuous R-19 layer wraps around the entire outside. Above-grade parts also have R-19 fiberglass batt insulation between wood framing (and R-30 in the ceiling). There are low-emissivity double-pane wood frame windows.

Additional heating is via a warm glycol solution circulating in the concrete floor slabs. Solar panels heat both domestic hot water (DHW) and the glycol solution. The hot water storage tank is above the panels so that water circulates via a thermosyphon. Two small pumps circulate glycol solution through the slabs. A propane burner backs up DHW system and a wood-fired boiler provides backup heat for the glycol solution (the boiler was not used during the monitoring period). There is a fireplace, which is rarely used. Propane is used for cooking. Electricity is from the grid, but there is a space for solar cells to be placed on the roof in the future. Lighting fixtures are compact fluorescent, and the use of daylight is maximized. The refrigerator is a high-efficiency model.

Table 5. Incremental Costs for House F

\begin{tabular}{|c|c|c|c|}
\hline \multicolumn{2}{|l|}{ Avoided } & \multicolumn{2}{|c|}{ Added } \\
\hline Item & Cost & Item & Cost \\
\hline $\begin{array}{l}\text { Construction of mechanical } \\
\text { space }\end{array}$ & $\$ 1,600$ & Flat plate collectors & $\$ 800$ \\
\hline $\begin{array}{l}\text { Propane forced air heater, } \\
\text { ducting, and controls }\end{array}$ & $\$ 4,000$ & Glycol solution and tubing & $\$ 700$ \\
\hline $\begin{array}{l}\text { Mechanical equipment } \\
\text { installation }\end{array}$ & $\$ 500$ & Pump and pump controls & $\$ 300$ \\
\hline Ducting installation & $\$ 1,000$ & Storage tanks & $\$ 400$ \\
\hline $\begin{array}{l}\text { Joisted floor with hardwood } \\
\text { covering }\end{array}$ & $\$ 6,000$ & Storage space & $\$ 400$ \\
\hline \multirow[t]{6}{*}{50 gallon hot water tank } & $\$ 300$ & $\begin{array}{l}\text { Installation of heating } \\
\text { systems }\end{array}$ & $\$ 500$ \\
\hline & & Heat exchanger & $\$ 100$ \\
\hline & & Propane flash heater & $\$ 300$ \\
\hline & & Refrigerator premium & $\$ 1000$ \\
\hline & & Lighting premium & $\$ 175$ \\
\hline & & Rigid foam insulation & $\$ 1,300$ \\
\hline Total avoided & $\$ 13,400$ & Total added & $\$ 5,975$ \\
\hline
\end{tabular}


This house is distinctive in many ways, including its stunning location by the ocean. Another way it is unusual is that the incremental cost of its energy efficiency measures is negative, with total labor and material costing only $75 \%$ of that for typical custom-built homes in the area. The added costs and avoided costs are summarized in Table 5, for an incremental avoided cost of $\$ 7,400$. The builder did not include the cost of windows, as thermopane windows are now required by the state building code.

\section{PV-Assisted House, Tallahassee, Florida}

House G's builder produces relatively few houses at a time, and lived in this $140 \mathrm{~m}^{2}\left(1508 \mathrm{ft}^{2}\right)$ house for one year before selling it. The Florida Solar Energy Center (FSEC) studied the house and did measure power drawn by various appliances but did not conduct long-term monitoring (Parker and Dunlop 1992). FSEC researchers identified a number of design and implementation irregularities and made suggestions for their correction. In particular, they noted a number of code violations, and that the solar hot water system was correctly sized for domestic hot water needs but undersized for space-heating needs. After the sale, some retrofitting was done. Only consumption data for the preretrofit period have been used in the compilation.

The house is well insulated with $\mathrm{R}-19$ walls and an $\mathrm{R}-40$ ceiling with a radiant barrier stapled to the under-side of the plywood roof decking. The ductwork (insulated to R-4.5), air handler and hydronic space heating coil are all located in the unconditioned attic. The roof has brown asphalt shingles. The windows are double glazed with aluminum frames. Most windows are on the north side (56\% of the total window area) with 9,22 , and $13 \%$ on the east, south, and west sides. The east and west side windows are not shaded. Nor is the exterior condenser of the air conditioner, which is on the east side of the house. The house has two complete sets of wiring-one direct current (DC) for the photovoltaic (PV) system and one alternating current from the grid. Most of the electricity comes from the 320 Wpak PV system, but the air conditioner (SEER 12, 2 ton), microwave oven and well pump run off the grid. An efficient 12-volt DC refrigerator is used. Appliances fueled by propane include the range, oven, and clothes dryer. Water heat is solar with a propane back-up. Space heat is also provided by the hot water system, with a hydronic coil warming the air. FSEC researchers commented that the two $3 \mathrm{~m}^{2}\left(32 \mathrm{ft}^{2}\right)$ solar collectors were undersized to provide both DHW and space heating, and that a better space heating design for Tallahassee's climate would be large, wellshaded south-facing low-emissivity windows with an appropriate amount of thermal mass.

\section{Advanced House with a Ground-Coupled Heat Pump, Tampa, Florida}

This $204 \mathrm{~m}^{2}\left(2200 \mathrm{ft}^{2}\right)$ house $(\mathrm{H})$ is a demonstration project sponsored by Tampa Electric Company, the Polk County Builders Association and the FAMU/USF Cooperative Master of Architecture Program, involving a long list of trade allies. The house combines traditional passive solar design 
with a sophisticated energy management system. Roof overhangs and trees deliberately left in place during construction provide shade. The envelope is superinsulated with a radiant barrier in the attic. The windows are double-pane low-emissivity with wood frames and enclosed blinds between the glazings. Space heating and cooling are via forced air, conditioned by a closed loop geothermal heat pump. The conditioned air and ventilation air are distributed by a central air handler with ducts in the conditioned space. Dampers have been installed to provide zone control. DHW requirements are met by waste heat from the geothermal heat pump and by a dedicated air source heat pump. The variable-volume $\mathrm{HRV}$ is controlled by a carbon dioxide sensor in the living room. Electricity uses of the HVAC system, DHW system, refrigerator, and hot tub have been submetered, with data stored every 15-minutes. Data for indoor air quality are being collected by the Electric Power Research Institute and should eventually be available to this analysis. Very little information about the occupants is available, other than the size of their household. The breakdown in their annual electricity use is as follows (in $\mathrm{kWh}$ ): total, 12700; heating, cooling, and ventilation, 3350; DHW, 1440; refrigerator, 950; hot tub, 870; and lighting and miscellaneous, 6100.

\section{Advanced House, Brampton, Ontario}

This all-electric $408 \mathrm{~m}^{2}$ house (I) was sponsored by the federal and provincial governments and by the local electric utility, as a forerunner to the current Advanced House Program. The house and results of the monitoring are described in a recent report (Enermodal Engineering 1992). Besides superinsulation (walls R-37 to 39 , ceiling R-60, basement floor R-9, sunspace to living area wall R12) and a sunspace which preheats the ventilation air, the house has an integrated mechanical system (IMS) for heat, DHW, cooling, and ventilation. Except for the sunspace, the windows are woodframed triple-pane with two low-emissivity coatings, two argon-gas layers, and butyl-rubber edge spacers. A personal computer-based control system was designed, among other things, to shut off the back-up heater in the hot water tank should the house's load exceed $10 \mathrm{~kW}$, to change the operation mode of the IMS between summer and winter, and to control a motorized skylight over the sunspace (the motorized skylight never worked well). Energy-efficient appliances and lighting were chosen. The residents used wood for back-up space heat. One striking aspect of this house is the high "parasitic" use of energy of pumps and fans. The breakdown in annual electric use is (in kWh): total, 18140; integrated mechanical system, 13300 (3750 was "parasitic"); refrigerator, 385; stove, 388; dishwasher, 217 and washer/dryer, 512 (both exclude energy required to supply hot water); and lighting and plug loads 3340 . It is estimated that $6.1 \mathrm{GJ}$ of wood were burned.

\section{Sumiya House, Sapporo, Japan}

This $136 \mathrm{~m}^{2}$ all-electric house ( $\mathrm{J}$ ) is based on Canada's R-2000 certification requirements. It features superinsulated tight construction, low-emissivity double-pane windows with PVC sashes, and an 
HRV system. The slab-on-grade construction has R-13 insulation between the wood floor and the slab, and polystyrene foam board beneath the slab. It is described in a recent compilation of Japanese low-energy houses (Kudo 1993). One unusual aspect is that the ceiling between the first and second floors is insulated. Space heat is provided by six electric thermal storage space heaters (one $2.45 \mathrm{~kW}$ and five $1.15 \mathrm{~kW}$ ) but the occupants say that three heaters would have been enough. It is still relatively uncommon for Japanese houses to have heating throughout the house. The equivalent leakage area is $0.63 \mathrm{~cm}^{2}$ per $\mathrm{m}^{2}$ of floor area.

This house has not been extensively monitored, but three different categories of electricity bills were collected. These are regular, late night, and snow-melting electricity (a literal translation from the Japanese). Late night electricity costs about one third of regular electricity and is used for constant loads drawn between $11 \mathrm{pm}$ and $7 \mathrm{am}$, such as water heaters and thermal storage space heaters. Snow-melting electricity, costing about $40 \%$ of regular electricity, is contracted for use with loads occurring for more than four months each winter except between $4 \mathrm{pm}$ and $9 \mathrm{pm}$, when the power is cut off. Typical uses are thermal storage space heaters, heated doormats, and driveway heaters (for melting snow). The annual energy use was simulated to be $18293 \mathrm{kWh}$. This is $38 \%$ more than the actual value measured for one year.

\section{R-2000 House with a Heat Pump, Halifax, Nova Scotia}

This $213 \mathrm{~m}^{2}$ all-electric house (K) was certified under Canada's R-2000 low-heating-energy house program, which means that it is superinsulated, tightly built, with a continuous ventilation system. As part of a study focusing on heat pump performance, whole-house, heat pump, and DHW energy consumptions were monitored for one year (Ugursal 1992). Other parameters measured include temperatures and relative humidities of outdoor air, return air, mixed air, and supply air. A two -career couple without children lived there during the monitoring. Efficient appliances and lighting were not an objective of this house's design. Over one year the house consumed a total of 23,000 $k W h$, with 12260 for heating, 1,190 for cooling, 3,020 for $\mathrm{DHW}$, and 6,470 for other uses.

\section{Zero-Heating-Energy House, Waedenswil, Switzerland}

This $150 \mathrm{~m}^{2}$ house $(\mathrm{L})$ is the western half of a three-story duplex in a development of four zero- and six low-heating-energy houses. The house has been extensively studied, with hourly values for 134 parameters having been recorded since June, 1991. Several components of its energy design were new and relatively untested, resulting in the need for considerable commissioning of the building. Within the first two years of occupancy, several systems were completely replaced-in particular the rubber liner for the thermal storage tank and the transparent insulation on the solar collectors. Performance data for the house in its correctly working state are not yet available, but even with its 
problems the house used very little energy. Although the design focuses on heating energy, the house has the best commercially available energy saving electric appliances in Switzerland.

The house is superinsulated tight construction with great attention to eliminating thermal bridges. The walls and roof both have a $U$-value of 0.025 . The walls are made of dense concrete blocks with $180 \mathrm{~mm}$ of extruded polystyrene insulation on the exterior. The roof is insulated with mineral fiber between wooden rafters, and on the interior side is a layer of extruded polystyrene $(40 \mathrm{~mm})$ with another $100 \mathrm{~mm}$ of mineral fiber (CANMET 1993). There are triple-pane argon-filled lowemissivity wood-frame windows, with the highest percentage on the south side, "although a superb view of the Lake Zürich to the north mandates a few north windows and the suboptimal north-south depth also necessitates a few east and west-facing windows for sufficient daylighting." (Kriesi 1990). The house is heated both by direct gain solar heat and by hot water circulating through a lowtemperature floor panel heating system. The water is heated by $33 \mathrm{~m}^{2}$ solar collectors, featuring transparent insulation and a thick layer of glass, oriented vertically on the south facade (the vertical orientation is to satisfy local building codes). No anti-freeze is used in the loop, but there is a resistance heater in case of extremely cold weather. Seasonal thermal storage occurs in a $20 \mathrm{~m}^{3}$ rubber-lined concrete insulated water storage tank, built between the two units of the duplex. No active space cooling is needed but in the summer the storage water has to be cooled in a cooling basin, which doubles as a wading pool. The hydronic system operates either in the pumped mode or by a thermosyphon, depending on whether there is enough solar radiation to cause thermal circulation. Back-up heat is provided by a wood stove. The occupants use the stove more often than required by heat demand because they enjoy it.

Heat recovery ventilation is used, with preheating (or cooling, in summer) of air drawn beneath the house. This preheating contributes nearly two thirds of the saved thermal energy from the HRV system. The radon concentration of indoor air is being monitored to make sure there is no problem with bringing ventilation air from under the house. The occupants report that air quality is generally good. In the summer the ventilation system is turned off and the occupants open windows. A waste water heat recovery system is used in the winter to preheat $\mathrm{DHW}$ from $10^{\circ} \mathrm{C}$ to $30^{\circ} \mathrm{C}$. During the summer the solar collectors completely heat the DHW.

\section{Rammed Earth Houses in Tucson, Arizona}

The builder of these houses (M) works with the owners to build custom houses on land they already own. His own house is included in this sample. The owners and the builder completed questionnaires and utility bill release forms, but the gas company refused to send the bills. Data for one all-electric house is complete, and the residents of the houses using gas have been asked to 
obtair their gas billing histories and forward them. These houses range in size from 89 to $195 \mathrm{~m}^{2}$ (960 to $2100 \mathrm{ft}^{2}$ ) and the annual incomes of their households range from $\$ 25,000$ to $\$ 80,000$.

The houses have 18-inch thick earthen walls and earthen floors, with insulated ceilings. The high thermal mass works with southern windows to minimize heat loads. Some houses have electric resistance heating installed as a back-up, and most occupants burn wood for about ten hours each week during January and February. No air conditioning is needed. Some houses have solar DHW systems.

\section{Canada R-2000 Type House, Sendai, Japan}

This $165 \mathrm{~m}^{2}$ tight, superinsulated Japanese house (N) is based on Canada's R-2000 construction methods. The energy use, indoor environment, and important building parameters such as the water content of the wood framing have been studied in detail by researchers at Tohoku University (Yoshino and others 1993). Space heating is provided by an oil-fired boiler with hydronic panel radiators. In addition, an electric kotatsu warms the occupants when they sit around the living room table. An oil-fired water heater provides DHW. The windows are double-glazed low-emissivity with PVC frames, and are fitted with automatic insulated weather shutters (CANMET 1993). Efficient appliances and lighting were not an objective of this house's design. The breakdown in annual energy use is (in GJ): total, 44; space-heating, 15.4; water-heating 16.3; and site electricity, 12.5. The house consumes about half as much energy for space-heating as do typical houses in the region, and about $70 \%$ of a contemporary comparison house. In making this comparison, it is important to note that in most Japanese houses only a few rooms are heated, so superinsulated, tight construction significantly improvements in comfort without increasing energy use.

\section{B. Whole-House Comparisons}

For each building (or group of buildings) discussed above, I have calculated several indicators of whole-house energy performance, presented in Table 6. Not surprisingly, the unadjusted data show that larger houses tend to use more energy. Building $E$ has the largest energy use, but that is an artifact because it is actually the average of 15- and 24-plex apartment buildings which are master metered. Where available, national averages for new construction from the 1990 RECS (U.S. Department of Energy 1993) are shown for comparison. ${ }^{28}$ National averages from RECS are shown for illustrative purposes only. The regional data (Appendix $\mathrm{C}$ ) are more meaningful as baselines.

28. The values given here are based only on houses with complete energy data, so they differ from the values stated in the RECS report. 
Table 6. Energy Performance Indicators

\begin{tabular}{|c|c|c|c|c|c|c|c|c|c|}
\hline \multirow[t]{2}{*}{ House $^{a}$} & \multirow{2}{*}{$\begin{array}{l}\text { Living Area } \\
\left(\mathrm{m}^{2}\right)\end{array}$} & \multirow{2}{*}{$\begin{array}{c}\text { Electricity } \\
(\mathrm{kWh} / \mathrm{y})\end{array}$} & \multirow{2}{*}{$\begin{array}{l}\text { Other } \\
(\mathrm{GJ} / \mathrm{y})\end{array}$} & \multicolumn{2}{|c|}{ Site Energy } & \multicolumn{4}{|c|}{ Primary Energy } \\
\hline & & & & $(G J / y)$ & $\left(M J / y-m^{2}\right)$ & $(G J / y)$ & $\left(M J / y-m^{2}\right)$ & (GJ/pers-y) & $\left(\mathrm{MJ} /\right.$ pers-y-m $\left.\mathrm{m}^{2}\right)$ \\
\hline$A(7)$ & 280 & 9235 & $104^{b}$ & 140 & 550 & 200 & 830 & 79 & 280 \\
\hline B (6) & 204 & 6947 & $102^{b}$ & 130 & 670 & 180 & 970 & 49 & 240 \\
\hline$C(5)$ & 147 & 5970 & $34.7^{b}$ & 100 & 740 & 150 & 1000 & 68 & 460 \\
\hline D (3) & 110 & 6358 & $46.9^{b}$ & 70 & 640 & 120 & 1100 & 45 & 410 \\
\hline E (19) & 1822 & 17670 & $617^{b}$ & 680 & 370 & 810 & 450 & 19 & 10 \\
\hline $\mathrm{F}$ & 374 & 3761 & $10.9 \mathrm{c}$ & 24 & 65 & 52 & 140 & 26 & 69 \\
\hline G & 140 & 2488 & $30.5^{\mathrm{c}}$ & 39 & 280 & 58 & 410 & 19 & 140 \\
\hline $\mathrm{H}$ & 204 & 12700 & $0^{d}$ & 46 & 220 & 140 & 680 & 69 & 340 \\
\hline I & 408 & 18129 & $6.1^{\mathrm{e}}$ & 71 & 180 & 200 & 530 & 72 & 180 \\
\hline J & 136 & 13284 & $0^{d}$ & 48 & 350 & 130 & 920 & 25 & 180 \\
\hline $\mathbf{K}$ & 213 & 23045 & $0^{d}$ & 83 & 390 & 250 & 1200 & 130 & 590 \\
\hline $\mathbf{L}$ & 150 & 2500 & $4.5^{\mathrm{e}}$ & 14 & 88 & 32 & 210 & 7.9 & 52 \\
\hline $\mathbf{M}$ & 181 & 6450 & $10.5^{\mathrm{e}}$ & 34 & 190 & 81 & 450 & 40 & 220 \\
\hline $\mathrm{N}$ & 165 & 3483 & 31.7 & 44 & 270 & 70 & 420 & 17 & 110 \\
\hline $\operatorname{RECS}^{f}(127)$ & 231 & 11110 & NAg & 120 & 580 & 200 & 1050 & 73 & 432 \\
\hline
\end{tabular}

a. The number of buildings included in the values is shown in parentheses, unless it is a single building.

b. Natural gas

c. Propane

d. All electric houses

e. wood

f. Residential Energy Consumption Survey (USDOE 1993)

g. Includes a mix of all-electric and houses which use fuels. 
Table 7. Ranking of Example Houses According to Different Normalizations

\begin{tabular}{|c|c|c|c|c|c|c|c|}
\hline & \multicolumn{2}{|c|}{ Total Energy } & \multicolumn{2}{c|}{ Energy per unit area } & \multicolumn{2}{c|}{ Energy per person } & $\begin{array}{c}\text { Energy per } \\
\text { person per } \\
\text { unit area }\end{array}$ \\
\cline { 2 - 9 } Rank & Site & Primary & Site & Primary & Site & Primary & Primary \\
\hline \hline 1 & L & L & F & F & L & L & E \\
\hline 2 & F & F & L & L & J & N & I \\
\hline 3 & M & G & I & G & N & E & F \\
\hline 4 & G & N & M & N & F & G & N \\
\hline 5 & N & M & H & M & G & J & G \\
\hline 6 & H & D & N & E & E & F & I \\
\hline 7 & J & J & G & I & M & M & J \\
\hline 8 & D & H & J & H & H & D & M \\
\hline 9 & I & C & E & A & I & B & B \\
\hline 10 & K & B & K & J & D & C & H \\
\hline 11 & C & I & A & B & B & H & A \\
\hline 12 & B & A & D & C & K & I & D \\
\hline 13 & A & K & B & D & C & A & C \\
\hline 14 & - & - & C & K & A & K & K \\
\hline
\end{tabular}

The houses are ranked according to various energy performance indicators (Table 7). Each indicator is subdivided into two categories, one considering site energy, and one primary energy. (The application of each indicator and which actors might favor certain indicators is discussed above (Section IV). As expected, which houses are ranked highest or lowest depend on which normalization schemes are used. The apartments (E) are excluded from the total energy ranking because it is not meaningful to compare whole multifamily buildings to single dwelling units without normalization.

Table 7 illustrates the influence of different normalization methods on the outcome of energy intensity calculations. Note that these rankings do not include adjustments for the effect of different climates on energy consumption. Houses $\mathrm{F}$ and $\mathrm{L}$ use relatively little energy so they perform well regardless of the normalization framework (although House F might compare less favorably if 
climate were addressed). The Japanese and Swiss houses and the efficient apartments use the least energy per person. Not surprisingly, houses for which only space heating energy was targeted (for example A, B, C, and D) tend to perform less well in this comparison of total energy use.

Which of these are low-energy houses, according to the existing definitions (discussed in Section III.A)? Consider a 50\% reduction in total energy use from the US average. Houses L, F, M, G, N, $\mathrm{H}$, and $\mathrm{J}$ meet this criterion, using less than $60 \mathrm{GJ} / \mathrm{y}$ of site energy (only Houses L, F, G, N, and M qualify if primary energy is considered). If the cut-off is relaxed to a $20 \%$ reduction, houses $\mathrm{D}, \mathrm{I}$, and $\mathrm{K}$ are also included. Houses $\mathrm{F}, \mathrm{L}, \mathrm{I}, \mathrm{M}, \mathrm{H}$, and $\mathrm{N}$ meet the criterion of a $50 \%$ reduction in site energy per unit of living area, with houses $\mathrm{G}, \mathrm{J}, \mathrm{E}$, and $\mathrm{K}$ qualifying under the criterion of a $20 \%$ reduction.

Some houses do not qualify if compared with the U.S. national averages but do qualify when compared to local baselines. For example, house I consumed slightly less than half the energy of a simulated baseline house, identical except that it had been built to the 1985 Ontario Building Code (although House I used $70 \%$ of the energy used by an identical simulated R-2000 house). Another example is the houses in group $A$, which use more energy than the national baseline (or the same, if primary energy is considered) but use only two thirds of the regional baseline quantity. If the effects of different climates are not taken into account by normalization then the only truly appropriate baseline is a local one.

Another type of existing definition discussed above, the presence or absence of conservation. measures, is not a useful definition by which to judge monitored energy performance data. However, it is interesting if a house with such measures performs badly, or if a house without such measures performs well. For example, the R-2000 program requires mechanical ventilation in tight houses. House $\mathrm{F}$ does not have mechanical ventilation, relying on the occupants to open and close windows and yet it is a low-energy house by almost any other definition. Conversely, Houses A, B, $\mathrm{C}$, and $\mathrm{D}$ contain all the components expected in superinsulated, tight houses, but are not low-energy houses by many definitions. Another example is a rammed earth house in the compilation, which did not qualify for a state-sponsored energy-efficient new house rebate because its construction so radically differed from the norm. The owner was told that the office had "no guidelines for evaluating mass", a fact which had nothing to do with the house's energy performance.

\section{Space Heating Estimates and Comparisons}

A number of houses in this compilation have submetered data for space conditioning equipment. All but one of these houses are all-electric. Only one all-electric house does not use the same equipment for both heating and cooling (the house in Sapporo, Japan does not need cooling). If the heating 
equipment performs other functions, then monitored energy use of that equipment alone is not sufficient to apportion energy use between end uses. To isolate the space heating component other data are needed as well. The extent of the additional data needed depends on the other functions of the equipment. For example, if cooling is the only other function (e.g., an air source heat pump), then hourly, or even daily, outdoor temperature data for the monitoring period would allow an educated guess as to whether heating or cooling was occurring, since both heating and cooling do not occur simultaneously. In more complicated systems, such as the one in House I, apportionment of the energy consumed among the end uses is difficult.

To understand the biases in estimates of space-heating energy obtained from whole-house utility billing data it is useful to compare them to the actual measured values. Various estimates for the houses with time-resolved whole-house energy data are shown in Table 8, for both raw and areaadjusted energy use. The simple estimates are obtained by subtracting a baseload value (derived from the summer rate of energy use) from annual whole-house energy use. They are not normalized to account for differences in the weather during the monitoring period from long-term average weather. The PRISM estimate of annual space-heating energy is obtained from a regression of whole-house energy consumption against outdoor temperature, and is adjusted to reflect long-term average weather conditions. PRISM estimates are not available for houses in areas with insufficient weather data, or for the house with the heat pump. The actual values were directly measured, and are only available for houses in which space-heating energy was submetered. There is only a slight difference between the PRISM and the simple estimates, with PRISM providing a slightly higher estimate. The good correspondence is due to the temporal correlation between summer and higher temperatures, and to the normalcy of weather during the monitoring period.

When compared to actual space-heating energy, the simple estimates (and by inference, PRISM estimates as well) are significantly different. For house N, the simple estimate is $36 \%$ too high. One reason for the overestimate is that other end-uses (e.g., water heating) also consume more energy in the winter than in the summer. If there is not a significant cooling load (or if another fuel is used for cooling) then some overestimation is to be expected. On the other hand, in the heat pump house (K) the simple estimates underestimate the amount of energy used for space heating. Note that PRISM in its current incarnation cannot be used effectively on houses with appreciable heating and cooling provided by a heat pump, unless the cooling and the heating seasons are separated by at least one period during which neither use occurs.

To assess the space heating performance of the houses in this compilation, where possible local baseline data are shown in Table 8 . All values are primary energy, except where indicated. 
Table 8. Space-Heating Energy Consumption Estimates

\begin{tabular}{|c||c|c|c|c||c|c|c|c||c|}
\hline \multicolumn{1}{|c||}{} & \multicolumn{5}{c||}{ Energy (GJ/y) } & \multicolumn{5}{c||}{ Energy Intensity } \\
(MJ/m ${ }^{2}$-y $)$ & $\begin{array}{c}\mathrm{kJ} / \mathrm{m}^{2}- \\
\text { HDD(C) }\end{array}$ \\
House & Simple & PRISM & Actual & Baseline & Simple & PRISM & Actual & Baseline & Estimate \\
\hline \hline A & 68 & 73 & - & 125 & 269 & 288 & - & 560 & 75 \\
\hline B & 68 & 73 & - & 125 & 336 & 366 & - & 560 & 94 \\
\hline C & 49 & 47 & - & 125 & 340 & 332 & - & 560 & 95 \\
\hline D & 27 & 28 & - & - & 249 & 257 & - & - & 70 \\
\hline E-1 & 290 & 310 & - & - & 201 & 214 & - & - & 57 \\
\hline E-2 & 320 & 330 & - & - & 180 & 187 & - & - & 51 \\
\hline E-3 & 410 & 440 & - & - & 186 & 200 & - & - & 52 \\
\hline J & $29 \mathrm{a}$ & - & - & - & 214 & - & - & - & 54 \\
& $76^{\mathrm{b}}$ & & & & 560 & & & & 140 \\
\hline K & $37^{\mathrm{a}}$ & - & 44 & - & 170 & - & 207 & - & 48 \\
& $110^{\mathrm{b}}$ & & 134 & & 520 & & 630 & & 145 \\
\hline N & 21 & - & 15.4 & 19.2 & 127 & - & 93 & 162 & 37 \\
\hline
\end{tabular}

a. Site energy

b. Primary energy

Although houses A, B, and C, might not be considered low-energy houses under the whole-house framework, they only require 38 to $58 \%$ of the energy required to heat comparable new houses in the area. ${ }^{29}$ An estimate of the area-adjusted energy use per heating degree day (base $18.3^{\circ} \mathrm{C}$ ) allows a comparison of the space heating energy intensity of houses in different climates.

\section{Space Cooling Comparisons}

Energy used for space cooling has been monitored in a few of the all-electric houses in this study. I have not been able to estimate energy used for space cooling of houses in which it was not directly monitored. Simply subtracting baseload energy use (determined from spring and fall periods) only works in climates without major cooling or heating during those periods. Also, for simple subtraction to give reasonable results cooling energy must be relatively large compared to the baseload. There is a joint heating and cooling model of PRISM, but this can only be used successfully in climates with distinct, nonoverlapping heating and cooling seasons. For houses with

29. Baseline data were received from Northern Illinois Gas (letter from Larry Stege, March 7, 1994). 
heat pumps, it is possible that sorting the heat pump energy use data into heating and cooling period bins will allow reasonable estimates. Because energy used for space cooling is a major component of peak power demand an improved understanding of the cooling load in so-called low-energy houses is desirable. A future focus of this compilation research should be to improve estimates of cooling energy. 


\section{Case Study: Bigelow Homes}

Bigelow Homes (BH) is a well-known production builder of superinsulated houses, building about 100 townhouses per year in the Chicago suburbs and exurbs during the early 1990 s. BH has built superinsulated houses since the mid-1980s, and is known both for building quantities of tight houses reliably and affordably and for a successful marketing strategy, which includes guaranteed heating bills for the first three years and a prize for the household with the lowest bill. We evaluated the energy performance of $21 \mathrm{BH}$ houses using occupant surveys and analysis of utility bills. The results confirm that occupants are satisfied with their houses, and that their heating bills are often less than half of what occurs in comparable standard new construction in the area. Furthermore, the houses cost little more to build than standard construction.

There are many good reasons to evaluate the energy performance of $\mathrm{BH}$ houses. The builder's relatively high profile in the energy-efficient house field makes them a natural object of study. Chicago's climate, with both heating and cooling requirements is challenging. Studying a number of houses differing only in their occupants is attractive. In addition, because BH builds for a variety of income groups the houses studied here include a wide spectrum of household types and housing types.

\section{A. The Houses}

The BH houses look ordinary, except for an occasional sunspace. The houses studied are grouped according to their energy design strategy and their level of detachment. The four types of houses studied are (A through D respectively) single-family detached (SFD) passive solar, regular SFD, duplex, and townhouse. The passive solar houses have south-facing sunspaces, or a majority of windows on the south side. No particular attention to orientation has been paid for the other houses. The duplexes are joined only at their garages. Of the three townhouses studied, one is an end unit. These houses range in living area from 86 to $350 \mathrm{~m}^{2}$ (930 to $3800 \mathrm{ft}^{2}$ ) including basements, and the incomes of their households range from $\$ 15,000$ to $\$ 200,000$ - a wide range of economic means. The construction and energy design of these houses is discussed above (Section VI.A).

\section{B. Sampling Procedures and Sample Composition}

Both the builder and the occupants cooperated with the study. BH provided a customer list and reviewed the materials to be sent to their customers. About 100 randomly chosen original owners living in houses built between 1987 and 1992 were sent surveys asking about their house, their use of it, and their satisfaction with it. As a token of thanks for participating, the owners were offered a 
Lawrence Berkeley Laboratory t-shirt. ${ }^{30}$ After one follow-up mailing, 23 completed questionnaires were received (an acceptable response rate, given the length of the survey the owners were asked to complete, but not high enough to rule out a self-selection bias). Townhouses were underrepresented while duplexes were overrepresented. During a one-day visit to the $\mathrm{BH}$ office the survey results were compared with records of what was actually built and reasonable agreement was found. Complete electricity and gas usage data for 21 houses were obtained from local utility companies. Estimates of space heating energy use were obtained using PRISM (Fels 1986). In the end, the BH data include basic but comprehensive information on energy usage, housing characteristics, energy design, the occupants' use of the house, their satisfaction with it, and their motivation for buying it.

The questionnaire included a great deal of information relevant to energy use of these households. Much of the information was not used directly. If the sample were a lot larger then the survey results could be used in a conditional demand analysis. Instead, the purpose of the survey was mainly quality control of the energy consumption data, for example to aid in understanding outliers and to eliminate periods during which the house was vacant.

\section{Energy Analysis}

A variety of energy performance indicators have been calculated for each house. Average values for each house type are shown in Table 9, together with regional baseline data (U.S. Department of Energy 1993). On average, the BH houses use only 40 to 60 percent of the space-heating energy that would be used by a comparable standard house. The small townhouses consume less energy than larger houses, both for space heating and for other uses. If energy per unit floor area is considered the large houses appear to perform better.

The houses were sorted into groups, based on such things as presence or absence of central air conditioning, type of fuel for various appliances, year in which the house was built and house size. House size was an important determinant of heating energy requirements. No other trends were evident in the energy performance data by these groups.

Distributions of energy performance indicators are shown for the BH sample in Figures 3 through 6. Where possible, local baseline data are also shown. Gas used for space heating and space-heatingenergy intensity were both significantly lower than the local baseline. Electricity use varied widely. Local baseline data for electricity use were not available but the average annual usage of 15 singlefamily detached houses without electric heat in the East North Central Division of the USDOE 1990 Residential Energy Consumption Survey was 10,000.kWh.

30. Note that this practice was not continued after $\mathrm{BH}$, because it was too expensive. 
Table 9. Energy Performance Indicators for Bigelow Homes

นू

\begin{tabular}{|c|c|c|c|c|c|c|c|c|c|c|c|}
\hline \multirow{2}{*}{$\begin{array}{l}\text { House } \\
\text { Type }\end{array}$} & \multirow[t]{2}{*}{$\mathrm{N}$} & \multirow{2}{*}{$\frac{\text { Area }}{m^{2}}$} & \multirow{2}{*}{$\frac{\text { Electricity }}{k W h}$} & \multicolumn{2}{|c|}{ Site Energy } & \multicolumn{3}{|c|}{ Primary Energy } & \multicolumn{3}{|c|}{ Heating Energy } \\
\hline & & & & GJ & $\mathrm{MJ} / \mathrm{m}^{2}$ & GJ & $\mathrm{MJ} / \mathrm{m}^{2}$ & GJ/pers & GJ & $\mathrm{MJ} / \mathrm{m}^{2}$ & $\mathrm{~kJ} / \mathrm{m}^{2}-\mathrm{HDD}$ \\
\hline$A$ & 7 & 280 & 9200 & 140 & .550 & 200 & 8.30 & 79 & 73 & 290 & 82 \\
\hline $\mathrm{B}$ & 6 & 204 & 6900 & 130 & 670 & 180 & 970 & 49 & 73 & 370 & 100 \\
\hline C & 5 & 147 & 6000 & 100 & 740 & 150 & 1000 & 68 & 47 & 330 & 93 \\
\hline $\mathrm{D}$ & 3 & 110 & 6400 & 70 & 640 & 120 & 1100 & 45 & 28 & 260 & 73 \\
\hline $\mathbf{R}$ & 16 & 380 & 10000 & 210 & 550 & 290 & 790 & 93 & $\therefore$ & -. & -- \\
\hline $\mathrm{U}$ & -- & 270 & -- & - & -- & $\cdots$ & -- & -- & 125 & 560 & 160 \\
\hline
\end{tabular}
A: Single-family detached, superinsulated and passive solar
B: Single-family detached, superinsulated
C: Duplexes, superinsulated
D: Townhouses, superinsulated
R: Baseline: 1990 RECS, Region 3 (WI, IL, IN, OH, MI), single-family detached
U: Baseline: Estimate for typical new single-family detached houses in service territory 


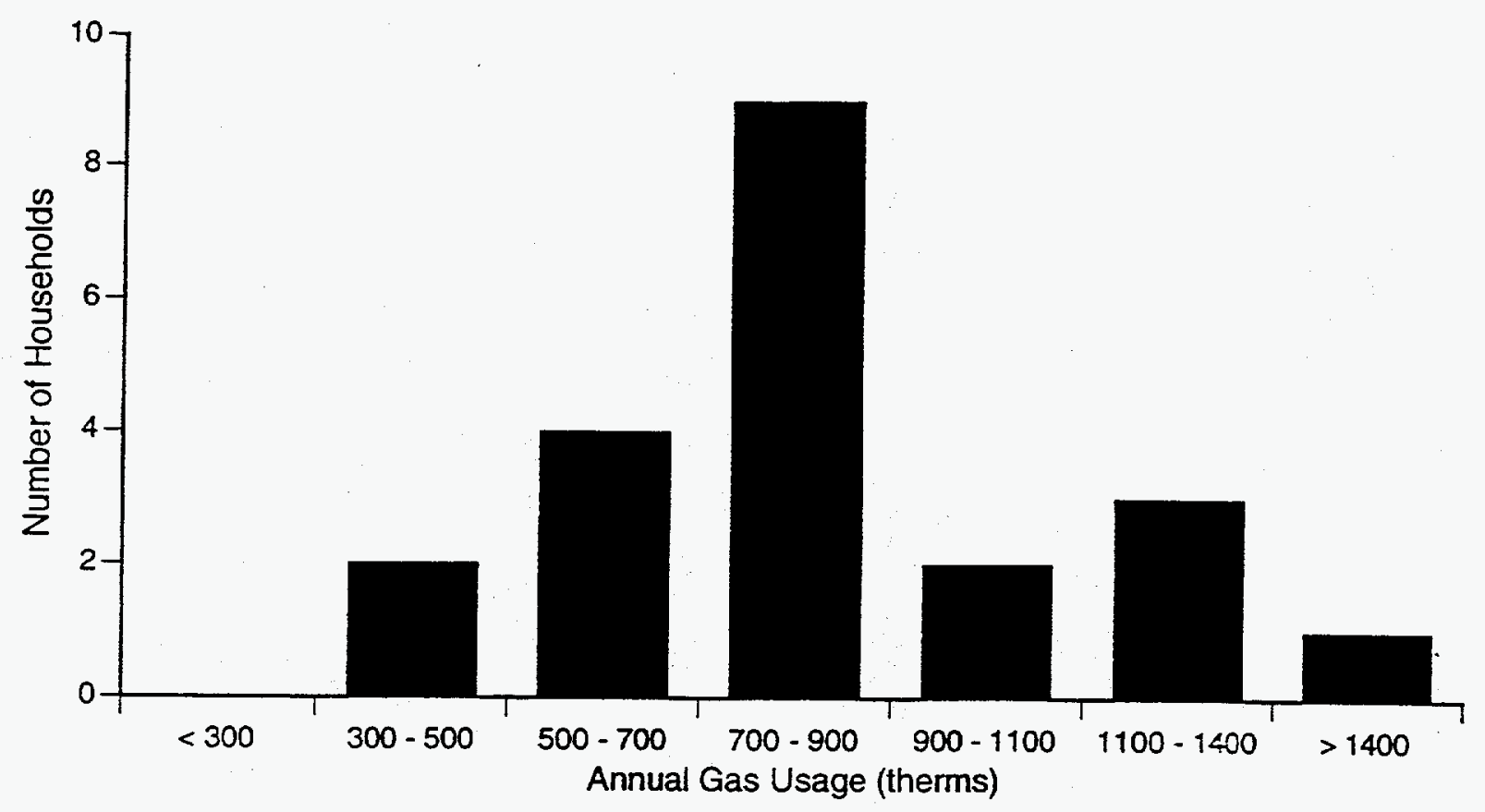

Figure 3. Bigelow Homes Total Gas Use

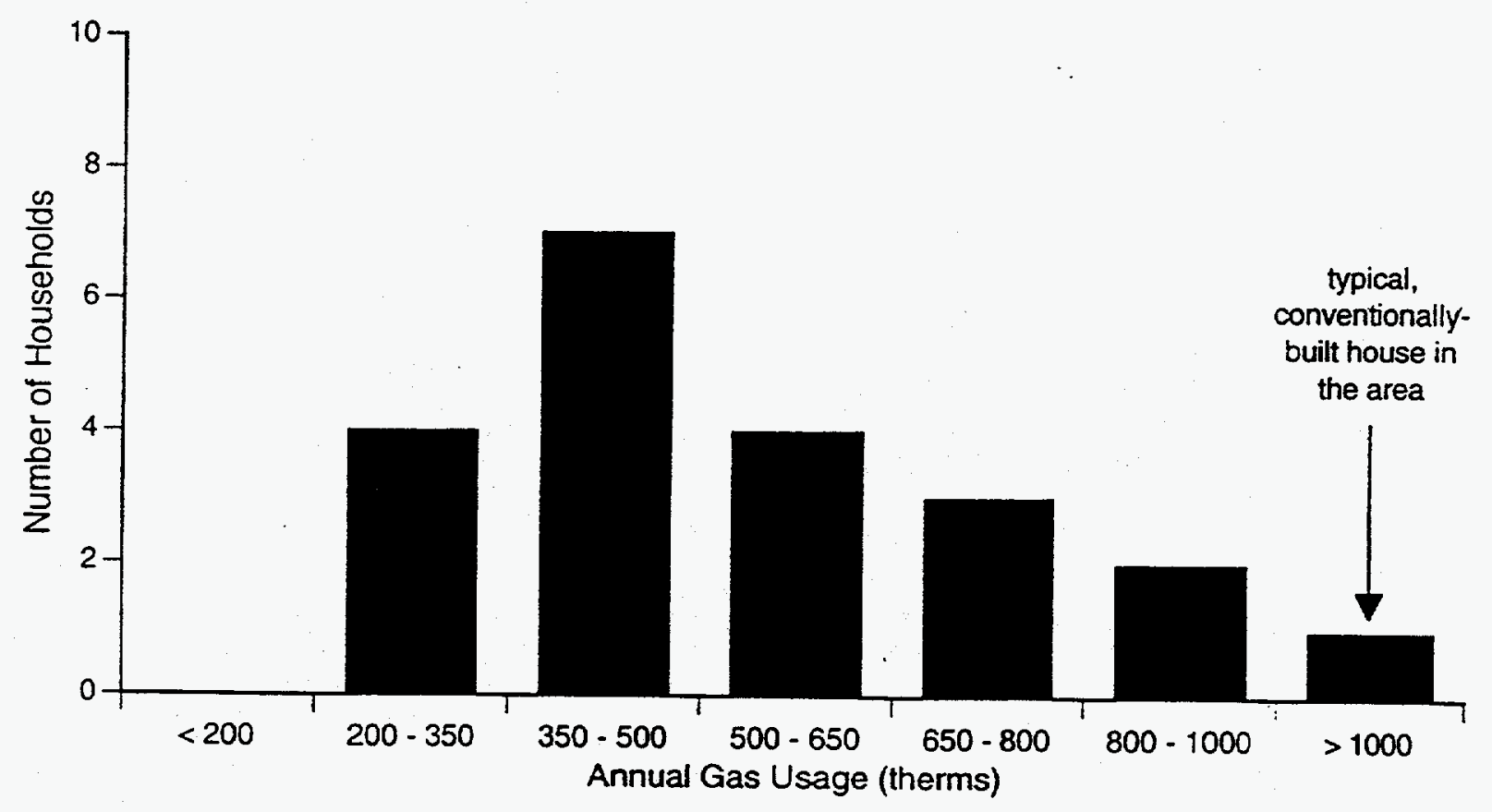

Figure 4. Bigelow Homes Gas Used for Space Heating 


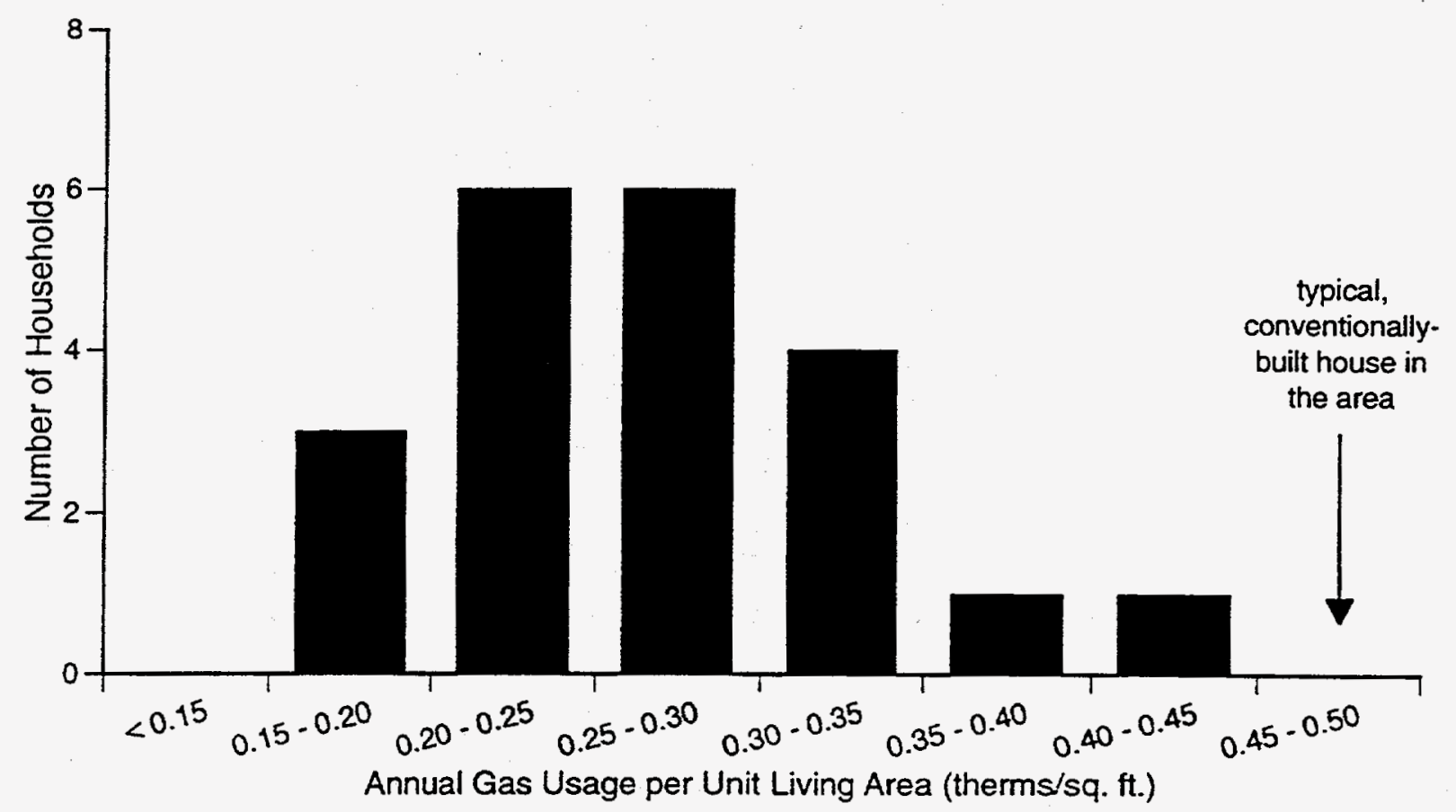

Figure 5. Bigelow Homes Area-Adjusted Space Heating Energy Intensity

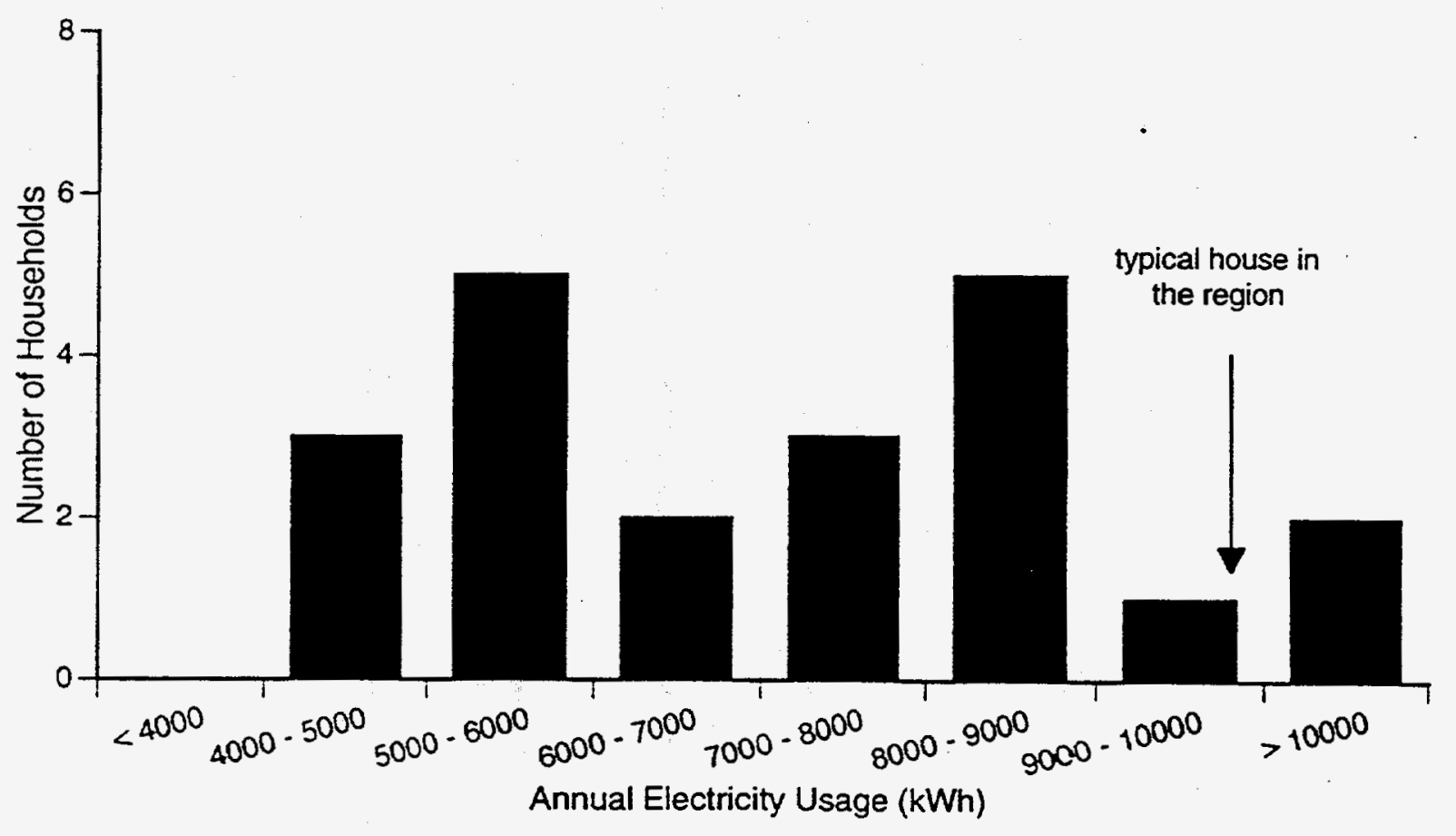

Figure 6. Bigelow Homes Total Electricity Use 
The BH houses' thermal performance compares well to that of an earlier generation of low-heatingenergy houses In Figure 7 the annual heating system output adjusted for floor area (shown by triangles) for the BH sample is superimposed upon a graph from a report about the earlier BECA new residential compilation of the early 1980s (Busch and Meier 1986). The furnace output for BH houses is based on an estimate of $78 \%{ }^{31}$ for the water heater and hydronic coil system efficiency (Apollo 1987), and the PRISM space-heating estimates. All the BH houses perform better than the 1980 standard building practice, most of them significantly so. Keeping in mind that these are built by a production builder for only several hundred dollars more than conventional construction, this result indicates impressive progress.

Nineteen houses have central air conditioners and one has a room air conditioner, used to cool the whole upstairs. Eleven showed significant peaks in electricity use during the summer of 1993. Cooling energy use could not be estimated using PRISM, but first order approximations were obtained by subtracting spring and fall baseline electric use from summer usage. Cooling usage varied widely, with a maximum of $13.5 \mathrm{kWh} / \mathrm{m}^{2}-\mathrm{CDD}$ (base $21.1^{\circ} \mathrm{C}$ ) for a house which reported open windows for 8 hours a day during the summer, a median of $2.9 \mathrm{kWh} / \mathrm{m}^{2}-\mathrm{CDD}$, and a minimum of $0.5 \mathrm{kWh} / \mathrm{m}^{2}-\mathrm{CDD}$. These cooling energy values are only approximate. A nonlinear relationship between the severity of the cooling season and the cooling energy intensity was seen for most houses (i.e., during the hotter summer more energy was required per $C D D$ ). Passive cooling strategies were not used in most of these houses, but would probably decrease cooling requirements significantly.

It is well known that the influence of occupants on building energy use is paramount. In the $\mathrm{BH}$ sample there are several pairs of virtually identical houses, with the same floor plans and living areas. Their energy use is shown in Table 10, along with other possibly relevant parameters. In all cases, the differences in occupants and their reported behavior appear to influence energy use in the expected way. For example, houses with more people living in them consume more energy, and houses with higher reported winter thermostat settings consume more energy. The house with anomalously high electricity use consumes less gas for heating, which might be expected due to the high internal gains. This house has a water bed, reports using the air conditioning all summer, and also reports opening windows for 8 hours per day in summer and 1 to 2 hours in winter. In general, electricity use varies much more between identical houses than does gas use.

The "take-back" effect may be present in the BH sample. This effect refers to occupants substituting increased comfort for saved energy, for example, by keeping the house at a higher temperature in the winter than they could afford to if they did not live in an efficient house. Ten households report

31. Personal communication, Perry Bigelow, 8/17/94. 


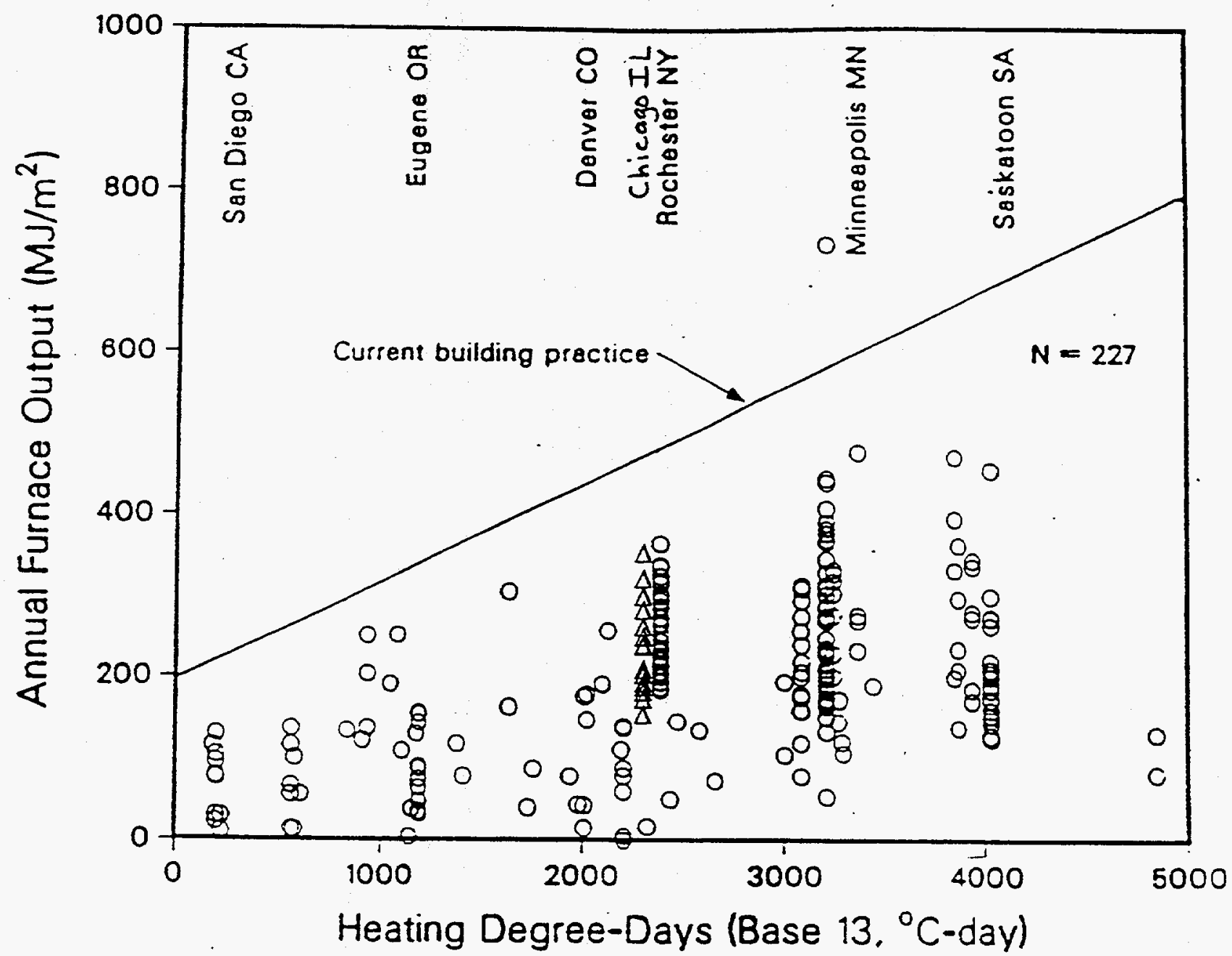

XCG $848-13188$

Figure 7. Annual Furnace Output Historical Comparison. The triangles are the $21 \mathrm{BH}$ houses. The other data are from Busch and Meier (1986), as is the graph. The 227 older houses were built before 1983. The "current building practice" line is simulated furnace output for a prototype house using 1980 standard construction practices, determined from a National Home Builders Association survey. 
Table 10. Energy Use of Identical Houses

\begin{tabular}{|c|c|c|c|c|c|c|c|}
\hline \multirow{2}{*}{$\begin{array}{c}\text { Number } \\
\text { of Units }\end{array}$} & $\begin{array}{c}\text { Area } \\
\left(\mathrm{m}^{2}\right)\end{array}$ & $\begin{array}{c}\text { Electricity } \\
(\mathrm{kWh} / \mathrm{y})\end{array}$ & $\begin{array}{c}\text { Gas NAC } \\
(\mathrm{GJ} / \mathrm{y})\end{array}$ & $\begin{array}{c}\text { Heating } \\
(\mathrm{GJ} / \mathrm{y})\end{array}$ & $\begin{array}{c}\text { Total } \\
(\mathrm{site}) \\
(\mathrm{GJ} / \mathrm{y})\end{array}$ & $\begin{array}{c}\text { Number of } \\
\text { Occupants }\end{array}$ & $\begin{array}{c}\text { Thermostat } \\
\text { Setting (winter, } \\
\text { summer) }\end{array}$ \\
\hline 2 & \multirow{2}{*}{106} & 5530 & 43 & 24 & 63 & 2 &,--- \\
\cline { 3 - 8 } & 8880 & 55 & 32 & 87 & 4 & 75,75 \\
\hline 2 & \multirow{2}{*}{111} & 4560 & 76 & 45 & 92 & 2 & 72,78 \\
\cline { 3 - 8 } & & 5260 & 79 & 45 & 98 & 4 & 72,76 \\
\hline 2 & \multirow{2}{*}{167} & 6300 & 75 & 39 & 98 & 2 & 70,68 \\
\cline { 3 - 8 } & & 8310 & 96 & 49 & 126 & 2 & 78,68 \\
\hline \multirow{2}{*}{3} & 204 & 4020 & 70 & 53 & 84 & 1 & $68, \mathrm{na}$ \\
\cline { 3 - 8 } & & 7840 & 75 & 51 & 102 & 2 & 69,75 \\
\cline { 3 - 8 } & & 13430 & 83 & 44 & 131 & 2 & 75,78 \\
\hline
\end{tabular}

keeping the thermostat at or above $72^{\circ} \mathrm{F}$ (two are at $78^{\circ} \mathrm{F}$ ), while eleven households keep the setting between 72 and $65^{\circ} \mathrm{F}$. In the 1990 RECS $19 \%$ of respondents in the coldest climate zone keep their thermostats at $74^{\circ} \mathrm{F}$ or higher (U.S. Department of Energy 1992).

\section{Survey Results}

People were asked to check off statements that described their motivations for buying a low-energy house and rank them in order of importance. The most frequent reasons were decreased energy bills, high quality construction, expectation of increased resale value, concern about the environment and sustainable use of resources, and increased comfort. By far the most important of these was the decreased energy bills. Quality of construction and environmental concerns were the next most important reasons. A smaller number of people said that they bought a low-heating-energy house for reasons unrelated to energy use, such as price and location. Only one person claimed he was unaware that he was buying an energy-efficient house.

People compared their comfort and their perceptions of the indoor environment in the current house to that in their previous residence (Table 11). Overall feelings of comfort were higher in their current houses. Most respondents were not concerned about living in a tight house. Only one respondent reported having tested the indoor air, although he did not state which tests were done. In general, people felt that indoor air quality was as good or better than in their previous residence. While perceptions of the occupant are very important, not all indoor air pollutants can be perceived 
by human senses (for example, radon gas). Exhaust only ventilation can create a negative pressure difference between the house and the surrounding soil, the driving force for radon entry. It would be desirable to conduct radon testing in a sample of these buildings.

Table 11. Perceptions of Comfort and Indoor Environment, Compared to a Previous House

\begin{tabular}{|c|c|c|c|}
\hline Category & Better & Same & Worse \\
\hline \hline Overall Comfort & 19 & 2 & 0 \\
\hline Temperature & 14 & 6 & 1 \\
\hline Drafts & 20 & 2 & 0 \\
\hline Humidity & 14 & 7 & 0 \\
\hline Dryness & 12 & 8 & 1 \\
\hline Noise & 15 & 6 & 0 \\
\hline $\begin{array}{l}\text { Overall Indoor } \\
\text { Environment }\end{array}$ & 12 & 8 & 0 \\
\hline Stuffiness & 10 & 10 & 0 \\
\hline Odors & 9 & 10 & 1 \\
\hline Dust Build-Up & 8 & 9 & 3 \\
\hline
\end{tabular}

Only about half the respondents indicated a rudimentary understanding of the existence and use of their ventilation systems. Eight people did not know that they had a continuously operating system. Another four knew that they had heat recovery ventilation or exhaust only ventilation, but claimed not to use them continuously. They estimated that their ventilation systems were used from "one hour per day" to "only in the winter". According to the builder, the on-off switches for the continuous ventilation systems are in the attic, to prevent the switches from being used frequently. These responses suggest that more education as to the proper use of the system would be helpful.

Most of the BH houses have been successful, but one of the 23 studied was not. It is the largest house encountered in this sample, at $530 \mathrm{~m}^{2}$ of floor area. The construction was satisfactory, but the owners declined to have the wood stove that was a standard part of the design installed. The heating system was undersized for cold days. On sunny winter days things were fine but when the outdoor temperature was $-10^{\circ} \mathrm{F}$ the occupants reported indoor temperatures between 48 and $58^{\circ} \mathrm{F}$. In addition, there were problems with DHW supply-complaints that "you can't bathe while the heat is on." This house was built in 1989. The builder tried various fixes, and in 1993 a conventional heating system with ducts was installed. The occupant has been happy with the house since then, but declined to return the utility release form. Energy data were not obtained for this house. 


\section{E. Reporting Results}

Communicating the results of research to its participants is an important part of an applied research project. Occupants received a summary of the energy consumption data for their household and a qualitative ranking of how their consumption compared to others in the $\mathrm{BH}$ sample. They also received histograms showing how their consumption compares to others. The letter is included here as Appendix D and the histograms are similar to Figures 3 through 6. Some participants asked to receive the report on the whole compilation. They have been noted, and should recieve a copy upon completion (perhaps in 1995). Another very important participant is the builder, who was sent a draft of sections VI and VII of this report to review.

\section{F. Economic Analysis}

A detailed accounting of incremental costs on a house-by-house basis was not available. Andrews (1994) has estimated the incremental costs of a typical townhouse to be between $\$ 500$ and $\$ 700$ per unit. The added costs of extra insulation, sealing, and low-emissivity windows are offset by eliminating ductwork and downsizing the heating and cooling equipment. Based on annual space heating energy savings of approximately 50GJ (Table 9) for single-family detached houses (and assuming that the incremental costs are twice as much for the larger single-family detached houses), the cost of conserved energy (CCE) for Bigelow's houses is between $\$ 1.00$ and $\$ 2.00$ per GJ ${ }^{32}$. For comparison, the average $\mathrm{CCE}$ for superinsulated houses with gas heat in the earlier BECA compilation was $\$ 3.92$ per GJ (Busch and Meier 1986). Note that the CCE calculated for the BH houses does not necessarily apply to the actual houses studied here. Probably the incremental costs were higher for houses built in 1987 than for houses built in 1990, as BH gained experience in building superinsulated houses.

Bigelow Homes reports a brisk demand for their houses. Any small increased cost that might be passed on to the buyer is not preventing people from buying these houses. Regardless of the outcome of the CCE calculation, the energy features in these houses are cost-effective for the builder.

\section{G. Conclusion}

Are the houses built by Bigelow Homes low-energy houses? If compared to local baseline houses they are low-heating-energy houses. But most of them are not low-energy houses when total energy use is considered. If the total energy use of the BH houses is compared to other low energy houses, as in Section VI above, the BH houses are among the highest. In fairness to the builder, it is

32. Using a 3\% real discount rate and a 30-year lifetime-the same assumptions as Busch and Meier (1986). 
important to note that decreasing the consumption of other end uses besides space heating was not a major design goal.

In summary, these houses consume only 40 to 60 percent of the space heating energy of a conventional new house. The occupants do not feel that they have sacrificed amenities for lower energy consumption. In fact, many report improved comfort, compared to where they used to live. Bigelow Homes has done an impressive job bringing superinsulated construction to the market. Two aspects that might be improved in future houses are specification of efficient appliances, and implementing passive cooling strategies. 


\section{Conclusions}

There are two types of conclusions for this work. The first is about the methodology for comparing houses-both what to compare and how to do it. The second type of conclusion is about the performance of the houses in the pilot comparative analysis.

A single definition of a low-energy house has not been developed. Instead, the implications of various definitions for different actors involved in increasing residential energy efficiency have been discussed. Several possible performance indicators have been presented. Most of these address whole-house energy use, rather than the more restrictive focus on space heating energy use found in earlier compilations. From applying these indicators to actual houses it is clear that different-but reasonable —definitions can yield very different energy rankings.

From a methodological perspective, the core of a performance ranking scheme is an energy normalization procedure. Normalization for the influence of climate can be done for heating in cold climates where even in efficient houses space heating is a dominant end-use, and for cooling in very hot climates where cooling dominates. For houses in other climates, other methods of normalization are needed. When comparing the performance of houses in the same climate zone normalization for the effect of different climates can often be conveniently ignored. Normalization for level of amenity is even more difficult, because it involves defining a standard level of residential services, and it is not obvious how or whether to normalize luxuries (or even which end-uses are luxuries). As more examples of low-energy houses are compiled, the normalization procedures will be refined.

Incremental costs have been an important focus of building energy-use compilations in the past. Methodological problems with the incremental cost framework have been discussed. Many of these problems can be circumvented given enough econometric analysis. But I have suggested that for many applications the information to be gained from a reasonably complete accounting of incremental costs is not worth the effort involved. Incremental costs are important as boundary conditions, however, and should not be completely ignored.

Even with only 50 houses, some conclusions about recently built low-energy houses are evident. As expected, houses for which the builder focused only on attaining low heating energy use generally do not perform as well as houses in which whole-house energy use was targeted. Another finding is that heat pumps are not a panacea. In general the performance of houses with heat pumps has not been impressive (though of course some houses and some kinds of heat pumps are better than others). A third finding is that one house (F) did indeed have a negative incremental cost for energyefficiency. Finally, superinsulated tight construction has arrived in the production builder's arsenal, 
and can even be found in apartments. When done by an experienced builder with proper attention to quality control, superinsulated tight construction is extremely cost-effective from both the builder and the occupant perspectives.

No single definition of a low energy house is universally applicable. Rather than develop a definition, it is my hope that this work will contribute to the current discussion about low-energy and green buildings in two ways. The first is to provide a necessary reality check by documenting actual performance of new, low-energy houses. The second is, by examining the implications of existing definitions, to foster a broader perspective and increased participation by different actors in what has, until now, mainly involved professionals, be they builders, bankers, researchers, or utility company staff. 


\section{References}

Adams, E. “Sun Prairie Apartments: A Conservationist's Dream.” Units Magazine (May/June 1993): 79-81.

AIA Research Corp. Passive Solar Design: A Survey of monitored Buildings. U.S. Department of Energy, 1978. HCP/CS-4113-2.

AlSayyad, N. "Housing Problems: Terminology and Definitions." In Design and Planning of Housing, ed. N. AlSayyad. 44-52. 1984.

Andrews, S Columbine Homes: A Colorado Case Study in Energy Efficiency. Office of Energy Conservation, State of Colorado, 1993.

Andrews, S. “Perry Bigelow: Energy Efficiency Maestro.” Home Energy 11 (2 1994): 13-18.

Apollo, Comfort Products. "Apollo Hydro Heat: The Inside Story." 12. Cumberland Street, Ashland City, TN 37015: 1987.

Bailey, K. D. Methods of Social Research. 3rd ed., New York: The Free Press, 1987.

Balcomb, J. D. New Housing Energy Efficiency-Performance Goals and Guidelines. National Renewable Energy Laboratory, 1993 (draft).

Berkeley Solar Group and Xenergy. Occupancy Patterns \& Energy Consumption in New Californai Houses (1984-1988). California Energy Commission, 1990. Consultant Report P400-90-009.

Buchanan, A. H. and B. G. Honey. "Energy and Carbon Dioxide Implications of Building Construction." Energy and Buildings 20 (1994): 205-217.

Busch, J. F. and C. A. Goldman. "Cross-Comparisons of New Energy-Efficient Houses." In American Council for an Energy-Efficient Economy 1992 Summer Study on Energy Efficiency in Buildings in Pacific Grove, CA, American Council for an Energy-Efficient Economy, 1986.

Busch, J. F. and A. K. Meier. Monitored Performance Of New, Low-Energy Homes: Updated Results From The BECA-A Data Base. Lawrence Berkeley Laboratory, 1986. LBL-18306.

CANMET, (Canada Centre for Mineral and Energy Technology). Comparison Analysis Report on Advanced Houses Around the World. Energy, Mines and Resources Canada, 1993.

Duffy, J. J. and D. S. Odegard. "Thermal Performance and Design Tool Comparison for 86 Northeast Passive Solar Residences As Estimated from Class C Audits." In Annual Meeting of the International Solar Energy Society. American Section in Houston, Texas, edited by G. Franta, American Section of the Interational Solar Energy Society, 721-726, 1982.

Dumont, R. S. "Measured Energy Consumption of a Group of 99 Low Energy Houses." In Biennial Congress of the International Solar Energy Society in Denver. Colorado, edited by M. E. Arden, S. M. A. Burley, and M. Coleman, Pergamon Press, 3287-3292, 1991.

Enermodal Engineering. Performance Of The Brampton Advanced House. Efficiency and Alternative Energy Technology Branch, CANMET, Energy, Mines and Resources Canada, 1992. 
Erhorn, H., J. Reiss, and M. Szerman, eds. Proceedings/Actes International Symposium Energy Efficient Buildings: Leinfelden Echterdingen. Germany, March 9-11.1993. Stuttgart: IRB-Verlag, 1993.

Faesy, R. "Lessons Learned from Four Years of Operating a Home Energy Rating System and Energy Efficient Mortgage Program." In American Council for an Energy-Efficient Economy 1992 Summer Study on Energy Efficiency in Buildings in Asilomar. CA, , 53-55, 1992.

Farhar, B. C. and J. Eckert. Energy-Efficient Mortgages and Home Energy Rating Systems: A Report on the Nation's Progress. National Renewable Energy Laboratory, 1993. NREL/TP-4615478.

Fels, M. F. "PRISM: An Introduction." Energy and Buildings 9 (1 1986): 5-18.

Fels, M.F., J. Rachlin, and R.H. Socolow. "Seasonality of Non-heating Consumption and Its Effect on PRISM Results." Energy and Buildings 9 (1 1986): 139-148.

Flouquet, F. "Local Weather Correlations and Bias in Building Parameter Estimates from EnergySignature Models." Energy and Buildings 19 (2 1992): 113-123.

Friedman, A. and V. Cammalleri. "Reducing Energy, Resources and Construction Waste Through Effective Residential Design." In Twelfth Annual International Energy Efficient Building Conference and Exposition in Dallas. Texas, Energy Efficient Building Association, E-12 - E-18, 1994.

Hamilton, B., B. Sachs, R. Alward, and A. Lepage. "Non-Instrumented Performance of 335 Passive Solar Homes." In 6th National Passive Solar Conference in Portland. Oregon, edited by J. Hayes and W. A. Kolar, American Section of the International Solar Energy Society, 3-7, 1981.

Hammond, R. and C. Jennings. "Stand-Alone Remote PV Home--Lessons Learned." In American Society of Mechanical Engineers Solar Energy Conference in Reno. Nevada, , 91-97, 1991.

Hayashi, N. “An Analysis on Residential Energy Demand in Major Industrial Countries; Primarily Based on International Comparisons." Energy in Japan 107 (1991): 63-76.

Heard, B. S. Y. Chu, C. Goldman, and J. Busch. Energy Conservation in Residential Buildings: How Well Does It Work in California? Universitywide Energy Research Group, Unviersity of California and Califomia Energy Commission, 1985.

Hitchcock, G. "An Integrated Framework for Energy Use and Behaviour in the Domestic Sector." Energy and Buildings 20 (1993): 151-157.

Holdren, J. P. "Population and the Energy Problem." Population and Environment: A Journal of Interdisciplinary Studies 12 (3 1991): 231-255.

Keck, G. F. and W. Keck. "The Development of Passive solar Applications in the Midwest." In Passive Solar: Subdivisions, Windows, Underground in Kansas City, Missouri, edited by $\mathrm{H}$. Wade, J. Cook, K. Labs, and S. Selkowitz, American Solar Energy Society, 3-25, 1983.

Kimura, K., M. Udagawa, W. Fukumitsu, and E. Lee. "Field Research on Thermal Environment and Energy Consumption of the House with Solar Air Conditioner." (in Japanese) 1993.

Kriesi, R. "Double Family Buildings with Zero Heating Energy in Waedenswil." In Advanced Solar Low-Energy Houses: Examples from Task XIII Experts, 61-67. International Energy Agency, 1990.

Kudo, M. "Japan Two by Four Architecture Association President's Prize: Sumiya House." (in Japanese) Institute of Building Energy Conservation 14-1 (76 1993): 34-37. 
Marchio, D. and A. Rabl. "Energy-Efficient Gas-Heated Housing in France: Predicted and Observed Performance." Energy and Buildings 17 (1991): 131-139.

Meier, A. K. "Supply Curves of Conserved Energy." Ph.D. thesis, University of California, Berkeley, 1982.

Meier, A. K., J. Busch, and C. C. Conner. "Testing the Accuracy of a Measurement-Based Building Energy Model with Synthetic Data." Energy and Buildings 12 (1988): 77-82.

Meier, A. K. and B. Nordman. "A Thermal Analysis of the Model Conservation Standards for New Homes in the Pacific Northwest U.S.A." Energy 13 (11 1988): 833-844.

Millhone, J. P., M. Jenior, and B. C. Farhar. "The National Collaborative on Home Energy Rating Systems and Energy-Efficient Mortgages." In American Council for an Energy-Efficient Economy 1992 Summer Study on Energy Efficiency in Buildings in Pacific Grove. CA, American Council for an Energy-Efficient Economy, 167-176, 1992.

Minehart, D. L. and A. K. Meier. "Using Synthetic Data to Explore the Usefulness of PRISM's Parameters at Inferring Causes of Changes in Normalized Annual Consumption." Energy 19 (2 1994): 135-148.

Miner, R. and S. Loken. "ReCRAFT 90: Materials Choices and Performance." In Twelfth Annual International Energy Efficient Building Conference and Exposition in Dallas. Texas, Energy Efficient Building Association, E-39 - E-53, 1994.

Nagata, Y.. Comparative Analysis of Energy Intensity Between the U.S. and Japan. CRIEPI, Central Research Institute of the Electric Power Industry, 1993. EY92003.

Nieminen, J. "Low-Energy Residential Housing - A Case Study." In International Symposium Energy Efficient Buildings in Leinfelden-Echterdingen. Germany, edited by H. Erhorn, J. Reiss, and M. Szerman, IRB-Verlag, 193-198, 1993.

Oka, T., M. Suzuki, and T. Konnya. "The Estimation of Energy Consumption and Amount of Pollutants Due to the Construction of Buildings." Energy and Buildings 19 (1994): 303-311.

Parker, D. S. and J. P. Dunlop. Monitoring of an Energy-Efficient Solar Home for the City of Tallahassee: Task 1 Report: System Description and Initial Audit Findings. Florida Solar Energy Center, 1992. FSEC-CR-502-92.

Pettersen, T. D. "Variation of Energy Consumption in Dwellings Due to Climate, Building and Inhabitants." In Cold Climate HVAC '94 Conference in Rovaniemi. Finland, edited by J. Sateri and E. Kainlauri, Federation of Societies of Heating, Air-Conditioning and Sanitary Engineers in Finland (FINVAC), 355-364, 1994.

Potts, M. The Independent Home. Post Mills, Vermont: Chelsea Green Publishing Co., 1993.

Ritschard, R. L., J. W. Hanford, and A. O. Sezgen. Analysis of the Impacts of Energy Conservation Codes in New Single-Family Homes. Gas Research Institute, 1992. GRI-91/0158.

Rosenfeld, A.H., W.G. Colborne, C.D. Hollowell, S.P. Meyers, L.J. Schipper, B. Adamson, B. Hidemark, H. Ross, N. Milbank, M.J. Uyttenbroeck, and G. Olive. "Building energy use compilation and analysis (BECA): An international comparison and critical review." Energy and Buildings 3 (4 1981): 315-332.

Russell, P. with J. Hemmer. Energy-Smart Building for Increased Quality. Comfort, and Sales. Washington, DC: Home Builder Press, 1993. 
Shea, M., S. Mahajan, and C. Newcomb. "A Plan for Low Cost Data Collection on Passive Solar Homes in California." In 5th National Passive Solar Conference in Amherst, Massachusetts, edited by J. Hayes and R. Snyder, American Section of the International Solar Energy Society, 361-364, 1980.

Shurcliff, W. A. Solar Heated Buildings of North America: 120 Outstanding Examples. Harrisville, New Hampshire: Brick House Publishing Co., 1978.

Sinha, R., K. Cooper, W. Mayhew, and B. Sibbit. "Results of Level B Monitoring of Seven R-2000 Houses." In Innovative Housing in Vancouver, BC. Canada, , in press, 1993.

Socolow, R. H., ed. Saving Energy in the Home: Princeton's Experiments at Twin Rivers. Cambridge, MA: Ballinger, 1978.

Sonderegger, R. C. "Movers and Stayers: The Resident's Contribution to Variation Across Houses in Energy Consumption for Space Heating." Energy and Buildings 1 (3 1978): 313-324.

Stram, D. O. and M. F. Fels. "The Applicability of PRISM to Electric Heating and Cooling." Energy and Buildings 9 (1 1986): 101-110.

Sullivan, P. W. and M. R. Katz. "An Analysis of the Incremental Construction Costs of Passive Solar Buildings." In 4th National Passive Solar Conference in Kansas City, Missouri, American Section of the International Solar Energy Society, 670-673, 1979.

Suter, P. "Environmental Impacts of Energy Conservation in Buildings: Real Case Studies." 1993.

Swisher, J. Passive Solar Performance: Summary of 1981-1982 Class B Results. Solar Energy Research Institute, 1983. SERI/SP-281-1847.

Tatum, J. S. "The Home-Power Movement and the Assumptions of Energy-Policy Analysis." Energy 17 (2 1992): 99-107.

Tatum, J. S. "Technology and Values: Getting beyond the "Device Paradigm" Impasse." Science Technology.\& Human Values 19 (1 1994): 70-87.

U.S. Bureau of the Census. Statistical Abstract of the United States: 1992. Washington, DC: 1992.

U.S. Department of Energy, Energy Information Administration. Housing Characteristics 1990. 1992. DOE/EIA-0314(90).

U.S. Department of Energy, Energy Information Administration. Household Energy Consumption and Expenditures 1990. 1993. DOE/EIA-0321(90).

Ugursal, V. I. Experimental and Analytical Investigation of the Thermal Performance. Energy Consumption and Economic Feasibility of R-2000 Houses Equipped with Heat Pumps. Canadian Electrical Association, 1992. 825 U 694.

Vories, R. and K. George. "Analysis of Home Energy Rating Systems: Results of Brief Interviews." In 1992 Annual Conference of the American Solar Energy Society in Cocoa Beach. Florida, American Solar Energy Society, 397-401, 1992.

Yoshino, H., M. Nagatomo, S. Matsumoto, and Y. Ishikawa. "One-Year Measurement of Indoor Climate and Energy Consumption of Super Insulated Houses in a mild Climate Region of Japan." Architectural Reports of the Tohoku University 32 (1993): 213-227. 
Appendix A. Flyer for Solicitation 


\section{LOW-ENERGY HOUSING? SEND US YOUR DATA, PLEASE!}

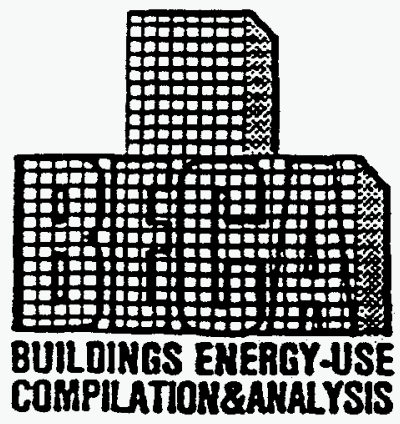

Measured data provide important feedback to builders, planners, and evaluators on how well calculations, computer models, and "rules of thumb" actually predict energy performance. Many buildings are monitored, but few are compared. We at Lawrence Berkeley Laboratory are currently compiling and analyzing monitored performance data for new low-energy residences." The results will permit us to:

- identify energy-efficiency successes

- identify cost-effective energy conservation measures

- assess progress in building energy-efficient homes in the past decade

- update the definition of a low-energy home.

We are interested in warm climates as well as cool ones, so that we may include energy used for space cooling.

We need from you:

- case studies

- leads and contacts

- floppy disks and e-mail

- reports and articles

You'll get from us:
Necessary data:

- physical description of building

- energy design strategy

- measured energy consumption

- outcoor temperatures (or name of nearest airport)

- a comparison of your building to other similar ones

- a final report on the project

We also seek data on the cost of building these low-energy homes, because costeffectiveness is a major concern. We welcome data that are more detailed than the requirements above. Examples include submetered energy by end-use (e.g., space heating, space cooling, domestic hot water, refrigeration); continuously monitored temperatures and occupancy; ventilation and indoor air quality data; and more frequent (daily or weekly) energy use records. Even if your buildings aren't efficient, we would like your data for use as a possible baseline for comparisons.

For further information and to contribute data or leads, please contact:

Barbara Litt

Energy Analysis Program

Phone: (510) 486-5159

Building 90, Room 4000

Fax: (510) 486-6996

Lawrence Berikeley Laboratory

Intemet: BRLitt@LBLgov

Berkeley, CA 94720 
Appendix B. Occupant Questionnaire 


\section{Case Studies of New Low-Energy Homes Homeowner Questionnaire}

This questionnaire asks for information about your house. how you use it, and how comfortable you are in it. Please answer as completely as possible and return the questionnaire with the energy performance data or with the signed utility release form. Your answers will be kept confidential. Not all questions will apply to your house. so please skip those that do not. If you have any questions. call Barbara Litt (510-486-5159) or Brian Pon (510-486-6829). If you would prefer to give us the answers over the telephone. we can call you back at a time convenient for you.

Please return to: $\quad$ Barbara Litt

Energy Analysis Program

Building 90 . Room 4000

Lawrence Berkeley Laboratory

Berkeley, CA 94720

Fax: $510-468-6996$

\section{Respondent}

Your name

May we contact you if we need to clarify an answer? $\square$ Yes $\square$ No

Phone numbers: Work

Home

Good times to reach you:

\section{House Characteristics}

Date built:

Location:

city state country

Total living area: $\square \mathrm{ft}^{2} \quad \square \mathrm{m}^{2}$

Is all of this area heated in the winter?

$\square$ Yes $\square$ No If no, how much is heated?

Is all of this area cooled in the summer?

$\square$ Yes $\square$ No If no, how much is cooled?

Do you keep parts of the house at different temperatures in winter? QYes $\square$ No in summer? $\square$ Yes $\square$ No

If yes, how do you do this?

House Type: $a$ single-family detached $\square$ fourplex separate thermostats with different settings

closing doors and closing vents

other (describe) $\square$ duplex $\quad$ triplex

townhouse other (describe)

If a townhouse, are you in an end unit?

QYes

No 
Are there vauited (very high) ceilings in any rooms? D Yes a No

If yes, in which rooms?

How many floors are there. not including an unfinished basement?

Is there a crawl space? $\square$ Yes No

Is there a basement? $\square$ Yes $\mathrm{No}$

If yes, check any that apply:
$\square$ finished
anfinished
completely below grade
$\square$ above grade on one or more sides

Do you have a garage? $\square$ Yes $\square$ No

If yes, check any that apply:
$\square$ attached to the house
$\square$ in the basement
detached

Please provide a sketch of the house's layout and floor plan. showing all levels. Use additional paper if necessary. If you have an article or other papers describing the house. enclose a copy. Please indicate south if known. Also indicate the locations of trees and shrubs that might shade or sheiter the house. 
Windows:

\begin{tabular}{|l|l|l|}
\hline Orientation & $\begin{array}{l}\text { Window Area } \\
\left(\square \mathrm{ft}^{2} \mathrm{~g} \mathrm{~m}^{2}\right)\end{array}$ & Typers $)$ of glazing \\
\hline \hline South & & \\
\hline West & & \\
\hline North & & \\
\hline East & & \\
\hline Skylights & & \\
\hline
\end{tabular}

\section{You And Your Use Of The House}

Are you the house's original owner? $\square$ Yes $\square$ No

When did you move in?

Is this house your primary residence? Q Yes $\square$ No

How many weeks per year is the house occupied?

\begin{tabular}{|l|l|}
\hline How many people are & Number \\
\hline normaily in residence? & \\
\hline home weekdays (for example. from 9 a.m. to 3 p.m.)? & \\
\hline full-time students? & \\
\hline tobacco smokers? (Do they smoke indoors? Q Yes $\square$ No) & \\
\hline
\end{tabular}

Is this the first home you have owned?

DYes $\square$ No

Is your house part of a new housing development?

$\square$ Yes $\square$ No

Was the house custom built?

QYes $\square$ No

Were you involved in the house's design and construction? $\square$ Yes $\square$ No

If yes, what was your role (check any that apply)?

$\square$ hired an architect or builder to design

$\checkmark$ hired a general contractor

$Q$ designed myself

$\square$ supervised construction closely

$\square$ served as general contractor and hired specialists

$\square$ built myseif

$\square$ other (describe)

Annual income range for your household:

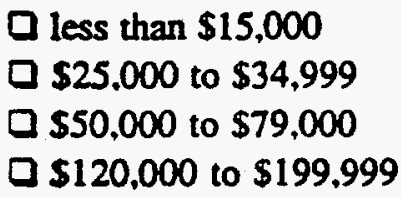

Q $\$ 15,000$ to $\$ 24,999$

a $\$ 35,000$ to $\$ 49,000$

a $\$ 80,000$ to $\$ 119,999$

Q $\$ 200,000$ or more

Period monitored (or for which utility bills are available): from

to monthtyear 
Please list months during this time when the house was vacant for more than one week.

\begin{tabular}{|l|l|l|}
\hline Month & Year & Number of Weeks Vacant \\
\hline & & \\
\hline & & \\
\hline & & \\
\hline & & \\
\hline & & \\
\hline
\end{tabular}

What are typical indoor temperatures?

\begin{tabular}{|l|l|l|l|l|}
\hline \multicolumn{1}{|c|}{ Use of House } & $\begin{array}{l}\text { Winter } \\
\text { Room } \\
\text { Temp. }\end{array}$ & $\begin{array}{l}\text { Winter } \\
\text { Thermostat } \\
\text { Setting }\end{array}$ & $\begin{array}{l}\text { Summer } \\
\text { Room } \\
\text { Temo. }\end{array}$ & $\begin{array}{l}\text { Summer } \\
\text { Themostat } \\
\text { Setting }\end{array}$ \\
\hline Davtime. someone home & & & & \\
\hline Davtime. nobody home & & & & \\
\hline Nighttime. sleeping hours & & & & \\
\hline
\end{tabular}

Is this house more or less comfortable than those you have lived in before?

$\begin{array}{lccc}\text { Categery } & \text { More comforrable } & \text { About the same } & \text { Less comforable } \\ \text { Temperature } & \square & 0 & \square \\ \text { Draftiness } & \square & \square & \square \\ \text { Humidity } & \square & \square & \square \\ \text { Dryness } & \square & \square & \square \\ \text { Noise } & \square & \square & \square \\ \text { Overall } & \square & \square & \square\end{array}$

\section{Energy-Using Equipment And Appliances}

Major Appliances:

\begin{tabular}{|c|c|c|c|c|}
\hline Appliance & $\begin{array}{l}\text { Number } \\
\text { of Units }\end{array}$ & Primary Fuel* & Maker & $\begin{array}{l}\text { Were they new } \\
\text { when you moved } \\
\text { into the house? }\end{array}$ \\
\hline Refrigerator & & & & QYes Q No \\
\hline Freezer & & & & QYes a No \\
\hline Range & & & & QYes a No \\
\hline Oven & & & & QYes a No \\
\hline Washer & & & & $\square$ Yes aNo \\
\hline Dryer & & & & QYes Q No \\
\hline Water Heater & & & & QYYes Q No \\
\hline Portable Heaters & & & & DYes aNo \\
\hline
\end{tabular}

${ }^{*} E=$ electric, $G=$ gas, $P=$ propane: if something else, describe. 
Please check if you have any of the following features inside or outside of the house.

Eeature
well pump
sump pump
sauna
hot tub
swimming pool
water bed
ceiling fans
grow-lights
dehumidifier
humidifier
machine shop

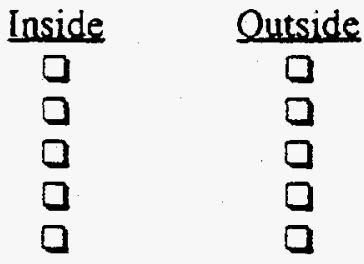

How many? How many?<smiles>[O][O-]</smiles>

Do you have a fireplace? $\square$ Yes $\square$ No

Do you have a wood stove? $\square$ Yes

No

How often and why do you use them?

\section{Eireplace}

$\square$ often, to heat the house

occasionally for back-up heat

$\square$ other

hours used each week:

\section{Wood stove}

$\square$ often. to heat the house

occasionally for back-up heat

0 other

hours used each week:

How much wood have you bumed in the past twelve months? Please refer to the enclosed diagram indicating the amount of wood in one cord.
$\square$ None
a One half cord
A few logs
a More than $1 / 2$ but less than 1 cord
$1 / 4$ to $1 / 3$ cord
a One cord or more

If more than one cord, how many cords did you bum?

If you have hobbies or do work at home that uses a lot of energy briefiy describe them.

Do you have pets? a Yes $\square$ No If yes, what kind, and how many?

\section{Energy-Efficient Design Strategies}

What makes this a low-energy house? (Please check all that apply.)

\begin{tabular}{|c|c|c|}
\hline super-insulation & $\square$ tight construction & $\square$ earth sheitering \\
\hline $\begin{array}{l}\text { passive solar } \\
\square \text { most windows on the south side } \\
\square \text { overhangs for shading } \\
\square \text { sunspace } \\
\square \text { water heating } \\
\square \text { landscaping } \\
\square \text { other (describe) }\end{array}$ & $\begin{array}{l}\text { active solar } \\
9 \text { photovoltaic cells } \\
\text { water heating } \\
\text { Q other (describe) } \\
\text { a efficient appliances }\end{array}$ & $\begin{array}{l}\square \text { thermal mass } \\
\\
\text { heat pump }\end{array}$ \\
\hline efficient furnace & $\square$ efficient air conditioner & other (describe) \\
\hline
\end{tabular}


Space heat

Primary fuel:

$\square$ gas

alectricity

oil

$\square$ other (describe)

$\square$ wood

Heating system:

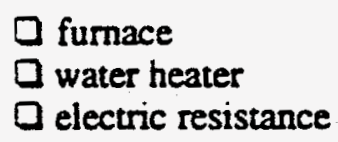

air-source heat pump

ground-source heat pump

a electric resistance

$\square$ other (describe)

Distribution system: $\square$ hot water radiant

0 forced air

$\square$ electric radiant

other (describe)

Have you had any equipment failures or major repairs of the space heating system? $\square$ Yes $\square$ No If yes, please describe:

\section{Cooling and Ventilation}

\begin{tabular}{|c|c|c|c|}
\hline \multirow[b]{2}{*}{ Equipment or method } & \multirow[b]{2}{*}{ Present? } & \multicolumn{2}{|c|}{ Hours used each day in } \\
\hline & & summer & winter \\
\hline central air conditioner & QYes Q No & & \\
\hline room air conditioner & $\begin{array}{l}\text { DYes a No } \\
\text { (how many? }\end{array}$ & & \\
\hline night ventilation & QYes Q No & & \\
\hline heat pump & QYes QNo & & \\
\hline $\begin{array}{l}\text { exhaust only venulation } \\
\text { (for the whole house) }\end{array}$ & aYes a No & & \\
\hline hear recovery ventilation & QYes QNo & & \\
\hline exhaust fan in bathroom & DYes Q No & & \\
\hline exhaust fan in kitchen & QYes a No & & \\
\hline summer whole house fan & aYes Q No & & \\
\hline evaporative cooler & DYes a No & & \\
\hline opening windows & QYes $\square$ No & & \\
\hline other (describe) & & & \\
\hline
\end{tabular}

Have you had any equipment failures or major repairs of the cooling andor ventilation system?

Q Yes a No

If yes, please describe: 
Water heat

Primary fuel:

$$
\begin{array}{ll}
\square \text { gas } & \square \text { electricity } \\
\square \text { oil } & \square \text { wood } \\
\square \text { soiar } & \square \text { other (describe) }
\end{array}
$$

Is there a hot water storage tank? Yes $\square$ No

Is your domestic hot water system linked to your space heating system? Q Yes

Is your domestic hot water system linked to your space cooling system? 口 Yes a No

Have you had any equipment failures or major repairs of the water heating system? Yes a No If yes, please describe:

\section{Indoor Air Quality}
Has the indoor air been tested?
Y Yes
a No
Don't know

If yes, for what was it tested? (If you know the results please write them here or attach them.)

Was a test of air tightness done? $\quad$ Yes $\square$ No $\square$ Don't know

(If yes, and you know the resuits please write them here or attach them.)

How does the air in this house compare with air in other houses you have lived in?

$\begin{array}{lccc}\text { Category } & \text { Better } & \text { About the same } & \text { Worse } \\ \text { Stuffiness } & \square & \square & \square \\ \text { Odors } & \square & a & a \\ \text { Dust build-up } & \square & \square & a \\ \text { Overall } & \square & a & a\end{array}$

\section{Costs}

Did your builder tell you how much the energy-efficiency features cost? Y Yes $\square$ No If yes, what did they cost?

What was the purchase price of your home?

If you built the house yourself, please estimate the incremental cost of the energy-efficiency features if possible.

Incremental Cost $=$ Added Cost - Avoided Cost $=$ 


\section{Motivation For Energy Efficiency}

Why did you buy an energy-efficient house? (Please check any that apply and rank the three most accurate statements. with " $\mathrm{l}$ " being the most important.)

I am concemed about the environment and sustainable use of resources.

I think the house will have increased resale value compared to other houses.

I knew it was energy-efficient but I bought the house for other reasons entirely.

Please describe the reasons:

$\square$ Decreased energy bills over the house's lifetime are important to me.

A friend, neighbor, or relative convinced me that energy efficiency was important.

This house is more comfortable (for example, quieter. no drafts, more even temperatures).

The construction is of high quality.

Q My builder suggested it.

By accident I didn't know it was energy-eficient.

O Other (describe)

\section{Additional Comments:}




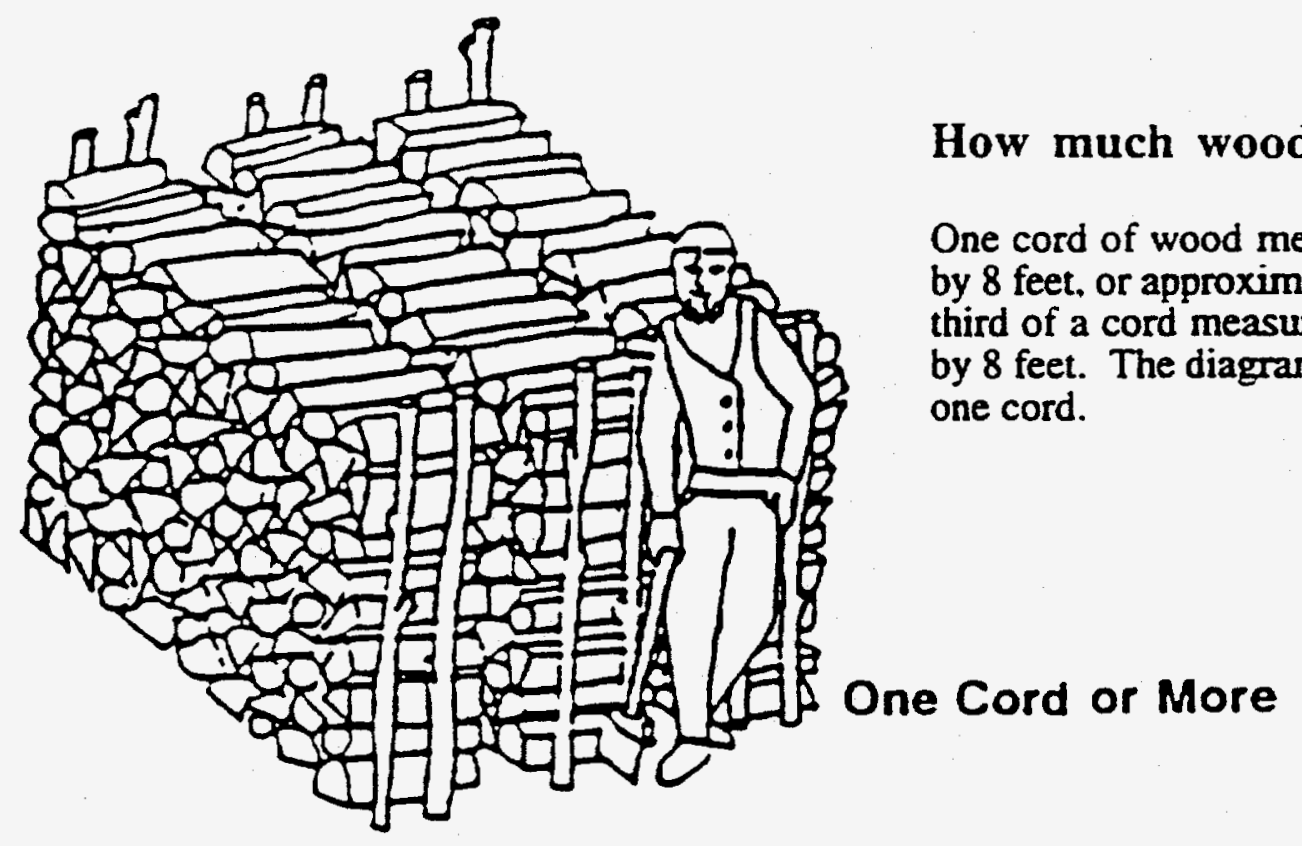


Appendix C. Baseline Data from the 1990 Residential Energy Conservation Survey 
Summaries of 1990 RECS Baseline Annual Energy Consumption

\begin{tabular}{|c|c|c|c|c|c|c|c|c|c|c|}
\hline Region & Number & $\begin{array}{l}\text { GJ tolal- } \\
\text { site }\end{array}$ & $\begin{array}{l}\text { GJ total- } \\
\text { source }\end{array}$ & $\begin{array}{c}M J / m 2 . \\
\text { sile }\end{array}$ & $\begin{array}{c}M J / m 2 \\
\text { source }\end{array}$ & $\begin{array}{l}\text { GJ/pers- } \\
\text { sile }\end{array}$ & $\begin{array}{l}\text { GJ/pers- } \\
\text { source }\end{array}$ & $\begin{array}{c}M J / \text { per- } \\
\text { m2 }\end{array}$ & Area $(\mathrm{m} 2)$ & $k W h$ \\
\hline \multicolumn{11}{|c|}{1987 to 1990 All Dwelling Units } \\
\hline lolal & 127 & 117 & 198 & 577 & 1051 & 43 & 73 & 432 & 231 & 11110 \\
\hline 1 & 13 & 111 & 161 & 649 & 983 & 52 & 75 & 451 & 178 & 6848 \\
\hline 2 & 8 & 90 & 160 & 497 & 964 & 44 & 78 & 474 & 189 & 9595 \\
\hline 3 & 19 & 188 & 260 & 621 & 880 & 64 & 90 & 355 & 337 & 9879 \\
\hline 4 & 15 & 124 & 208 & 669 & 1151 & 46 & 76 & 437 & 260 & 11469 \\
\hline 5 & 18 & 62 & 147 & 515 & 1259 & 24 & 61 & 566 & 153 & 11736 \\
\hline 6 & 24 & 126 & 241 & 503 & 1028 & 43 & 81 & 402 & 279 & 15734 \\
\hline 7 & 5 & 84 & 169 & 713 & 1467 & 42 & 87 & 880 & 139 & 11548 \\
\hline 8 & 11 & 123 & 190 & 636 & 1021 & 46 & 69 & 368 & 219 & 9213 \\
\hline 9 & 14 & 100 & 171 & 510 & 939 & 27 & 47 & 258 & 191 & 9819 \\
\hline \multicolumn{11}{|c|}{1987 to 1990 Single-family detached } \\
\hline lotal & 77 & 140 & 232 & 514 & 886 & 45 & 75 & 296 & 300 & 12545 \\
\hline 1 & 2 & 146 & 200 & 788 & 1051 & 50 & 67 & 418 & 207 & 7414 \\
\hline 2 & 3 & 102 & 202 & 313 & 642 & 49 & 94 & 287 & 312 & 13695 \\
\hline 3 & 16 & 207 & 287 & 553 & 794 & 67 & 93 & 248 & 383 & 10968 \\
\hline 4 & 11 & 142 & 228 & 656 & 1021 & 54 & 86 & 416 & 318 & 11762 \\
\hline 5 & 7 & 64 & 161 & 312 & 860 & 22 & 54 & 286 & 234 & 13174 \\
\hline 6 & 18 & 148 & 268 & 453 & 811 & 46 & 82 & 252 & 338 & 16502 \\
\hline 7 & 4 & 86 & 168 & 627 & 1261 & 32 & 66 & 528 & 155 & 11315 \\
\hline 8 & 6 & 117 & 190 & 449 & 793 & 30 & 51 & 242 & 266 & 10014 \\
\hline 9 & 10 & 119 & 199 & 549 & 980 & 30 & 50 & 244 & 216 & 11061 \\
\hline
\end{tabular}


Summaries of 1990 RECS Baseline Annual Energy Consumption (continued)

\begin{tabular}{|c|c|c|c|c|c|c|c|c|c|c|}
\hline Region & Number & $\begin{array}{l}\text { GJ total- } \\
\text { site }\end{array}$ & $\begin{array}{l}\text { GJ total- } \\
\text { source }\end{array}$ & $\begin{array}{c}M J / m 2- \\
\text { site }\end{array}$ & $\begin{array}{c}\text { MJ/m2- } \\
\text { source }\end{array}$ & $\begin{array}{l}\text { GJ/pers- } \\
\text { site }\end{array}$ & $\begin{array}{c}\text { GJ/pers- } \\
\text { source }\end{array}$ & $\begin{array}{c}\text { MJ/per- } \\
m 2\end{array}$ & $\begin{array}{c}\text { homearea } \\
-m 2\end{array}$ & kWh \\
\hline \multicolumn{11}{|c|}{1987 to 1990 mobile homes } \\
\hline total & 23 & 85 & 158 & 822 & 1577 & 36 & 68 & 739 & 107 & 10304 \\
\hline 1 & 4 & 85 & 135 & 700 & 1144 & 38 & 60 & 486 & 140 & 8784 \\
\hline 2 & 1 & 208 & 258 & 1250 & 1551 & 42 & 52 & 310 & 166 & 6867 \\
\hline 3 & 3 & 87 & 116 & 983 & 1340 & 51 & 69 & 927 & 90 & 4071 \\
\hline 4 & 3 & 82 & 176 & 786 & 1776 & 23 & 53 & 543 & 99 & 12912 \\
\hline 5 & 4 & 65 & 143 & 749 & 1655 & 27 & 64 & 756 & 87 & 10624 \\
\hline 6 & 5 & 66 & 166 & 665 & 1658 & 34 & 80 & 844 & 105 & 13579 \\
\hline 7 & 1 & 78 & 170 & 1059 & 2288 & 79 & 170 & 2288 & 74 & 12482 \\
\hline 8 & 2 & 117 & 195 & 1089 & 1797 & 26 & 43 & 402 & 108 & 10581 \\
\hline 9 & 0 & & & & & & & & & \\
\hline
\end{tabular}

1987 to 19902 to 4-plexes, rowhouses, etc.

$\begin{array}{ccccccccccc}\text { tolal } & 22 & 81 & 140 & 546 & 1065 & 44 & 74 & 516 & 146 & 8102 \\ 1 & 4 & 130 & 170 & 606 & 797 & 71 & 91 & 406 & 219 & 5438 \\ 2 & 4 & 52 & 104 & 446 & 1059 & 41 & 73 & 655 & 103 & 7203 \\ 3 & 0 & & & & & & & & & \\ 4 & 1 & 51 & 80 & 456 & 710 & 26 & 40 & 355 & 113 & 3926 \\ 5 & 6 & 60 & 191 & 563 & 1313 & 23 & 60 & 504 & 119 & 11080 \\ 6 & 1 & 46 & 138 & 584 & 1770 & 23 & 69 & 885 & 78 & 12667 \\ 7 & 0 & & & & & & & & & \\ 8 & 3 & 139 & 188 & 708 & 961 & 91 & 121 & 596 & 200 & 6701 \\ 9 & 3 & 58 & 118 & 422 & 925 & 23 & 47 & 353 & 140 & 8166\end{array}$


Summaries of 1990 RECS Baseline Annual Energy Consumplion (continued)

\begin{tabular}{|c|c|c|c|c|c|c|c|c|c|c|}
\hline Region & Number & $\begin{array}{l}\text { GJ tolal- } \\
\text { sile }\end{array}$ & $\begin{array}{l}\text { GJ lotal- } \\
\text { source }\end{array}$ & $\begin{array}{c}\text { MJ/m2- } \\
\text { sile }\end{array}$ & $\begin{array}{l}\text { MJ/m2- } \\
\text { source }\end{array}$ & $\begin{array}{c}\text { GJ/pers- } \\
\text { site }\end{array}$ & $\begin{array}{l}\text { GJ/pers- } \\
\text { source }\end{array}$ & $\begin{array}{l}\text { MJ/per- } \\
\text { m2 }\end{array}$ & $\begin{array}{c}\text { homearea } \\
-m 2\end{array}$ & kWh \\
\hline \multicolumn{11}{|c|}{1987 to $1990>=5$ units } \\
\hline tolal & 5 & 72 & 126 & 543 & 1125 & 38 & 71 & 741 & 121 & 7477 \\
\hline 1 & 3 & 96 & 157 & 544 & 972 & 48 & 79 & 486 & 156 & 8323 \\
\hline 2 & 0 & & & & & & & & & \\
\hline 3 & 0 & & & & & & & & & \\
\hline 4 & 0 & & & & & & & & & \\
\hline 5 & 1 & 36 & 110 & 705 & 2134 & 36 & 110 & 2134 & 51 & 10053 \\
\hline 6 & 0 & & & & & & & & & \\
\hline 7 & 0 & & & & & & & & & \\
\hline 8 & 0 & & & & & & & & & \\
\hline 9 & 1 & 33 & 50 & 377 & 577 & 7 & 10 & 115 & 86 & 2364 \\
\hline \multicolumn{11}{|c|}{1980 to 1990 All Dwelling Units } \\
\hline lotal & 482 & 96 & 182 & 563 & 1118 & 38 & 73 & 488 & 194 & 11721 \\
\hline 1 & 26 & 108 & 178 & 684 & 1118 & 50 & 84 & 525 & 194 & 9549 \\
\hline 2 & 33 & 87 & 182 & 421 & 907 & 38 & 78 & 394 & 217 & 12927 \\
\hline 3 & 54 & 136 & 207 & 744 & 1174 & 54 & 84 & 560 & 222 & 9685 \\
\hline 4 & 47 & 110 & 189 & 624 & 1091 & 43 & 74 & 440 & 223 & 10737 \\
\hline 5 & 90 & 64 & 160 & 441 & 1137 & 28 & 70 & 555 & 161 & 13190 \\
\hline 6 & 50 & 105 & 217 & 614 & 1400 & 40 & 82 & 584 & 203 & 15369 \\
\hline 7 & 27 & 94 & 216 & 600 & 1358 & 35 & 77 & 534 & 170 & 16692 \\
\hline 8 & 65 & 108 & 186 & 608 & 1085 & 43 & 72 & 454 & 198 & 10674 \\
\hline 9 & 90 & 85 & 153 & 490 & 955 & 30 & 57 & 385 & 184 & 9411 \\
\hline
\end{tabular}


Appendix D. Letter Reporting Resuits 


\author{
Energy Analysis Program \\ Building 90, Room 4000 \\ Tel. (510)486-5159 \\ e-mail: BRLitt@LBL.gov \\ Fax (510)486-6996
}

October 12, 1994

John and Jane Doe

Address

City, IL Zip

Dear Mr. and Mrs. Doe:

Thank you for participating in Lawrence Berkeley Laboratory's (LBL) study of recently built lowenergy houses. You have helped us improve our understanding of how much energy carefully built houses like yours consume. As a token of gratitude, enclosed is an LBL T-shirt, of the size you indicated. Here is how your house performed, compared to the other Bigelow houses studied. You may also refer to the attached graph for this information.

Your average yearly gas usage is $\underline{750}^{*}$ therms, for an annual bill of approximately $\$ 390$. This value is typical of the group of households living in houses built by Bigelow Homes in our study.

We estimate that the amount of gas you use for heating your house each year is $\underline{390}$ therms, or approximately $\$ 170$. There is some uncertainty in the estimation procedure, and we think that this is a slight overestimate of the actual amount used for heating. This value is among the lowest in the group of Bigelow Homes that we studied. Your household uses $\underline{33}$ percent of what a typical, conventionally built, new house in your area uses for space-heating. When these results are adjusted for differences in house size, your house consumes $\underline{0.33}$ therms per square foot of living area, or 66 percent of a typical, conventionally built, new house.

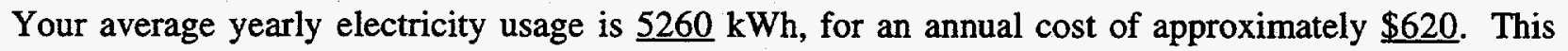
value is among the lowest within the Bigelow houses studied. If you want to find out how to decrease your household electricity consumption I suggest that you have an energy audit through your utility company.

I hope you find these results of interest. If you have any questions about them or would like further information, please call me at the number above.

$$
\text { Sincerely, }
$$

\title{
Barbara Litt
}

\footnotetext{
* Underlined values and expressions are specific to each house.
} 